\title{
THE USE OF SHAPE AND COLOR THEORY IN INTERPRETING CHARACTER TRAITS
}

A Graduate Thesis
presented to
the Faculty of the Graduate School
at the University of Missouri-Columbia
In Fulfillment
of the Requirements for the Degree
Master of Arts
By CURTIS HENDERSON
JIM FLINK, Thesis Supervisor
MAY 2021


The undersigned, appointed by the dean of the Graduate School, have examined the thesis proposal entitled

THE USE OF SHAPE AND COLOR THEORY IN INTERPRETING CHARACTER TRAITS

Presented by Curtis Henderson,

A candidate for the degree of Master of Arts,

and hereby certify that, in their opinion, it is worthy of acceptance.

Jim Flink

Mike Kearney

Fang Wang

Mark Swanson 


\section{ACKNOWLEDGEMENTS}

Many people have influenced me personally and academically over the years. Without their continuous love and support, this thesis would not have been possible. I am sincerely grateful to everyone I have had the pleasure of conversing with while developing this thesis.

First, I would like to thank my committee chair Professor Flink for his continued guidance and encouragement throughout this process. I would also like to thank my additional committee members, Professors Wang, Kearney, and Swanson, for their advice and support while developing this research. Also, a special thanks to Professor Swanson for agreeing to step in and join my committee last minute.

I want to thank my father, Gary Henderson, for his continuous support and my mother, Yvonne Brazeal, for her wisdom, guidance, and emotional support. You both have been there with me every step of my academic journey. I could not have completed this thesis without the loving support of my wife, Erin Henderson. You were always willing to help in any way you could and were in full support of my academic goals. Finally, I would like to thank my friend, Derick Kermendy, who provided stimulating discussions and encouragement toward academic growth. 


\section{TABLE OF CONTENTS}

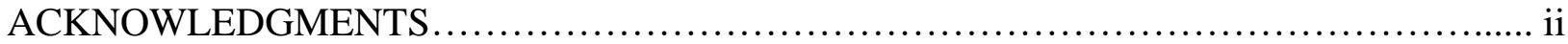

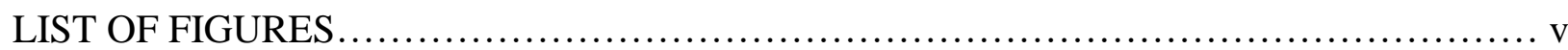

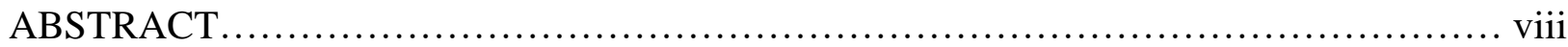

Chapter

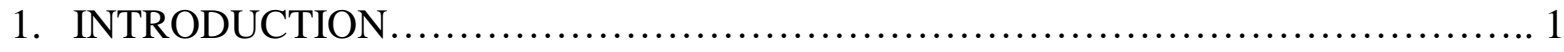

Shape Theory in Design................................................... 3

Color Theory in Design.................................................. 6

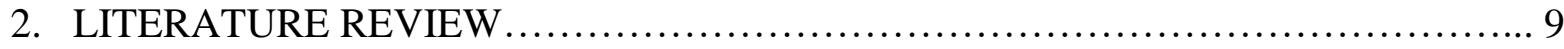

Statement of Research Questions............................................. 18

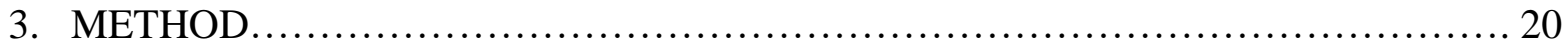

Research Design........................................................ 20

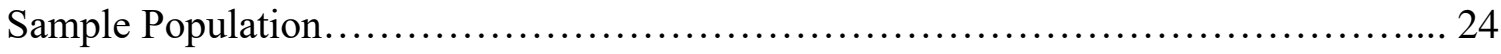

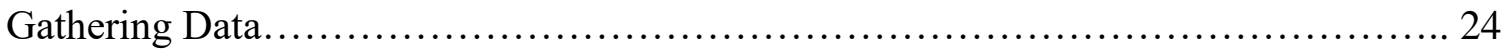

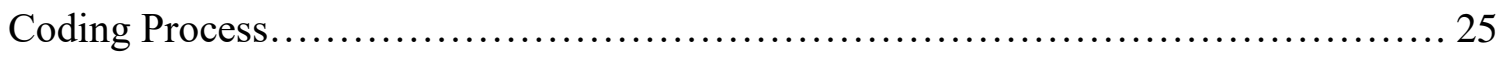

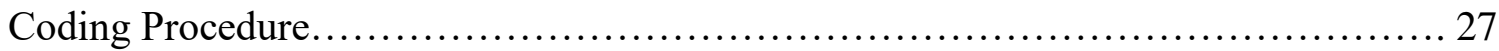

Maintaining Credibility................................................... 28

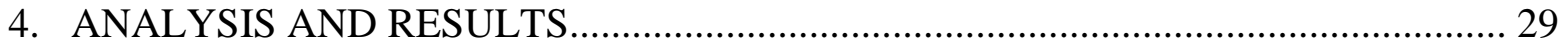

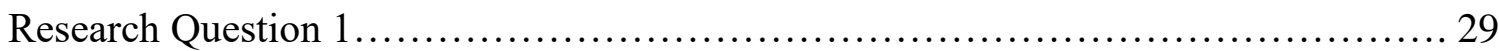

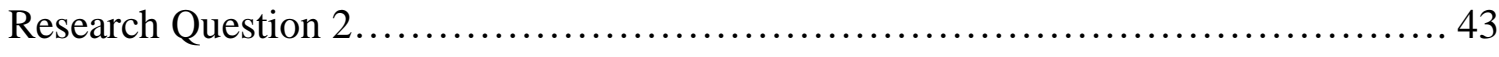

Research Question 3.................................................... 51

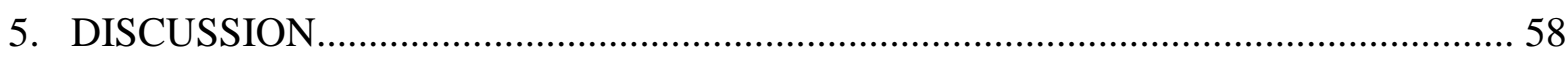

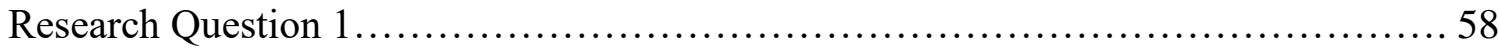




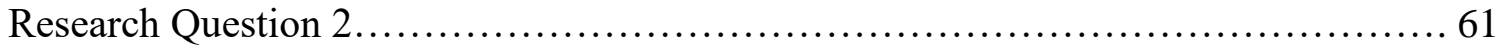

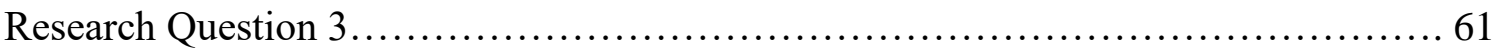

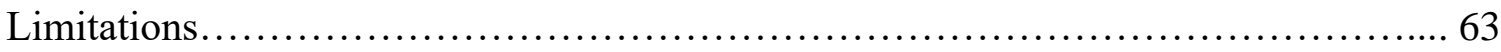

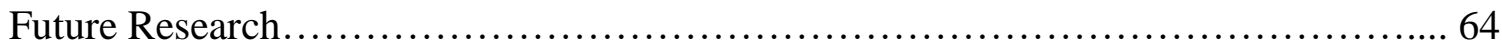

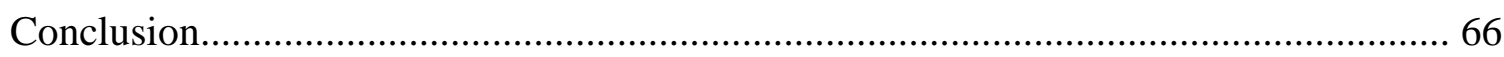

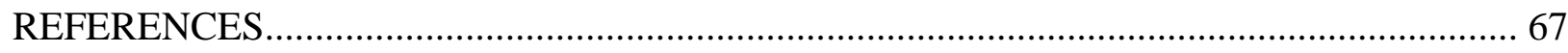

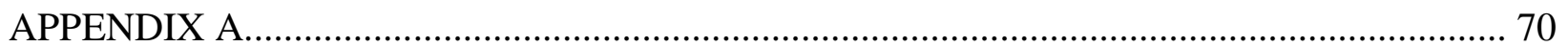

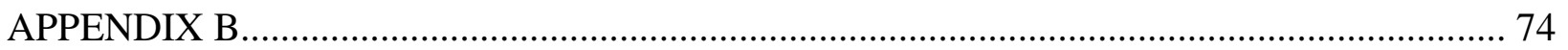




\section{LIST OF FIGURES}

Figure $\quad$ Page

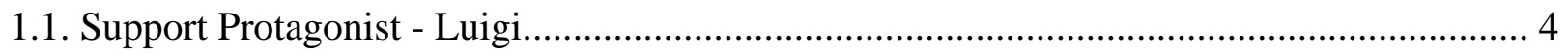

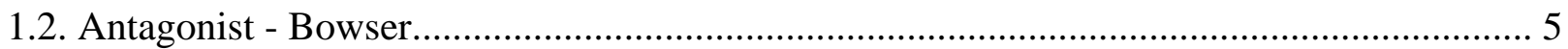

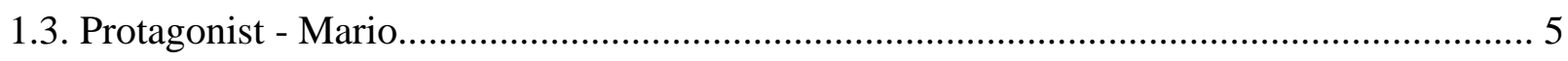

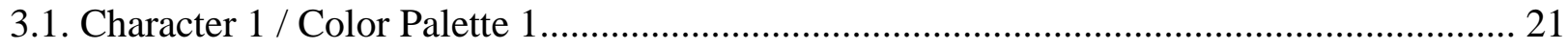

3.2. Character 1 / Color Palette 2.............................................................................. 21

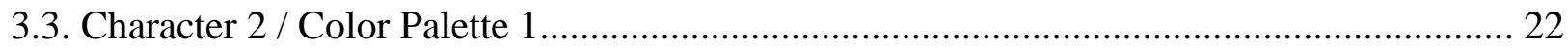

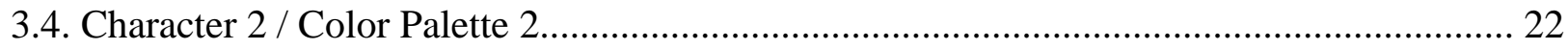

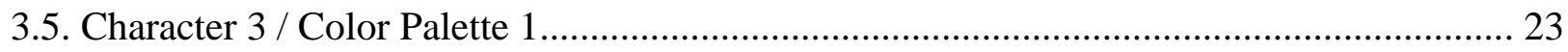

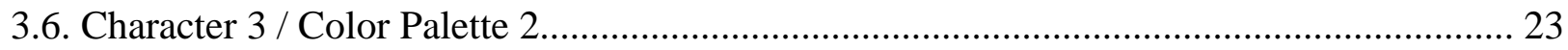

4.1. Silhouette 1: What is the oval shape of the character?............................ 29

4.2. Silhouette 1: Describe your overall impression of the character..................... 30

4.3. Ch. 1 / Color Palette 1: Describe your overall impression of the character............... 31

4.4. Ch. 1 / Color Palette 1: What personality traits do you associate with this character?....... 31

4.5. Ch. 1 / Color Palette 2: Describe your overall impression of the character.................. 32

4.6. Ch. 1 / Color Palette 1: What personality traits do you associate with this character?........ 33

4.7. Silhouette 2: What is the oval shape of the character?............................................. 34

4.8. Silhouette 2: Describe your overall impression of the character.................... 35

4.9. Ch. 2 / Color Palette 1: Describe your overall impression of the character............... 36

4.10. Ch. 2 / Color Palette 1: What personality traits do you associate with this character?..... 36

4.11. Ch. 2 / Color Palette 2: Describe your overall impression of the character.............. 37 
4.12. Ch. 2 / Color Palette 2: What personality traits do you associate with this character?..... 38

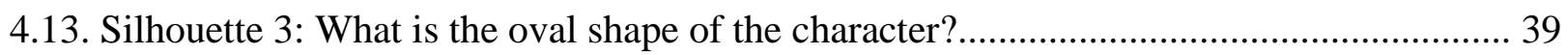

4.14. Silhouette 3: Describe your overall impression of the character.................... 40

4.15. Ch. 3 / Color Palette 1: Describe your overall impression of the character............. 41

4.16. Ch. 3 / Color Palette 1: What personality traits do you associate with this character?...... 41

4.17. Ch. 3 / Color Palette 2: Describe your overall impression of the character............... 42

4.18. Ch. 3 / Color Palette 2: What personality traits do you associate with this character?...... 43

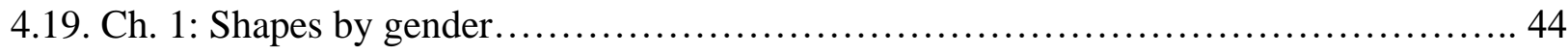

4.20. Ch. 1 / Color Palette 1: Character traits by gender................................ 45

4.21. Ch. 1 / Color Palette 2: Character traits by gender.............................. 45

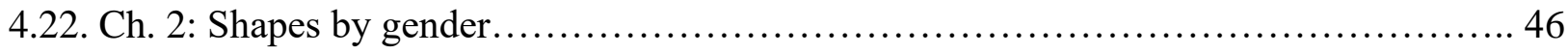

4.23. Ch. 2 / Color Palette 1: Character traits by gender.............................. 47

4.24. Ch. 2 / Color Palette 2: Character traits by gender.............................. 47

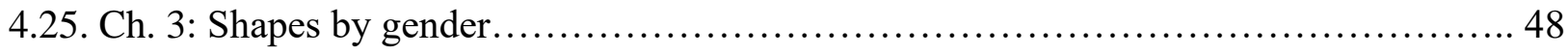

4.26. Ch. 3 / Color Palette 1: Character traits by gender................................ 49

4.27. Ch. 3 / Color Palette 2: Character traits by gender.............................. 50

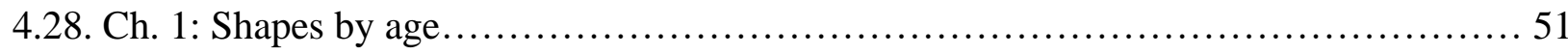

4.29. Ch. 1 / Color Palette 1: Character traits by age................................ 52

4.30. Ch. 1 / Color Palette 2: Character traits by age................................ 52

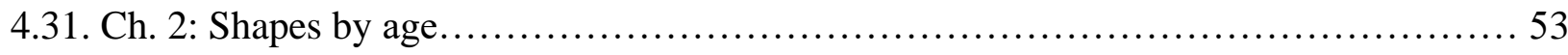

4.32. Ch. 2 / Color Palette 1: Character traits by age................................. 54

4.33. Ch. 2 / Color Palette 2: Character traits by age................................. 55

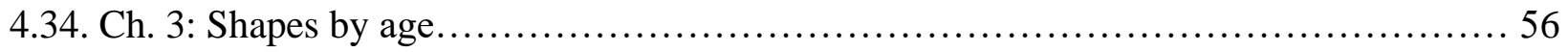


4.35. Ch. 3 / Color Palette 1: Character traits by age............................... 57

4.36. Ch. 3 / Color Palette 2: Character traits by age.................................... 57 
THE USE OF SHAPE AND COLOR THEORY IN INTERPRETING CHARACTER TRAITS

Curtis M. Henderson

Jim Flink, Thesis Supervisor

\begin{abstract}
Video games are richly ingrained in the world's media culture. Video games are rapidly growing their audience reach through new technological advances and innovative interactive engagement. Characters that create powerful social and emotional connections with players throughout the gameplay are essential for a video game's success. However, character design and interaction principles do not seem to be widely understood within the game development community.
\end{abstract}

This paper analyzes the theory of how people perceive shape and color and then applies these beliefs to personally designed characters that I created. When speaking of shape, I am referring to the actual geometric dimensionality of an object, such as a circle, square, or triangle. When speaking of color, I am referring to the full-color spectrum in an artist's palette, such as blue, indigo, and violet, etc. This study reports the findings of previous research concerning video game character design. It then provides a new research plan for a qualitative study to attempt to design characters that evoke intended emotions with their audience. It also presents a full questionnaire with new unique character designs that will be distributed to the public in the future. The overall goal of this research is to build a better picture of what character designers should include to resonate with their intended audience successfully. 


\section{CHAPTER 1 INTRODUCTION}

Playing a video game nowadays is like entering another world, one with unique sights, sounds, and realities. Gaming is also growing in frequency. In a research study conducted by the Entertainment Software Association in 2019, seventy-five percent of American households have at least one gamer. The Entertainment Software Association estimates this equates to over 164 million American players. This enormous consumer market has made the video game industry one of the most profitable media forms in the United States. According to the Entertainment Software Association, the total consumer spending among the video game industry in 2018 was over $\$ 43.4$ billion, a much larger number on a global scale and one that will most likely continue to rise in the future.

One of the most important aspects of a video game is the characters. Characters are, mostly, the heart of video games. A video game may have an engaging story and impressive graphics, but it may fail to resonate with its players without well-developed characters.

Designers must understand what character traits to include to evoke certain emotions. A designer does not want their characters to suggest something they do not mean to imply.

There have been many iconic video game characters over the years. Some characters are so memorable they push beyond the video game barrier. For instance, many people know who Mario is, whether they have played Super Mario Brothers or not. Super Mario Brothers is the best-selling video game franchise in the world since 1985 (Martin, 2019). Mario has appeared in over 200 video games and has sold more than 600 million units (Martin, 2019). Mario is an iconic character, and he is a big reason why over thirty years later, new Mario games are being released today. 
Many of the most successful video games released have several iconic characters. The video game, Overwatch, is a perfect example of character design driving success. Overwatch is a chaotic multiplayer first-person shooter, with thirty-two unique characters players can choose from (IGN, 2019). The number of relatable characters is one of the game's greatest attributes, and it currently ranks $50^{\text {th }}$ on the best-selling games of all-time list in just three years (IGN, 2019). Overwatch has also generated over $\$ 1$ billion from in-game spending as of 2019 (Ivan, 2019). Overwatch's in-game spending system consists of loot boxes, one of the game's primary sources of income, which includes skins, sprays, highlight intros, emotes, victory poses, player icons, and voice lines, all of which are directly tied to character design (Ivan, 2019). All in-game spending is for customizing the thirty-two pre-established characters. Overwatch's success is attributed to the player's want and need for a character that is relatable. Players want a character they can get to know and share their gaming experience.

Video games rely heavily on quality character designs. A great character designer requires ability, expertise, a strong imagination, and good intuition. To be successful, a character designer needs to create captivating art. Their goal is to convince players that their characters are coherent and belong in the world they inhabit. Since the players will essentially become or interact with these characters, they need to stand out as individuals with distinct personalities. The character designs must then reflect those personality traits. In most production cases, artists work on drawings of these characters, which are then scanned into a computer and animated. Not only do these characters need to be visually appealing to their audience, but they also must be applicable for video game insertion.

This study focuses on the production of three separate character designs within a stylized video game world that I created. This study examines how visual attributes through shape and 
color theory can successfully communicate a character's personality. The goal is to successfully develop characters that express the intended personality traits that are suitable for the chosen video game's style.

\section{Shape Theory in Design}

"In the study of art, a shape is an enclosed space, a bounded two-dimensional form that has both length and width" (Esaak, 2019). Shapes are the building blocks that artists use to create images in a two-dimensional or three-dimensional space. Shape theory in design is the psychological belief that the viewer will perceive a set of predetermined emotions when viewing specific types of geometric shapes (Solarski, 2012, p. 176).

Everything in the world has some form of shape. There are four two-dimensional shapes called the square, rectangle, triangle, and circle, also known in three-dimensional as the cube, rectangular prism, cone, and sphere (Solarski, 2012, p. 180). Shapes are the foundation of art and are essential for creating compelling designs. Understanding the basics of shapes and how they work together aids in avoiding the creation of unintended artwork.

There are two types of shapes called geometric and organic. Geometric shapes are described as regular and mathematical. Organic shapes are most often irregular and asymmetrical. Geometrical shapes are most commonly found in architecture, and organic forms are found in nature (Bancroft, 2006, p. 32). Shape communicates universally because the concept of smooth versus sharp-edged shapes originates from natural forms (Solarski, 2012, p. 177). Based on humanity's primal instincts, rounded shapes tend to be safe, while angular shapes demonstrate caution (Solarski, 2012, p. 179). These instinctive reactions are based on the sense of touch and, while this sense is not present in visual art, the viewers tend to apply their real-life 
experiences onto similar shapes (Solarski, 2012, p. 179). All life formations have to start as a shape, and the prescription of shapes all suggest different characteristics.

Shapes in the orientation of a square relate to straight, vertical, and horizontal lines that display strength, stability, and confidence (Bancroft, 2006, p. 34). "Squares can both be large and daunting or comforting and clumsy" (Bancroft, 2006, p. 34). Squares mostly depict loyal and devoted characters who are dependable and are commonly used for superheroes or strong characters (Bancroft, 2006, p. 34). Squares tend to project feelings of stability, trust, honesty, order, conformity, security, equality, and masculinity (Tillman, 2011, p. 68).

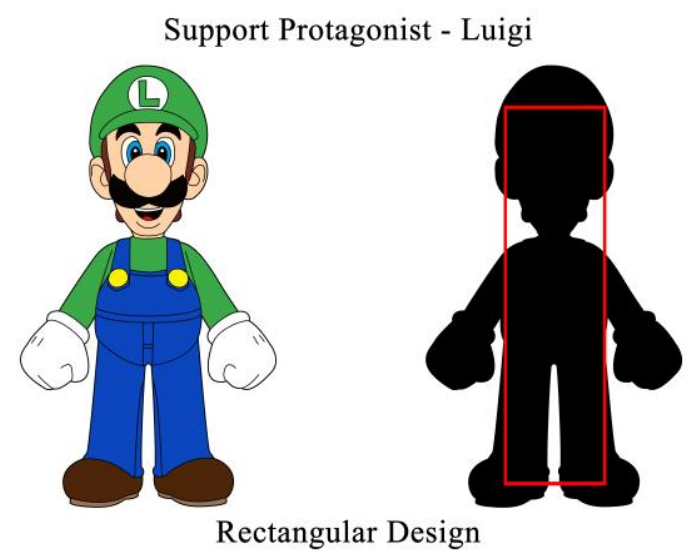

Figure 1.1: Support Protagonist - Luigi

Triangles relate to diagonal and sharp angular lines and are the most dynamic of the three shapes. Villains are often based upon dominant triangular concepts, as they appear malicious, sinister, and communicate with the most aggression (Bancroft, 2006, p. 35). A triangle, generally, conveys the following: Action, Aggression, Energy, Sneakiness, Conflict, and Tension. (Tillman, 2011, p. 70). Most antagonists are designed around triangular concepts (Solarski, 2012, p. 180). 


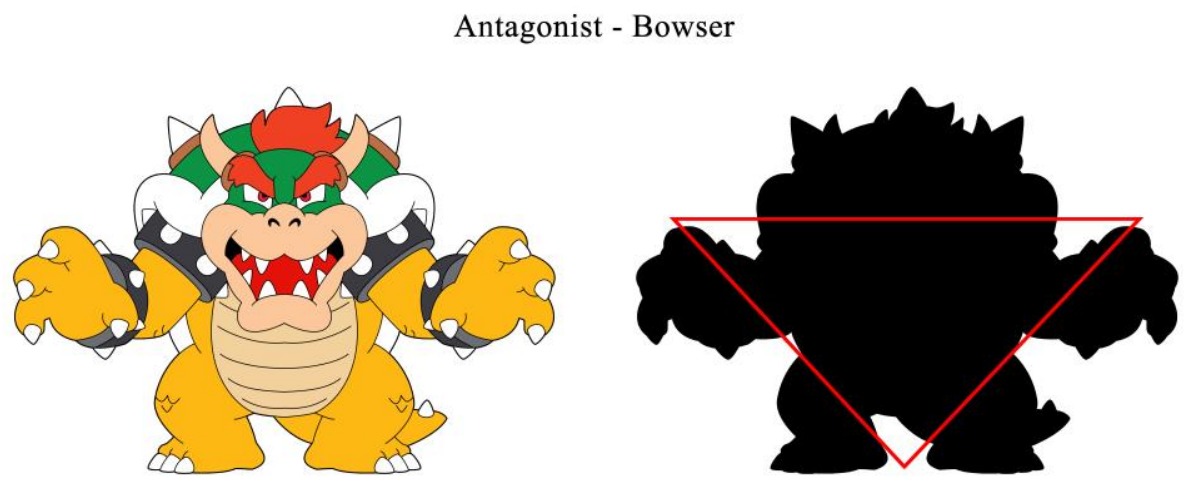

Triangular Design

Figure 1.2: Antagonist - Bowser

Curved and circular shapes are considered the safest shape as they do not have sharp or dangerous corners. Circular shapes in nature have a tendency to be soft and harmless and evoke likable characters (Bancroft, 2006, p. 36). Many of the most well-known protagonists are designed around circular concepts (Solarski, 2012, p. 180). Generally, when people look at a circle, specific terms come to mind: completeness, gracefulness, playfulness, comforting, unity, protection, childlike (Tillman, 2011, p. 72).

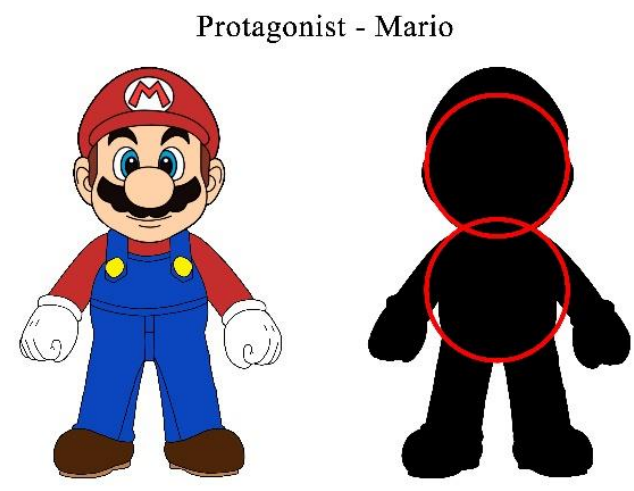

Circular Design

Figure 1.3: Protagonist - Mario

Most characters are more complex than a standard shape, and maintaining a clear visual message is vital to the effectiveness of the design. Tillman (2011) suggests starting every design 
with a silhouette as the overall shape will speak for a character's personality (p. 75). A silhouette is an outline of a character that is filled in with black (Tillman, 2011, p. 75). This exercise aims to create a combination of shapes that are fully recognizable when it is in a complete silhouette view. The goal is to compare the visual message presented when the design is either in a detailed or silhouetted view.

The instinctive communication of shapes makes them a powerful tool, especially in the visual feedback of video game characters. Shape design seems to be the basis of creating easily distinguishable characters that communicate a basic idea. Many of the most famous characters have distinct silhouettes that are easy to distinguish, such as with the characters from Super Mario Brothers. An easy to visualize shape also prevents them from being mistaken for someone else. Solarski (2012) provides this example, a silhouette of the letter A would not be mistaken for B and vice versa (p. 180). Solarski's (2012) example demonstrates that it is essential not to get hung up on small details but rather design a character around basic shapes.

\section{Color Theory in Design}

"Color is the element of art that is produced when light, striking an object, is reflected back to the eye" (Esaak, 2019). Color is the basis that artists use to bring their artwork to life by instilling emotional responses in the viewer's psyche. Color theory in design is the psychological belief that the viewer will perceive a set of predetermined emotions when viewing specific colors (Solarski, 2012, p. 224).

To understand color theory, evaluating the color wheel is necessary. The color wheel has been around for centuries, even before the development of contemporary graphic design as we know it, and it is now considered traditional art (Tillman, 2011, p. 111). Colors belonging to the color wheel can be divided into two basic groups; primary and secondary colors (Solarski, 2012, 
p. 224). Primary colors are red, yellow, and blue (Solarski, 2012, p. 224). In the traditional color theory, primary colors cannot be derived from the combination of any other color, and, in return, these colors constitute all other colors (Solarski, 2012, p. 224). Secondary colors are green, orange, and purple (Solarski, 2012, p. 224). They are created as a result of mixing primary colors. For example, yellow plus blue equals green; yellow plus red equals orange; red plus blue equals purple (Solarski, 2012, p. 224). If a primary and secondary color is mixed together, the color brown is formed.

In addition to the color wheel's colors, two fundamental colors are essential to color theory: black and white. Black and white are directly related to light frequencies. There are two ways of thinking about black and white. White is the presence of all colors or the absence of color (Solarski, 2012, p. 227). Black is also the presence of all colors or the lack of color, and it depends on what the individual chooses to believe (Solarski, 2012, p. 227). Many scholars have debated whether black and white are colors, but they will be considered colors for this study.

Every color evokes a different set of emotions. The theory of color recognizes these as the most common emotions associated with each color:

- The color red generally evokes feelings of action, confidence, courage, vitality, energy, war, danger, strength, power, determination, passion, desire, anger, and love (Tillman, 2011, p. 92).

- The color yellow evokes feelings of wisdom, joy, happiness, intellect, caution, decay, sickness, jealousy, cowardliness, comfort, liveliness, optimism, and overwhelming (Tillman, 2011, p. 92). 
- The color blue evokes feelings of trust, loyalty, wisdom, confidence, intelligence, faith, truth, health, healing, tranquility, understanding, softness, knowledge, power, integrity, seriousness, honor, coldness, and sadness (Tillman, 2011, p. 92).

- The color purple evokes feelings of power, nobility, elegance, sophistication, artificial luxury, mystery, royalty, magic, ambition, wealth, extravagance, wisdom, dignity, independence, and creativity (Tillman, 2011, p. 93).

- The color green evokes feelings of nature, growth, harmony, freshness, fertility, safety, money, durability, luxury, optimism, well-being, relaxation, honesty, envy, youth, and sickness (Tillman, 2011, p. 93).

- The color orange evokes feelings of cheerfulness, enthusiasm, creativity, fascination, happiness, determination, attraction, success, encouragement, prestige, illumination, and wisdom (Tillman, 2011, p. 93).

- $\quad$ The color black evokes the feeling of power, elegance, formality, death, evil, mystery, fear, grief, sophistication, strength, depression, and mourning (Tillman, 2011, p. 93).

- The color white evokes the feeling of cleanliness, purity, newness, virginity, peace, innocence, simplicity, sterility, light, goodness, and perfection (Tillman, 2011, p. 93).

- The color gray is a balance of black and white. It is an emotionless, moody color that is typically associated with meanings of dull, dirty, and dingy, and conservative (Tillman, 2011, p. 94).

The colors on this list demonstrate how they are perceived, but their tint and shade also play an essential role in emotional perception. Something as simple as changing the exact hue or 
saturation of a color can also evoke a completely different emotion (Tillman, 2011, p. 94). Tint and shade are a mixture of a primary or secondary color with either white or black (Tillman, 2011, p. 94). Think about black and white as being sides of a spectrum. The closer a color's tint or shade is to either side of the spectrum, the more they will adopt some of the emotions associated with black or white (Tillman, 2011, p. 94). Cultural differences can influence these effects, with a color that is happy and uplifting in one country, becoming depressing in another (Tillman, 2011, p. 116). However, the typical emotions evoked by all of these colors are based on American color theory.

\section{CHAPTER 2 LITERATURE REVIEW}

Several scholars have used either shape theory, color theory, or both to guide their artistic research studies. Shape and color are the premises for creating compelling characters that resonate with a particular audience. The research studies that follow demonstrate how critical understanding color and shape theory is for successful artistic design.

Nieminen (2017) conducted a questionnaire that investigated the relevance and benefits of psychology in character design. Nieminen (2017) constructed her research by first looking at psychological theories to explain how psychology influences visual elements in character design. Based on previous psychological research studies, Nieminen (2017) focused her study on the theory of unconscious, motivation, conflict, and backstory.

The questionnaire was developed to cover broad psychological themes of motive, internal and external personality, and flaw. The participants were asked to design their own characters in a controlled step-by-step process that Nieminen (2017) constructed. The first part of the questionnaire had the participants describe a character by their external appearance and write a 
short description of the character's past. The next part focused on the characters' motivations, both internal and external. The third part concentrated on the character's public and personal self. The fourth part asked about the flaws and conflicts in the character's life. The fifth part focused on the participant's psyche while designing their character. The questions attempted to explain whether the participants found the designing difficult and if they feel they were successful in developing their intended characters (Nieminen, 2017, p. 46). These questions' focus was to establish how familiar the participants were with considering a character through psychology.

The data showed that the "participants intertwine their design work between considerations of personality and appearance of a character" (Nieminen, 2017, p. 47). Nieminen (2017) concluded that this "means that their characters portray personality predominately in a visual way" (p. 47). The data also found for many participants; the most manageable parts of the questionnaire were those relating to appearance and basic personality. Most participants indicated the hardest part was to answer the question "why a character does the things they do" (Nieminen, 2017, p. 47). Another problematic area was pinpointing the conflict within a character. According to Nieminen (2017), this indicates the participants only have a shallow knowledge of their characters, not yet knowing them at a deeper level (p. 47). Nieminen (2017) believes this is because many personality aspects, like motivation and flaws, are not things they have to consider consciously (p. 47). Nieminen (2017) concluded that "The brain processes large quantities of information about other people; more than the conscious mind could handle, due to this fact, humans act in a certain way towards people without necessarily being able to explain why they do it" (p. 47).

I think this study does an excellent job of staying on topic, considering the amount of ground they are trying to cover in one research study. However, the way they tested is somewhat 
flawed. Nieminen (2017) took the participants through a step-by-step character design process with their questionnaire format but asking people to develop a character without any prior context is difficult. Nieminen (2017) advised people to think of an existing movie, book, or game as a reference, but I feel the author could have controlled this variable better (p. 46). I think Nieminen (2017) should have picked a popular game or movie and told the participants to design a character that would fit into that world. This study does provide some valuable insight into the psyche of a person as they go through the video game process. Nieminen (2017) study found that most people can visually design, but designing a character's backstory is problematic for many (p. 53).

Fogelstrom (2013) investigated "if there are further limitations or considerations that need more attention when designing purposeful characters" (p. 2). Fogelstrom's (2013) aim was to understand if culture, age, and gender affect the choice of shape and color schemes of character designs (p. 2). Fogelstrom (2013) utilized an online survey that produced results from 72 participants (p. 2). Each participant was given a series of character designs, each reflecting one of these attributes; female, young adult, independent, adventurous, and confident (Fogelstrom, 2013, p. 10). The participants were then instructed to pick one character design and then state what shape, silhouette, and color palette they associate with the chosen character. The participants were given five shape silhouettes and five color palettes from which to choose.

Fogelstrom (2013) concluded that two shapes were the more frequently chosen silhouettes over the others to match the character profile. The two selected shapes contrasted in their design. One had a rounded design, while the other had a rectangular. Fogelstrom (2013) noted that general shape interpretations of round shapes are more feminine than the rectangular shapes that are more masculine (p. 23). 
Fogelstrom (2013) found that this is much harder to predict when it came to color schemes. Fogelstrom (2013) stated that the number of times each color palette was chosen was "fairly equal" across the board (p. 23). Fogelstrom (2013) indicated that when the same color schemes were compared to one another with the different shapes, it was clear that the chosen shape affected the choice of the color scheme (p. 23).

The way Fogelstrom (2013) set up her test for shape was a great idea, and I plan to utilize this approach for my study. However, I strongly dislike the way Fogelstrom (2013) tested for color. I would never give the participants a set of five color palettes to choose from, as it is too limiting. Fogelstrom (2013) also did not provide any reasoning for the colors they chose for the palettes. Fogelstrom (2013) even noted that they did not choose colors based on psychological color theories because they felt it did not relate to their focus of the research study (p. 23). I cannot entirely agree, and I think that by not putting any thought into why she chose specific color palettes, she caused the results for this test to be so even. I think the participants had no clue what to pick.

Ekstrom (2013) conducted a study further to explore the art of character design for video games. Ekstrom's (2013) focus was on how visual attributes and shapes, in particular, can be used to communicate a character's personality (p. 5) effectively. Ekstrom (2013) developed several characters that attempt to express intended personalities and fit within a similar style.

Ekstrom (2013) chose two game styles, one stylized and the other semi-realistic, to design their characters around. For the more stylized game, Ekstrom (2013) decided to work with Team Fortress 2, developed by Valve Corporation. The style of Team Fortress 2 "is cartoony and focuses heavily on character shape and silhouette" (Ekstrom, 2013, p. 4). The semi-realistic game that Ekstrom (2013) chose to work with is The Walking Dead, developed by Telltale 
Games. The style of The Walking Dead "is an overall realistic look but takes a lot of inspiration from the original comic book series by Robert Kirkman” (Ekstrom, 2013, p. 4).

Ekstrom (2013) utilized an online survey that featured their designed characters and characters from their chosen games, which were then followed by a series of similar questions regarding style and personality traits (p. 6). Ekstrom (2013) implemented a five-point scale ranging from 0 , very realistic, to 5, very cartoony (p. 28). Ekstrom (2013) gave the participants a list of personality traits to identify if any correspond with the character's design (p. 28). Ekstrom (2013) chose specific keywords that they associated with each character, such as proud, clumsy, sleepy, loud, quiet, gentle, cheerful, and cunning.

After Ekstrom (2013) analyzed the responses from 38 participants, they concluded that, overall, the personality traits associated with the characters matched the keywords that had been picked for them (p. 37). However, Ekstrom (2013) noted that some participants wrote that they perceived personality traits that were not among the options (p. 37).

Ekstrom (2013) also found that when it comes to graphical style, the participants have varying opinions, "making it a difficult subject to evaluate" (p. 37). "Many of the participants perceived both The Walking Dead and Team Fortress 2 to be similarly realistic and vice versa while some thought that Team Fortress 2 appeared to be more realistic than The Walking Dead" (Ekstrom, 2013, p. 37). Ekstrom's (2013) results also indicated that the graphical style of the characters in the case studies leaned more toward the cartoony/stylized side and contradicted some of the styles that the characters were designed. (p. 37).

Overall, I like the way Ekstrom (2013) designed her method. There are many similarities with Nieminen's (2017) study, but Ekstrom (2013) eliminated the issue of not providing context for the characters. With that said, I think Ekstrom (2013) should have picked another semi- 
realistic style example other than The Walking Dead game because it is too similar to Team Fortress 2, and Ekstrom's (2013) results indicate this (p. 37). I also think Ekstrom (2013) should have stuck with open-ended questions regarding the character's personality traits. Limiting the participants to predetermined answers for a subjective research question provides little value in their responses. Ekstrom (2013) even noted that the study participants wrote in answers that were not offered (p. 37). What I learned from this study is to let the participants elaborate on their responses.

Islam, Nahiduzzamann, Why, and Ashraf (2010) attempted to explain how character poses and proportions can represent certain character traits. Islam et al. (2010) did this by developing "an online casual role-playing puzzle game to let players choose meaningful tags" relating to "role, physicality, and personality for characters" (p. 2). Islam et al. (2010) compiled over 200 full-body, front-facing character images from popular art platforms. Islam et al. (2010) designed their seventy-three characters and then simplified them into silhouettes to bring attention to the character's shape and pose (p. 4).

Islam et al. (2010) methodology takes place in a video game. The goal was to have the players rate each silhouette character with a label from 25 predetermined names (p. 5). The labels are designed to uncover two different types of data related to the character's silhouette. The first type is the shape-proportion data of all the images, and the second type is the user's perceptions of those images. After compiling the player's viewpoint from the online video game, Islam et al. (2010) found that there is a standard connection between character traits and a character's given shape and pose and how people perceive them (p. 6). Islam et al. (2010) noted that there is an $83 \%$ chance that a character will evoke a predictable perception base on the character's proportions and pose (p. 7). 
Islam et al. (2010) method is unlike any other study reviewed. Truthfully, I found this study challenging to follow. Islam et al. (2010) used a silhouette style to illustrate the character's shape, just like in Fogelstrom's (2013) and Ekstrom's (2013) studies, but the way they structured their methodology made interpretation difficult. My confusion came from their use of a video game to compile data. Islam et al. (2010) did not provide a game document for their game design, just a summary of what went into the game and a couple of pictures. Islam et al. (2010) attempted to explain the way they compiled the data, but they got rather technical explaining the programming of their game. If the reader does not have a video game programming background, it is difficult to understand their analysis. Islam et al. (2010) created a unique method that required more participant interactions, but the conclusion of the analysis left a lot to be desired.

Fredriksson (2017) explored how character design guidelines can be combined and remixed to create characters whose motivations are ambiguous to the viewer (p. 2). Fredriksson (2017) divided their study into two parts. In the first part, Fredriksson (2017) analyzed the quantitative data from an online survey to attempt to answer the question of how flexible design guidelines are and how far they can be stretched. The second part of the study is done with a second online survey collecting qualitative data, including characters made by Fredriksson (2017) and designed from the guidelines found from the first survey.

The first survey revealed that $81 \%$ of participants chose the color scheme of red, yellow, and blue to represent a good character (Fredriksson, 2017, p. 32). According to Fredriksson (2017), this data is in line with previous design studies (p. 32). When it came to posture, 63\% chose the pose aiming for a good character (Fredriksson, 2017, p. 31). The overall character's shape is of a circle, which is reflective of most good characters (Fredriksson, 2017, p. 31). 
In addition to the first survey, $92 \%$ of the participants chose a dark, blue, and green color scheme to represent evil characters (Fredriksson, 2017, p. 34). According to Fredriksson (2017), this data is in line with previous design studies (p. 34). However, when it came to posture, only $52 \%$ chose the correct evil pose (Fredriksson, 2017, p. 34). The overall character's shape is of a triangle, which is reflective of most evil characters (Fredriksson, 2017, p. 34).

Fredriksson (2017) received many different responses for their second part of the study, which was an open-ended survey focused on their personally designed characters. Fredriksson (2017) presented the respondents with two different orientations and color schemes for each character. Only one character Fredriksson (2017) designed passed the test. Fredriksson (2017) succeeded in producing a character that the participants perceived as a good character but failed to make an evil character design that the participants all agreed on. Fedriksson (2017) noted that it is hard to predict what changes in color, shape, or posture influence a personal perception. "For some participants, it was enough to simply change the color or pose and facial expression, while others stayed with their original opinion of the character all the way through the changes" (Fedriksson, 2017, p. 56).

Fredriksson (2017) received mixed results. Islam et al. (2010) indicated that character traits could predict character motives, but Fredriksson (2017) was unsuccessful in proving this fact. The issue could be a designer error. Designers have a wide range of skills, and it is possible Fredriksson's (2017) design, for an evil character, was missing many traditional evil expressions. This was my observation while reviewing this study. All of the reviewed studies are limited to the designer's skill set, but in studies like the ones discussed, it is difficult to control this issue.

Ouverson (1992) explored the effects of color and design on audience attitude, behavior, and media perception. Ouverson (1992) discusses some of the theories of human interaction and 
perception of color. To test the theory of color, Ouverson (1992) proposed a study "to investigate whether or not four different versions of a brochure would have a significant effect on the professional attitudes, business behaviors, and color and design preferences of potential readers" (p. 26).

Ouverson (1992) used a " 2 × 2 factorial design" (p. 26). The variables investigated included two levels of color and two levels of design (Ouverson, 1992, p. 26). Ouverson (1992) used a Family Daycare brochure as the focal point of the study. The brochure style was separated into four groups for testing and analysis. The four groups were static artwork on orange paper, dynamic artwork on orange paper, static artwork on cream paper, and vibrant artwork on cream paper (Ouverson, 1992, p. 26).

The study utilized a sampling survey questionnaire that was mailed to 306 family daycare providers (Ouverson, 1992, p. 30). Ouverson (1992) divided the 306 family daycares into two groups, one experimental and one controlled, consisting of 153 family daycares in each group. Each group received two sets of brochures, each with different designs. The questionnaire was based on a five-point scale of strongly disagree to strongly agree (Ouverson, 1992, p. 33).

Ouverson (1992) found that "no one color and design combination caused a significantly greater change in attitude" (p. 70). Some change in attitude did occur, as demonstrated by group means, but it was uniform among brochure groups. No one color and design combination caused a significantly greater change in behavior (p. 71). As for behavior change, the results would indicate that little or no behavior change will occur until attitude changes (Ouverson, 1992, p. 71). Analysis of variance tests found that color caused significant differences in the brochure rating on four of the five evaluation factors (p. 72). "Comparison of means showed that both orange brochures as a unit were given a higher rating than the cream brochures in all factors" 
(Ouverson, 1992, p. 73). Also, the orange brochure with the more dynamic artwork was given a higher rating than any other brochure in all facets. Ouverson (1992) said, "Based on the results of the brochure evaluation, the present study supports the use of color over a neutral black and white in a publication" (p. 73). The orange paper and red ink combination were rated more highly than the cream paper and black ink combination base on the results.

Ouverson (1992) analyzed color and how it relates to design, but not for character design, like the previous research studies. Unlike in previous reviews mentioned, Ouverson (1992) is not concerned with the shape or the position of the brochure's design. Ouverson's (1992) study is strictly on color perception. Ouverson's (1992) findings coincide with part of Fredriksson's (2017) findings and traditional color theory beliefs. However, Ouverson's (1992) findings contradict Ekstrom's (2013) findings, which indicate that color has little impact on a viewer's perception or attitude.

Even though video games are a rapidly growing media entertainment industry, the research seems to be lacking. Relatable character design is an essential component of successful game design, but few studies focus on a character's perception toward a given audience. With so many games being released every year, game designers can set themselves apart from the competition by listening to audience perception. Character design is one part of the video game creation process but an essential part of every game. This study will utilize some of the reviewed literature studies and attempt to expand upon their findings. The goal is to present additional character design insight into this growing media entertainment industry.

\section{Statement of Research Questions}

Based on the previous literature review, theory, and conclusion, the following research questions were derived: 


\section{RQ1: How do people associate character personality traits with geometric shapes and color palettes?}

This paper analyzes the theory of how people perceive shape and color and then applies these beliefs to personally designed characters that I created. This question is the focus of this research paper. The goal is to successfully develop characters that express the intended personality traits that are suitable for the chosen video game's style. The way I will go about answering this question is outlined in the method section of this paper.

\section{RQ2: What role does gender play in how people perceive character design?}

The theory of color states that different cultural backgrounds and gender can influence a person's interpretations of the design. While conducting research, I only saw Fogolstrom's (2013) study try to answer if gender affected character interpretations. Fogolstrom (2013) did not find a pattern regarding gender and character interpretations. However, given the lack of research, I think this study has an opportunity to add knowledge to the academic community. In the introductory survey section, I will ask for the respondent's gender. After analyzing all of the data to answer this study's central question, I intend to go back through the data and see what gender corresponds with each answer. There may be a pattern between genders. This information is valuable to all game designers that are trying to cater to a specific audience.

\section{RQ3: What role does age play in how people perceive character design?}

Like the question regarding gender perception, only Fogolstrom (2013) tried to answer if age affects character interpretations. Fogolstrom (2013) also did not find a pattern regarding age and character interpretations. However, given the lack of research in this area, I think this study can add knowledge to the academic community. Exactly like I outlined in the question regarding gender, I will ask for the respondent's age in the introductory survey section. After analyzing all 
of the data to answer this study's central question, I intend to go back through the data and see the age that corresponds with each answer. It possible there will be a pattern between ages. This information is valuable to all game designers that are trying to cater to a specific audience.

\section{CHAPTER 3 METHOD}

\section{Research Design}

For my method, I proposed a qualitative test in the form of a questionnaire. I created my questionnaire with open-ended questions designed to promote a narrative response. The questionnaire is similar to a one-on-one interview; however, the interviewer will not be present at the time the respondent is writing down their views and feelings. According to Brennen (2013), an open-ended questionnaire is a type of interview in "contemporary society" and is a popular method for conducting qualitative research (p. 27).

Qualitative analysis is applicable to my proposed research questions. I want to find out what people see when they look at certain designed characters. What is their perspective? Brennen (2013) says qualitative research is the process of "using language to understand concepts based on people's experience. It attempts to create a sense of the larger realm of human relationships" (p. 4). My study is all about making sense of people's perceptions and how they relate to character design theories.

Color and shape theories both state that certain psychological emotions are triggered in individuals when they view shapes and colors. I strived to take a qualitative approach to this study because everyone interprets things differently. By using an open-ended questionnaire in this study, I felt like I could get the most descriptive and accurate results. Then I took those collected responses and compared them to both shape and color theories. The idea was not to 
influence or limit the participants with predetermined answers that may or may not represent their actual perception.

I wanted my qualitative data collection method to consist of open-ended questions and detailed answers. This study's goal was to gain insight into an audience's thoughts and behavior. Providing platforms for people to share their thoughts presents an opportunity to find new ideas and problems concerning character design.

I designed three characters, each with unique attributes, within a stylized video game world I created. This study examines how visual characteristics through shape and color theory can successfully communicate a character's personality. The goal is to successfully develop characters that express the intended personality traits suitable for the chosen video game's style. I have designed three characters, each with unique attributes and back stories.
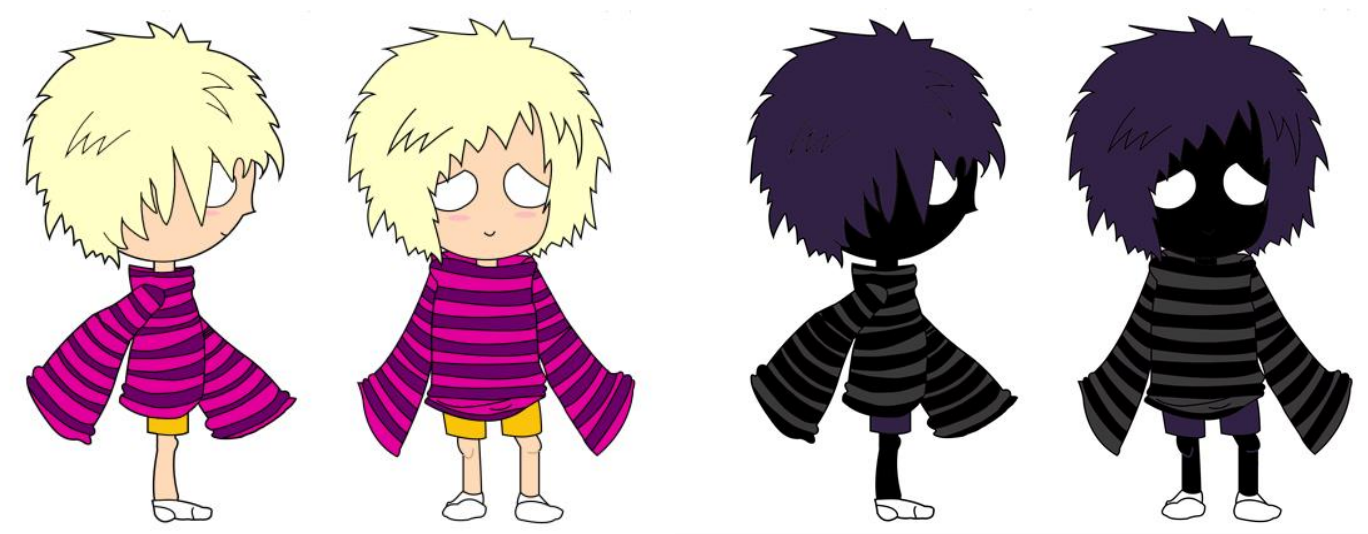

Figure 3.1 and Figure 3.2

The figure above is Sarah. Sarah is the protagonist of the game. Sarah is based on a circular concept and is intended to be a likable character. Her proportions are commonly used for friendly characters, with a large head and a small body (Solarski, 2012, p. 181). However, as the game progresses, Sarah is exposed to a toxic chemical that brings out her evil side, thus creating a different appearance. 
The choice of colors and shapes are based on color and shape theory principles outlined previously in this paper. For instance, yellow was chosen for her hair to demonstrate her good side. Yellow generally evokes feelings of joy, happiness, intellect, liveliness, and optimism (Tillman, 2011, p. 112). For her evil, the color black was chosen because it generally evokes the feeling of power, formality, death, evil, mystery, fear, grief, sophistication, strength, depression, and mourning (Tillman, 2011, p. 114). The questionnaire will display these designs separately and ask participants questions regarding their appearance and possible motives.

To make the visualization of shape easier for this study's participants, I will provide silhouette outlines of this character, which was successfully demonstrated in Ekstrom's (2013) research.
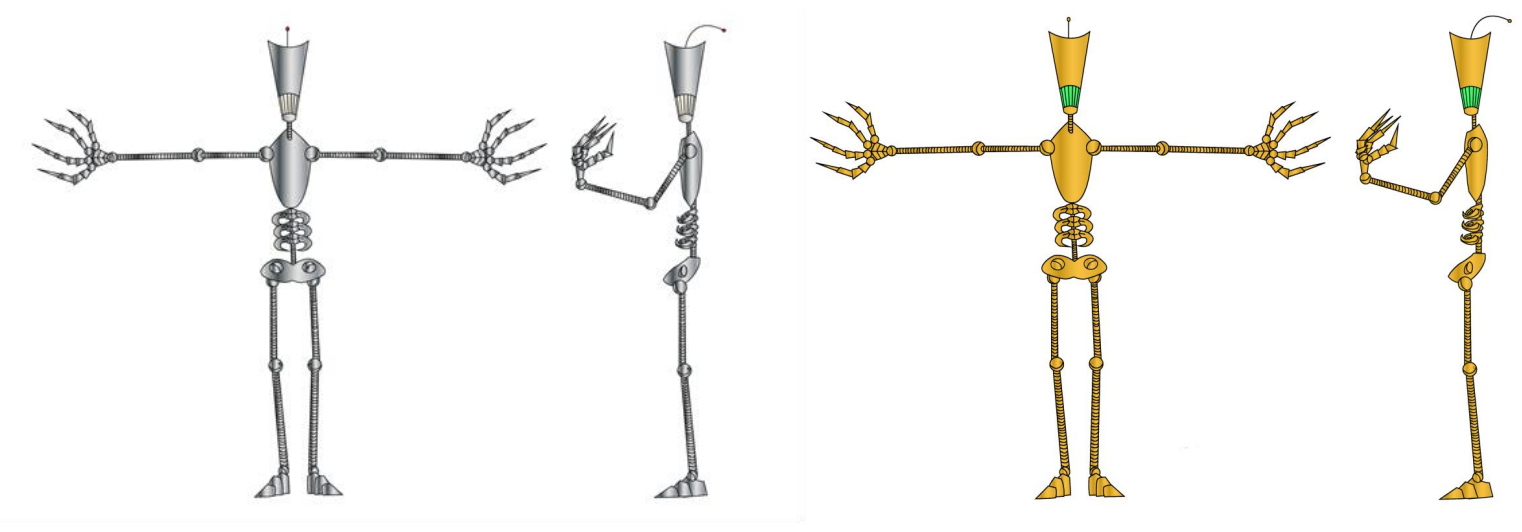

Figure 3.3 and Figure 3.4

The figure above is a Harvester Bot. The Harvester Bots are a supporting evil character in the game. The Harvester Bot is based on a tall rectangular concept and is intended to be a dangerous game obstacle. Its proportions are commonly used for loyal and devoted characters, with a tall, slender body with sharp fingers (Bancroft, 2006, p. 34). The Harvester Bots have no will of their own, and they are entirely devoted to the main antagonist. Their sole purpose is to take orders from the main antagonist. 
The choice of colors and shapes are based on color and shape theory principles outlined previously in this paper. For instance, the color gray was chosen because it is emotionless, dull, and conservative (Tillman, 2011, p. 115). The color orange was chosen because it evokes feelings of cheerfulness, enthusiasm, happiness, and wisdom (Tillman, 2011, p. 93). These are traits that the Harvester Bot is not supposed to have based on its back story. The aim is to strengthen the importance of choosing an appropriate color palette. The questionnaire will display these designs separately and ask participants questions regarding their appearance and possible motives.
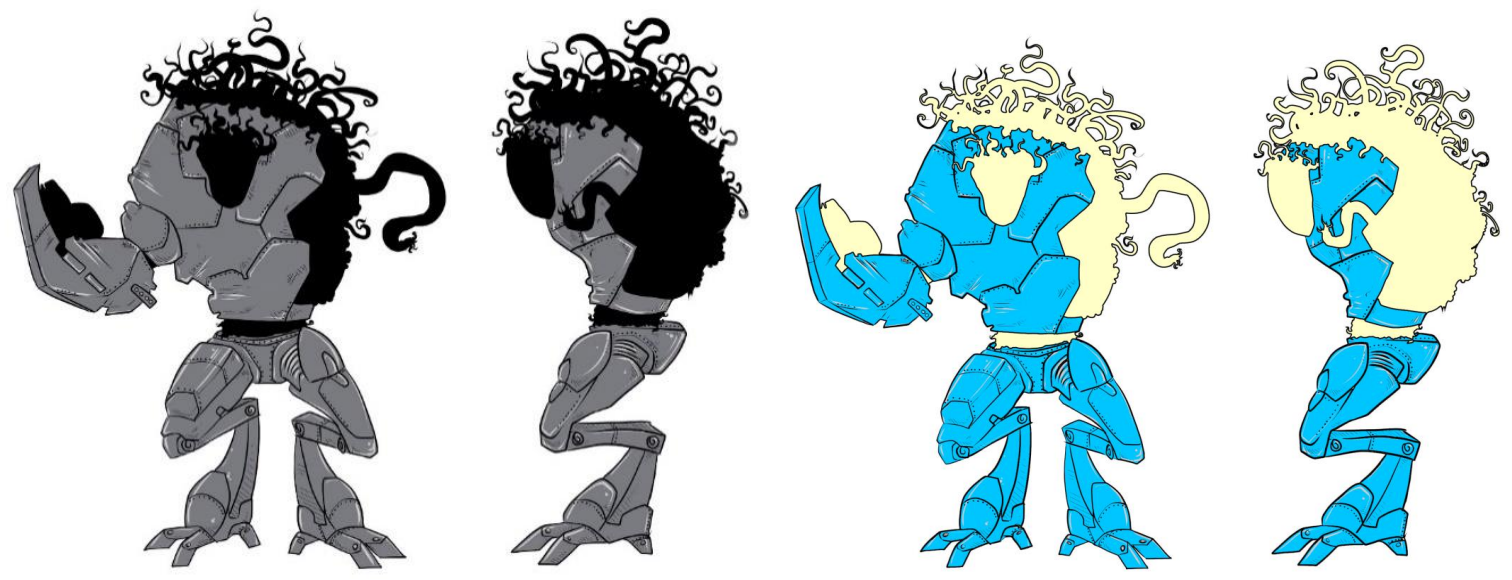

Figure 3.5 and Figure 3.6

The above figure is The Sightless One. The Sightless One is the main antagonist in the game and is based on a bulky triangular concept. It is intended to be a fearsome force that players struggle to overcome. Its proportions are commonly used for menacing characters, with a bulky asymmetrical body (Solarski, 2012, p. 181). The Sightless One's purpose is to create a post-apocalyptic world where it can rule over all of its inhabitants.

The choice of colors and shapes are based on color and shape theory principles outlined previously in this paper. For instance, the color black generally evokes the feeling of power, formality, death, evil, mystery, fear, grief, strength, depression, and mourning (Tillman, 2011, p. 
114). The color blue was chosen to evoke feelings of trust, loyalty, wisdom, confidence, healing, tranquility, understanding, softness (Tillman, 2011, p. 92). These are traits that the Sightless One is not supposed to have based on its backstory. The aim is to strengthen the importance of choosing an appropriate color palette. The questionnaire will display this design separately and ask participants questions regarding its appearance and potential motives.

\section{Sample Population}

I distributed this study over one month using Google Forms to gather data. My desired sample pool was anyone who has played video game-related content at some point in their life and is over 18. To collect accurate data, I decided to only to accept the first twenty participants. I utilized multiple online gaming community forum services, such as NeoGAF, GameFAQs, IGN, Gamespot, and Reddit. I made a post on each of these platforms inviting prospective test participants to participate. I provided a link that directed them to the questionnaire on Google Forms.

I was interested in the responses from people who have played video games in the past because I hoped they would draw on some of those personal experiences when answering my proposed questionnaire. I incorporated a yes or no type of question as part of a preliminary introduction to the questionnaire. Questionnaires that were not filled out entirely were removed from the results. This was due to insufficient data, and it may have skewed the results. However, this did not occur, so no surveys were omitted.

\section{Gathering Data}

Since I created a Google Forms document that held the questionnaire, I directed participants to this document to fill out. I set the settings within Google to send me an email when the participants finished the submission process. Google stored all the answers the 
participants provided in an easy-to-read format. I then put the submissions into separate folders to quickly reference them for analysis. I figured this was the most efficient way to gather and organize all the data.

For each character design, I asked a set of three questions. Each question is designed to focus on the participant's initial perception. For example:

1. Describe the overall shape of the above design.

2. Describe your overall impression of the above character.

3. What personality traits do you associate with the above character, and why?

In addition to these open-ended questions, I started the questionnaire off with some typical close-ended demographic-related questions. Subjective opinions and experiences will affect the results, and Tillman (2011) indicated that different cultures had affected color theory in past studies (p. 116). This study was also interested in determining patterns in perception among gender and age, so background questions about the participants were included in the questionnaire. Three questions were decided on to be used to collect background information. They are as followed:

1. What is your gender?

2. What is your age?

3. Have you ever played a video game?

After assigning numerical values to the coded participant's responses, I compared them with the compiled demographic data utilizing graphs to illustrate my findings. All the data was gathered into bar graphs that demonstrated the research findings. A bar graph seemed to be the most applicable with the amount of data collected.

\section{Coding Process}


Since I asked predominantly open-ended questions, I expected short to medium-range answers in different formats. I had an idea of the types of things the respondents would say, but I genuinely had no clue how they would perceive each design. Therefore, I used a textual analysis approach for compiling answers. I created three main categories: positive, negative, and neutral. These categories were based on the words and phrases from the responses I received. This method type of data collection and observation is called analytic induction (Jankowski \& Wester, 1991, p. 66). Utilizing a grounded theory method, I used an open-coding procedure. According to Jankowski and Wester (1991), grounded theory is the procedure of analytic induction and the discovery of emerging patterns in data (p. 67). While open-coding, I looked at the underlying meaning and uniform patterns in and across the data collected (Saldana, 2008, p. 6). Since I used a grounded theory method, I looked for theoretical coding throughout the textual analysis. During theoretical coding, I attempted to create a conceptual ordering of words and phrases to find connections between concepts that arose from the open-coding process. The theoretical coding process related to the main established categories and the relationships between categories and subcategories were analyzed.

My first step was to use a line-by-line approach to carefully examine words, phrases, or sentences for data relevant to the overall research question. If the response was a few sentences, I scanned the paragraphs for units of meaning and patterns of words pertinent to answering the research question, which was then denoted into descriptive codes. I expected many different codes, so I utilized a combination of Google Forms and Microsoft Excel to stay organized.

After conducting a line-by-line coding process, I then grouped the descriptive codes into similar categories. This process is called codifying (Saldana, 2008, p. 9). The categories are labeled to signify the interpretation represented by the grouping of the codes. Some categories 
were just temporary, though, as there were some revisions and regrouping throughout the analysis process (Saldana, 2008, p. 12).

In the last step, I established relationships conceptually by creating a hierarchy of categories and subcategories. Each main category was divided into separate subcategories (Saldana, 2008, p. 11). Saldana (2008) warned that this process could get messy, so I tried not to sub-categorize too much (p. 11). Saldana (2008) indicated the processes of coding, categorizing, and conceptual ordering will be a "cyclical act" with the researcher moving back and forth from one to the other (p. 9). The relationships that were explored and reduced were narrowed down to the least number of categories possible. Each word and phrase was coded, categorized, and conceptually ordered carefully before bringing this process to a full conclusion.

\section{Coding Procedure}

For the first character and RQ1, each question and design was coded individually. In other words, each visual design was treated separately. After looking at the responses, I categorized each word and phrase into three main categories: positive, negative, and neutral, based on how the respondents perceived each visual. For example, with Character 1 / Color Palette 1, I received some responses in the form sentences, so I looked for key descriptive words. I pulled out these words sweet, innocent, happy, cute, bright, cheerful for the positive category. All these words were placed into subcategories under a positive theme based on their general meaning and definition. The same steps were repeated for each character and question to obtain the results.

For RQ2 and RQ3, which pertain to age and gender, I used a similar procedure to RQ1. However, I divided and sectioned each survey submission into four age demographics: 18-25, 26-35, 36-45, 46 or older. For analyzing gender, I utilized three classifications; male, female, and 
prefer not to say. To answer RQ2 and RQ3, I focused the analysis on the quantitative question about the character's shape and the qualitative question asking for the respondents to list the traits they see in the design. Both questions are pertinent to answering both RQ2 and RQ3, respectively. Every response presented compelling results that, when analyzed and compared, helped answer my three research questions.

\section{Maintaining Credibility}

In addition to the coding procedure outlined in this paper, I included the definitions of each word I pulled out of the text in the appendix. I specifically stated my thought process for each coding category and the criteria I looked for when categorizing the data. I also implemented a test-retest method that required me to code the data sets without looking at the results. Once I had compiled the results, I then compared them for consistency with the other questions.

Ensuring consistency was difficult while inductive coding. My mental state and past experiences played a role in how I interpreted the data. For example, if a different person was given the same data, they may disagree with the codes I chose. (Zade, Drouhard, Chinh, Gan, \& Aragon, 2018, p. 1). A study by Zade et al. (2018) showed that different people coding the same survey would produce different results (p. 7). Brennen (2013) also said that some people would decode a text as the author intended regarding textual coding; others will take a negotiated position or oppositional view (p. 200). I attempted to mitigate this issue by logging all decisions and thoughts in the appendix of this paper. Not only did this help maintain credibility for this study, but it also aided in reviewing previous codes quickly to see if a new one was necessary. In addition, this process provided evidence to back up the choice of codes.

I also conducted a pilot study before the main study. The pilot study presented an opportunity to try out the survey with a few participants and to make adjustments before the 
main research. I wanted to conduct a pilot study to ensure that the respondents would understand the terminology in the questionnaire. The pilot study also served as an opportunity to check for bias terminology in the questions that may have impacted the participants' responses. This also ensured that the questionnaire could be completed in an appropriate time frame.

\section{CHAPTER 4 ANALYSIS AND RESULTS}

\section{RQ1: How do people associate character personality traits with geometric shapes and color palettes?}

\section{Character 1}

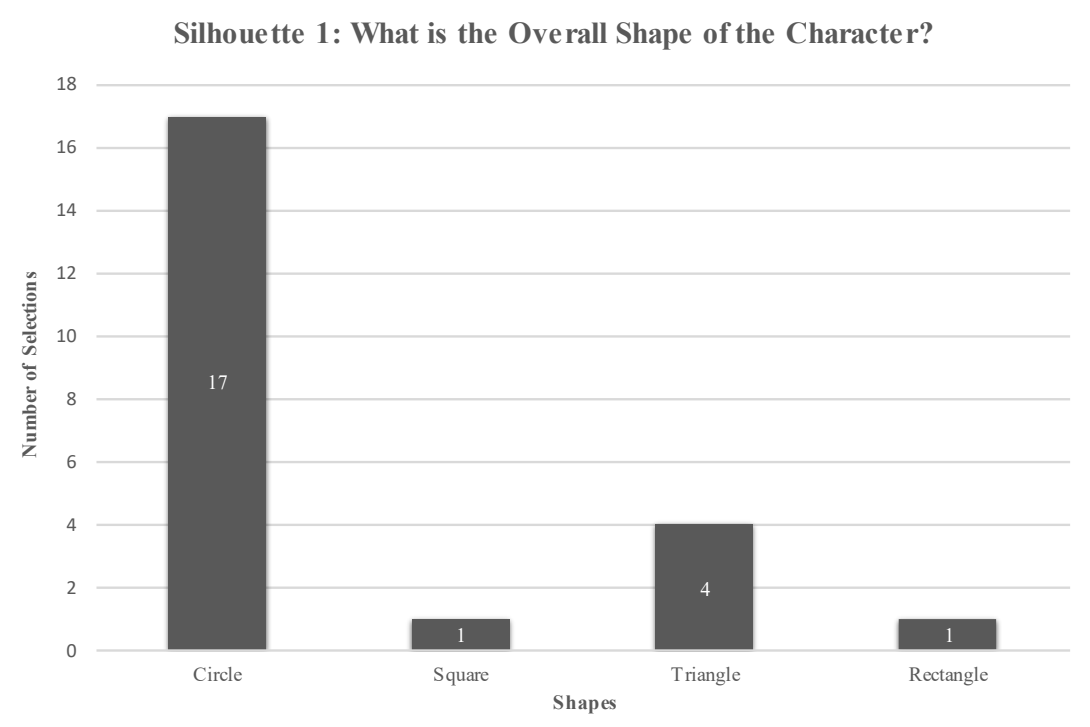

Figure 4.1: Silhouette 1 (What is the oval shape of the character?)

The first character was created based on a circular concept. From the data collected, nearly all the respondents, seventeen, associated this character with a circle. At least one person saw every shape in the design, but $85 \%$ of respondents confirmed that the design visually looks like a circle. Solarski (2012) stated, "Many of the most well-known protagonists are designed 
around circular concepts," so if this is true, then the answers should correlate with this theory (p. 180).

Silhouette 1: Describe Your Overall Impression of the Character.

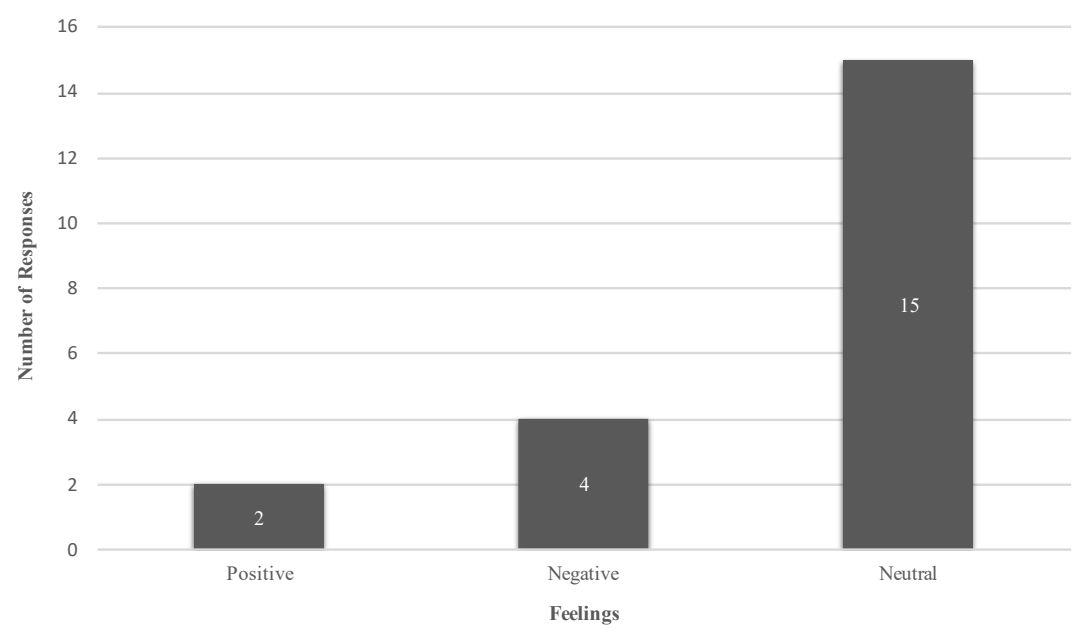

Figure 4.2: Silhouette 1 (Describe your overall impression of the character.)

Based on the data collected while only analyzing shape, most people were unsure what to think at this point. Most of the respondents chose to describe what they thought the silhouette was rather than focus on how the visuals made them feel. Neutral responses seemed to dominate this category with fifteen words or phrases. There were two positive and four negative words or phrases. Many respondents used neutral descriptive words, such as shy, child, kid, and hipster. 
Character 1 / Color Pale tte 1

Describe Your Overall Impression of the Character.

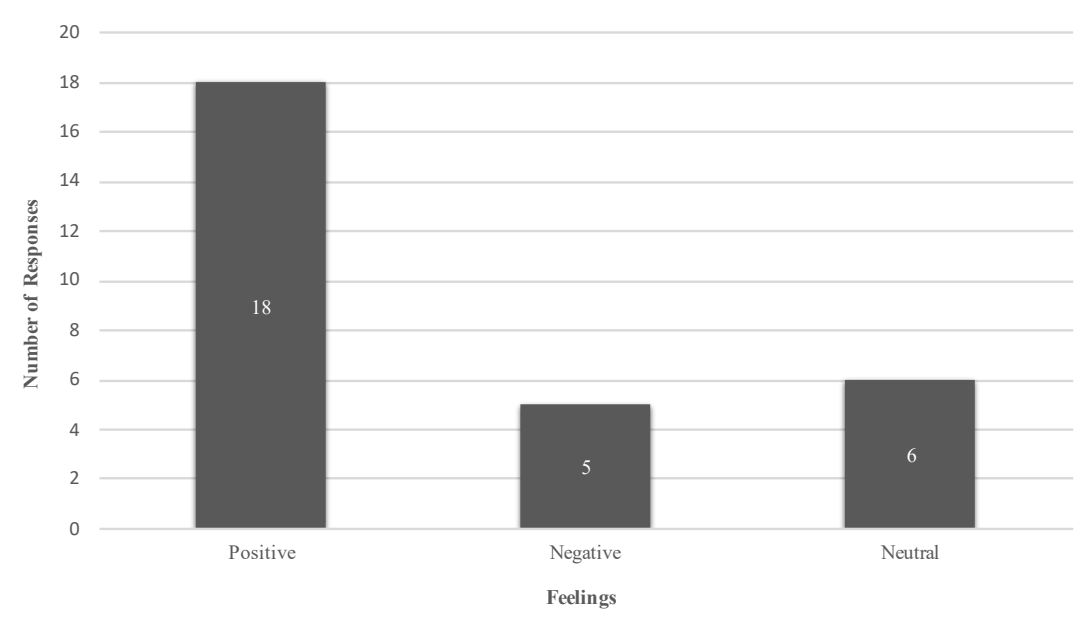

Figure 4.3: Character 1 / Color Palette 1 (Describe your overall impression of the character.)

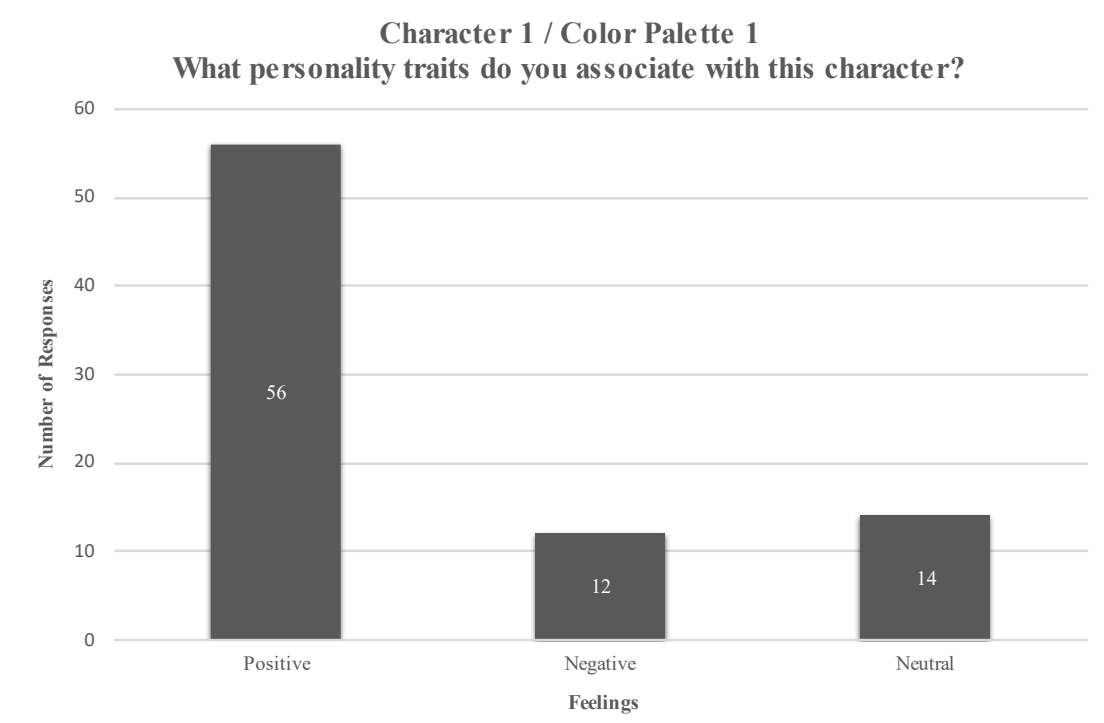

Figure 4.4: Character 1 / Color Palette 1 (What personality traits do you associate with this character?) 
Once a color palette was introduced, many of the respondents' impressions became more confident, as revealed by the more positive responses. $62 \%$ of words or phrases were categorized as positive when participants described their overall impression of the character. $68 \%$ of the descriptive words given were also positive when listing the character's traits. Some of the most common positive descriptive words were sweet, cheerful, humble, gentle, quiet, good, happy, innocent, caring, and loving.

Character 1 / Color Palette 2

Describe Your Overall Impression of the Character.

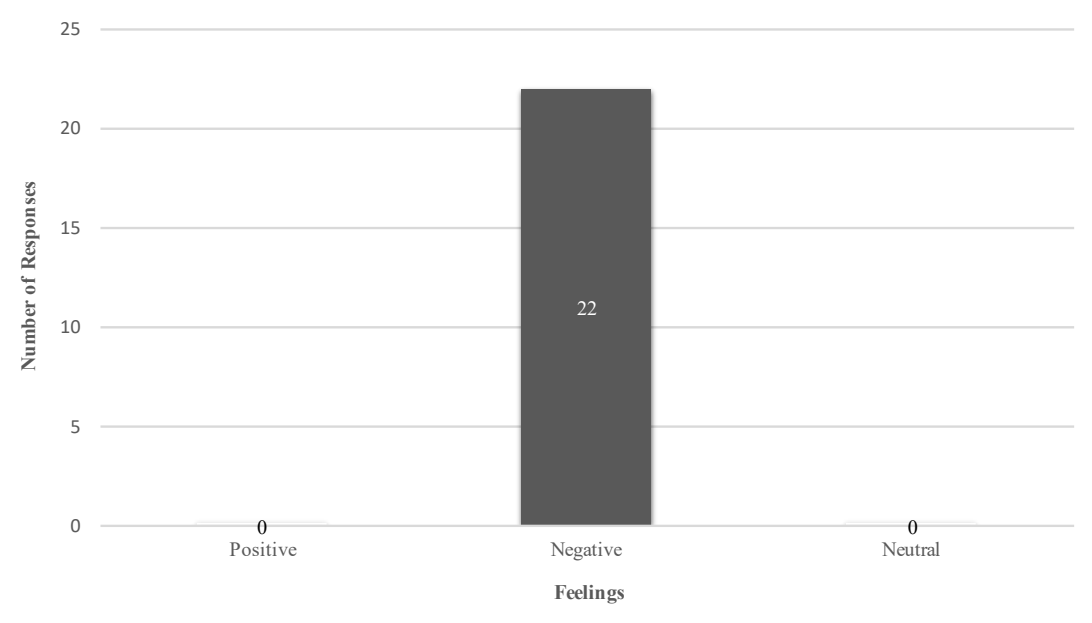

Figure 4.5: Character 1 / Color Palette 2 (Describe your overall impression of the character.) 


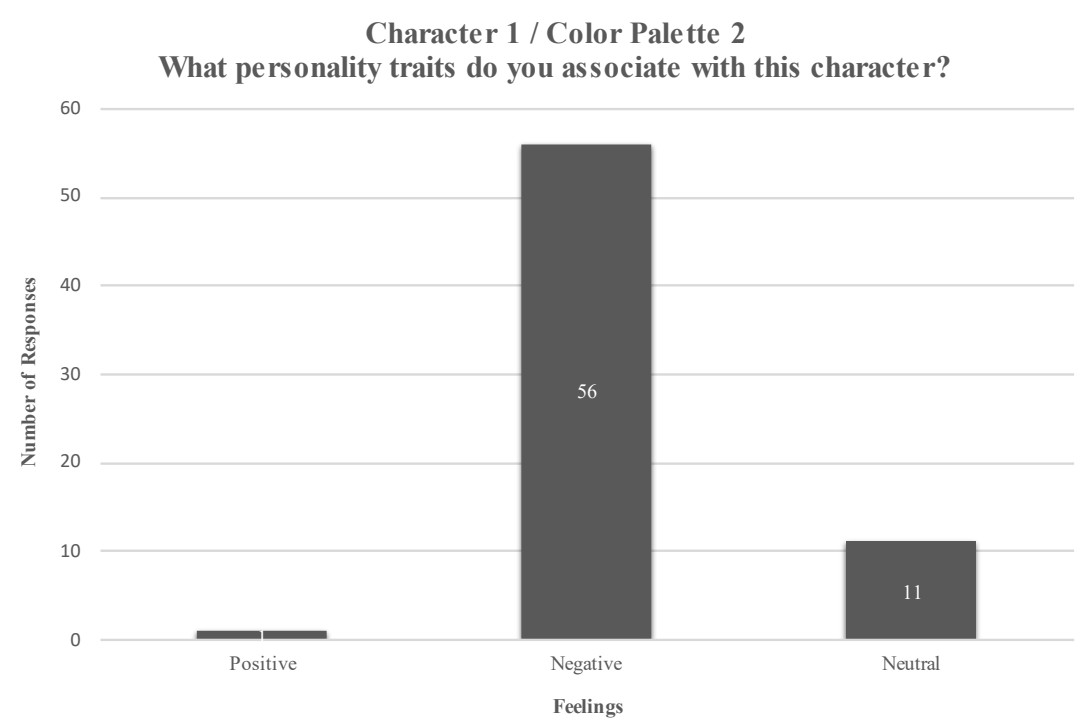

Figure 4.6: Character 1 / Color Palette 2 (What personality traits do you associate with this character?)

When a different color palette was introduced for the same character, nearly everyone's perception changed. No one stated they saw the character positively, with $100 \%$ of responses presenting a negative tone in describing their overall impression. When describing the character with traits, nearly all the descriptions fell into a negative or neutral category, with only one trait being classified as positive. $82 \%$ of the words chosen to represent this character were viewed as negative among the respondents. Respondents frequently used words such as depressed, sad, dead, soulless, dark, and evil.

\section{Character 2}




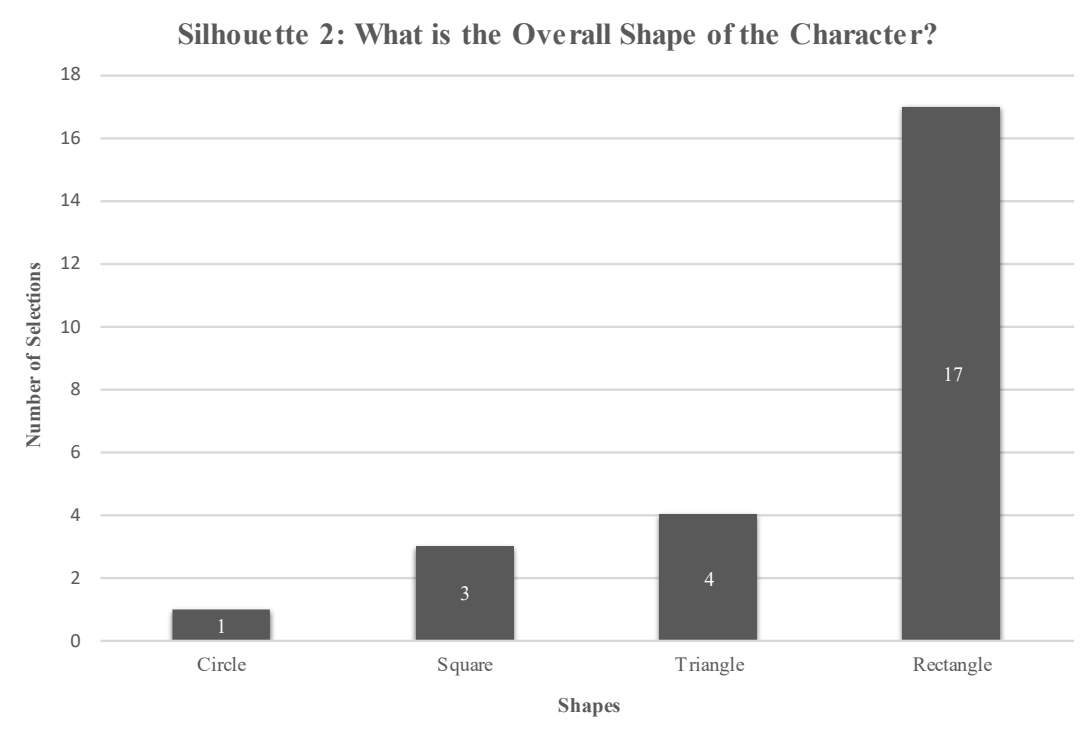

Figure 4.7: Silhouette 2 (What is the oval shape of the character?)

The second character was created with a rectangular concept in mind. When the participants were asked what the silhouette's overall shape is, seventeen of the respondents associated the design with a rectangle. Like the first character, at least one person selected every shape, but $85 \%$ of respondents confirmed the design visually looks like a rectangle. Bancroft (2016) said, "Shapes in the orientation of a square relate to straight, vertical, and horizontal lines that display strength, stability, and confidence (p. 34). Since rectangles can also evoke similar emotions based on their straight, vertical, and horizontal lines, this character should inspire similar feelings. 
Silhouette 2

Describe Your Overall Impression of the Character.

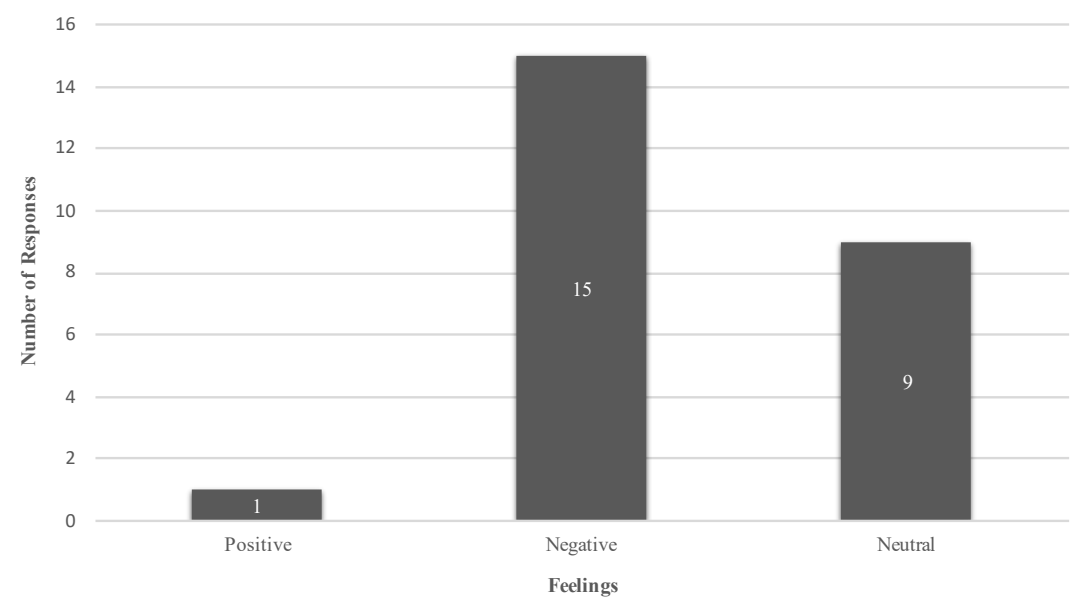

Figure 4.8: Silhouette 2 (Describe your overall impression of the character.)

When analyzing shape only, it seems that most people felt negative about the figure. Like the first character, most of the respondents chose to describe what they thought the silhouette was rather than focus on how the visuals made them feel. However, negative responses took this category, with $60 \%$ of people seeing this silhouette negatively. 
Character 2 / Color Pale tte 1

Describe Your Overall Impression of the Character.

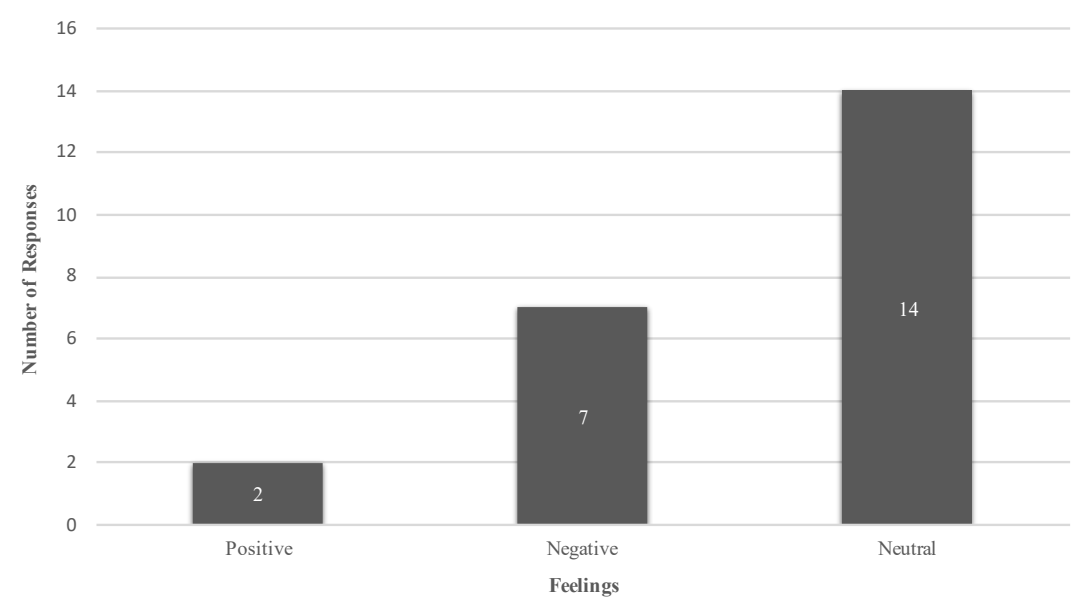

Figure 4.9: Character 2 / Color Palette 1 (Describe your overall impression of the character.)

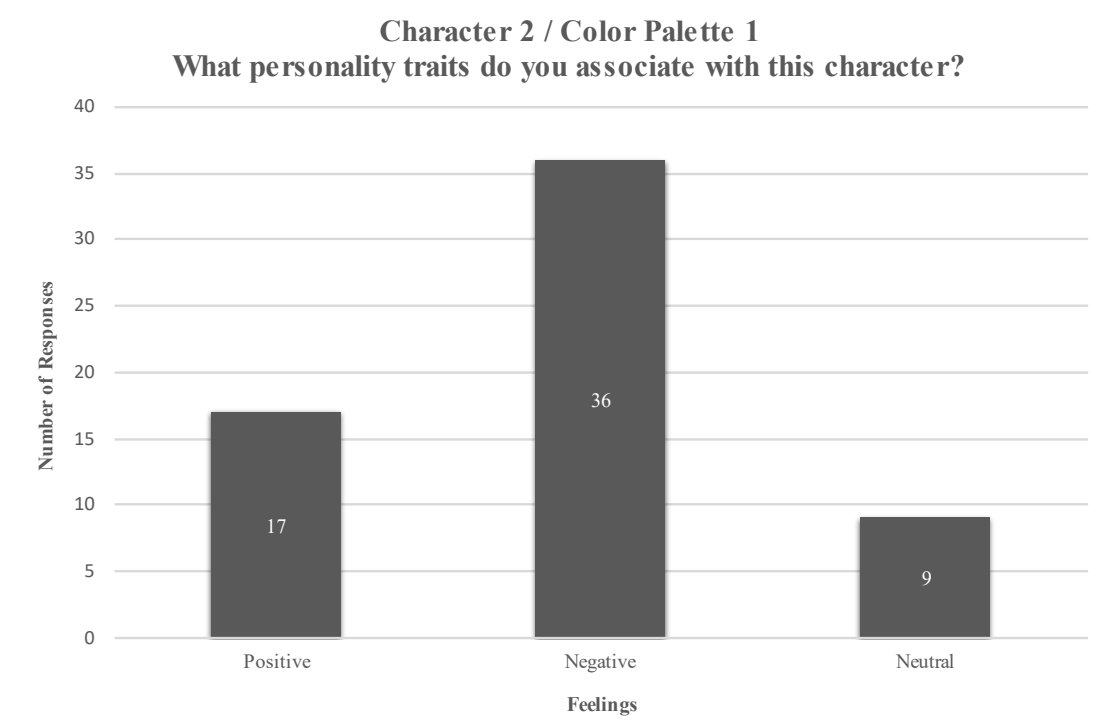

Figure 4.10: Character 2 / Color Palette 1 (What personality traits do you associate with this character?) 
Interestingly, after introducing color, many people shifted their impression response to more of a neutral tone. $61 \%$ of the responses indicated a neutral approach to describing their overall impression. Many respondents used words like mindless, skinny, skeleton, scarecrow, robotic, and alien. However, when they were asked to assign certain traits, they saw this character in a negative light. Some negative descriptive words often used were angry, aggressive, loud, evil, dangerous, pessimistic, scary, sinister, and deceptive. Thirty-six words were categorized as negative, with positive words showing up seventeen times. Nine words were neutral, but there was a dramatic increase in negative descriptive words.

Character 2 / Color Pale tte 2

Describe Your Overall Impression of the Character.

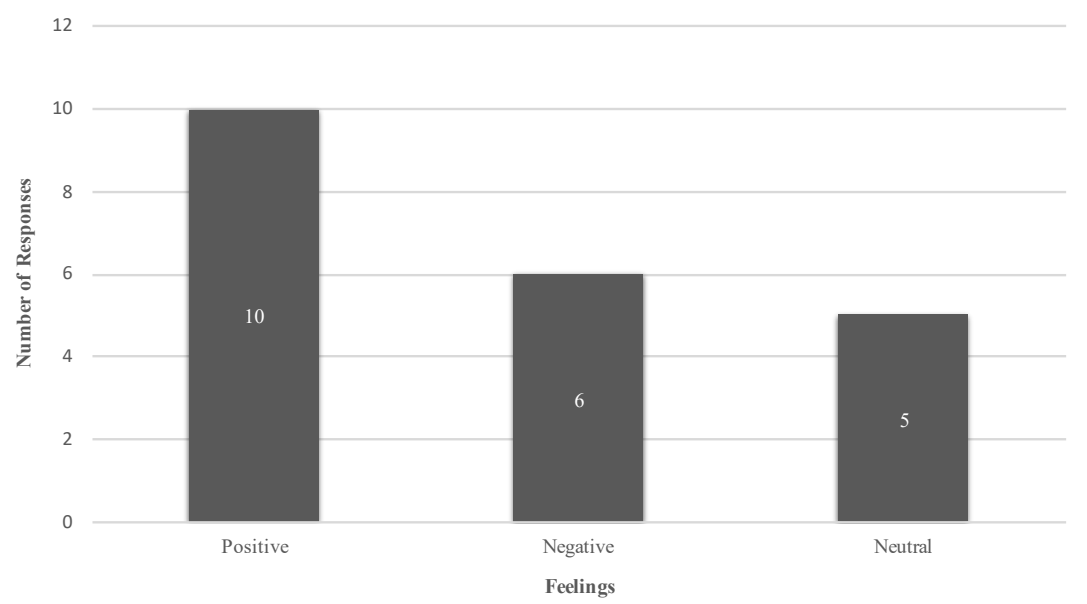

Figure 4.11: Character 2 / Color Palette 2 (Describe your overall impression of the character.) 


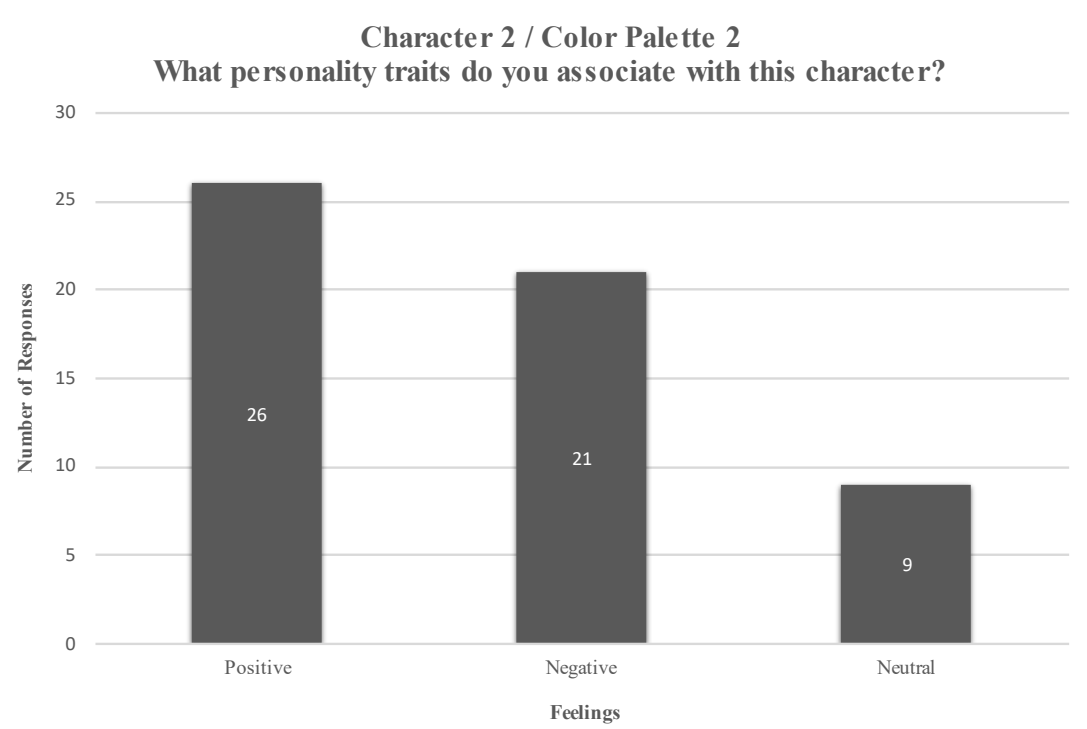

Figure 4.12: Character 2 / Color Palette 2 (What personality traits do you associate with this character?)

After a different color palette was introduced for the same character, many of the respondent's opinions changed. Participants used descriptive words like cheerful, friendly, intelligent, and happy. There was still a fair amount of people that perceived this character negatively, but there is no doubt there was also a shift in overall perception. When respondents assigned character traits, most of the viewers felt it necessary to state positive descriptive words with twenty-six words as opposed to twenty-one words that fell into the negative category. Respondents used words like dependable, cheerful, good, obedient, knowledgeable, and cunning. Both questions regarding this color palette were more consistent than color palette one, with the first question revealing $48 \%$ positive keywords compared to the second question giving $46 \%$ positive answers.

\section{Character 3}




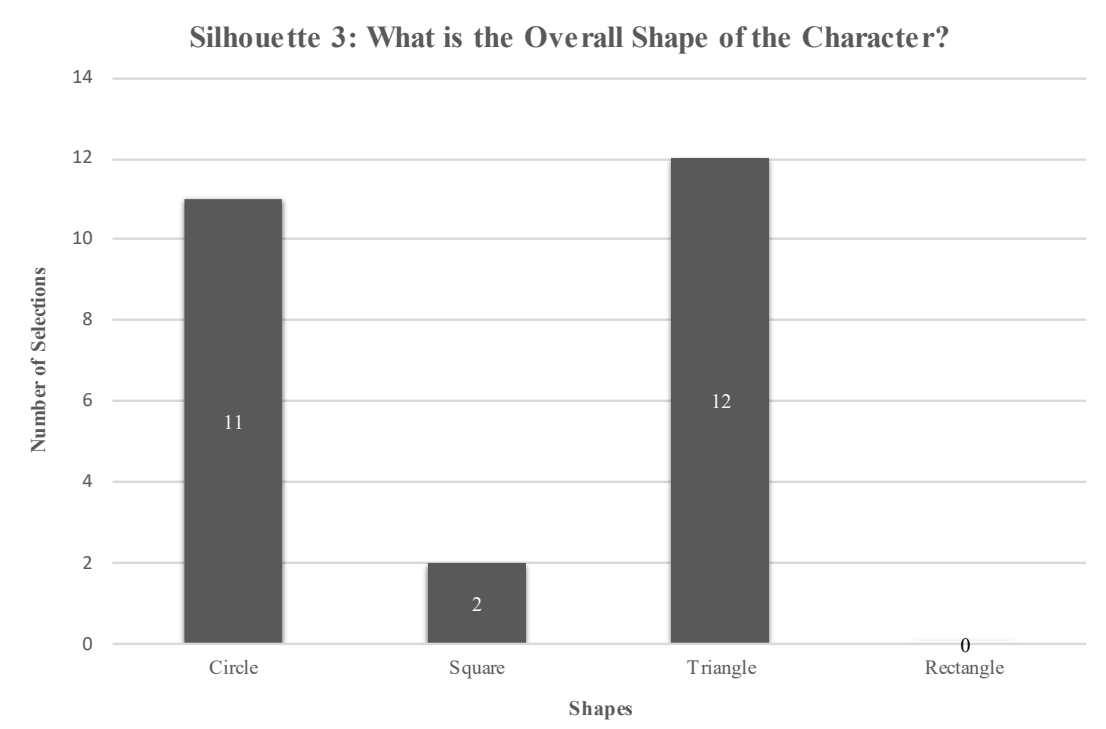

Figure 4.13: Silhouette 3 (What is the oval shape of the character?)

The third character's design was based on a triangular concept. However, according to the data, eleven people saw this character as a circle. Still, the majority of respondents selected a triangle with twelve, but in shape theory, these shapes evoke opposite emotions. Unlike the other two characters, not all the shapes were selected, with no one thinking this character was a rectangle. Technically, most respondents confirmed this design visually looked like a triangle, but a circle was close behind. Solarski (2012) stated, "Most antagonists are designed around triangular concepts" (p. 180). 
Silhouette 3

Describe Your Overall Impression of the Character.

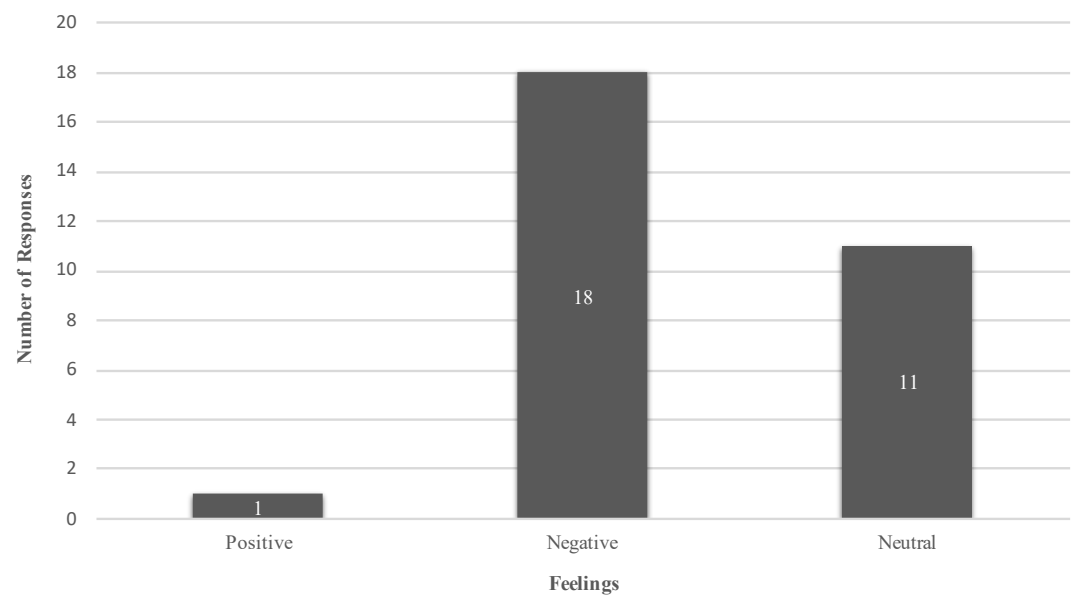

Figure 4.14: Silhouette 3 (Describe your overall impression of the character.)

When analyzing shape only, it seems that most people felt negative about the silhouette design. Like the previous two characters, many of the responses focused on the silhouette rather than how the visual made them feel. Even so, negative reactions took this category, with eighteen words or phrases being categorized as negative. 
Character 3 / Color Pale tte 1

Describe Your Overall Impression of the Character.

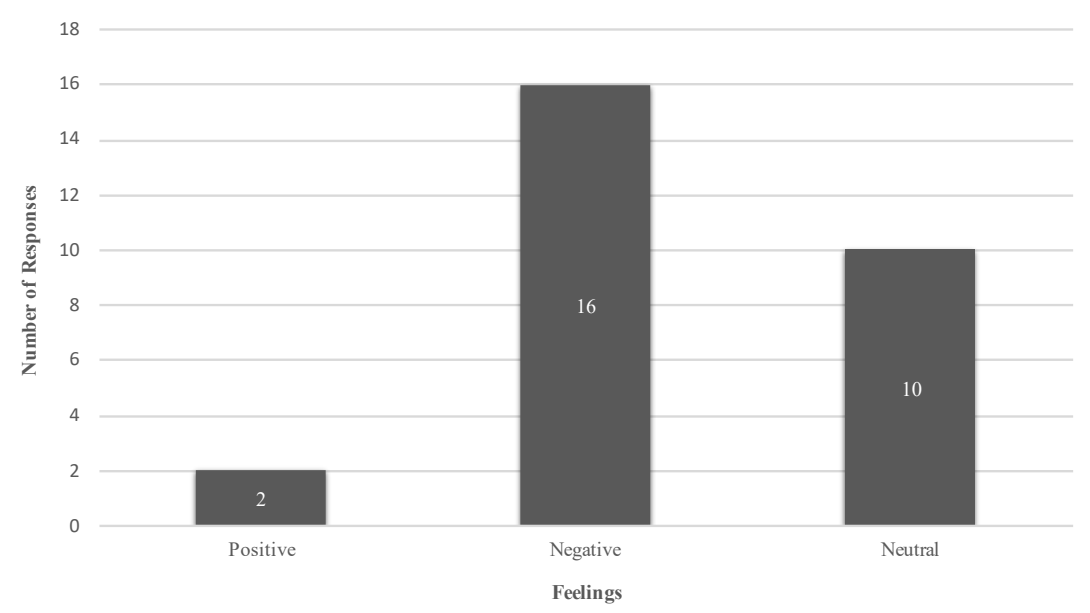

Figure 4.15: Character 3 / Color Palette 1 (Describe your overall impression of the character.)

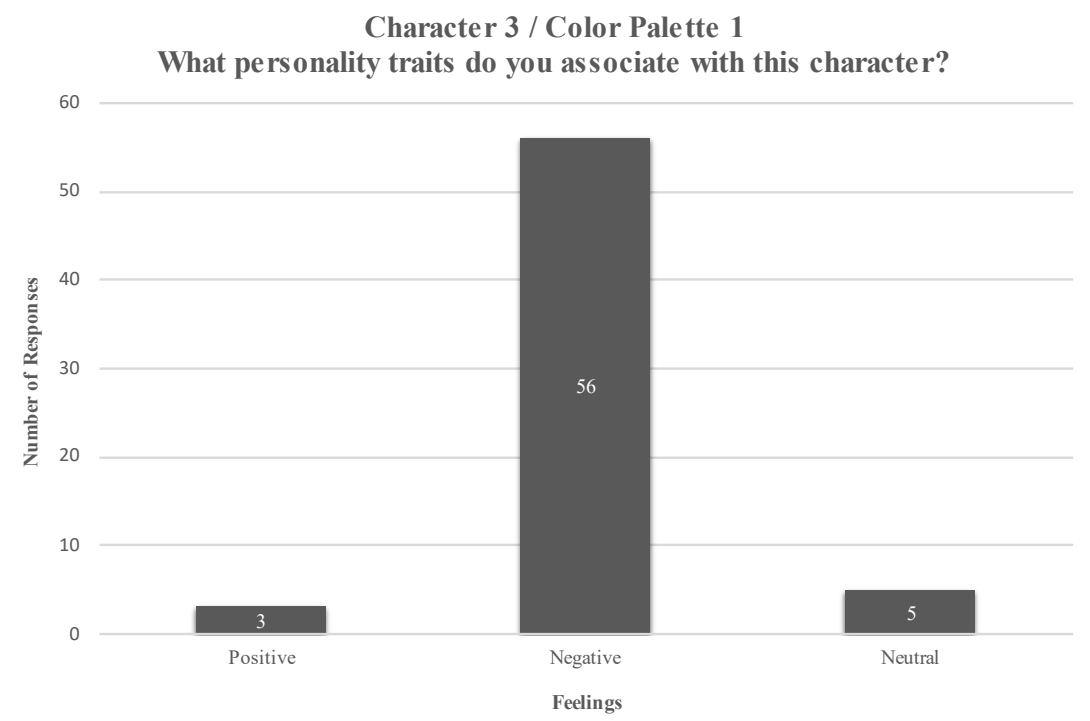

Figure 4.16: Character 3 / Color Palette 1 (What personality traits do you associate with this character?) 
Once a color palette was introduced, the data stayed relatively the same. Negative words and phrases populated most of the overall impression responses with 57\%. Words such as, dark, evil, depressed, scary, and angry populated most responses. When the participants were asked to assign traits to the character, the negative descriptions pulled well ahead of neutral words. Fiftysix words were categorized as negative, with neutral words showing up five times. Only three words were viewed as positive, and negative descriptive words dominated the answers. Some of the most frequently used negative traits were angry, aggressive, evil, pessimistic, loud, dark, evil, depressed, and fickle.

Character 3 / Color Pale tte 2

Des cribe Your Overall Impression of the Character.

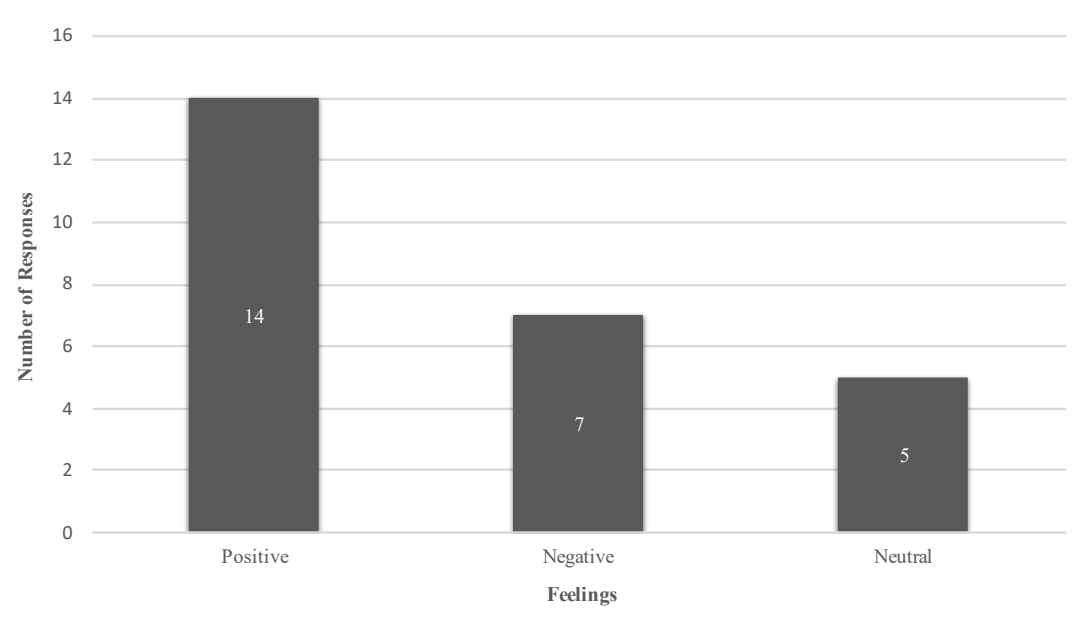

Figure 4.17: Character 3 / Color Palette 2 (Describe your overall impression of the character.) 


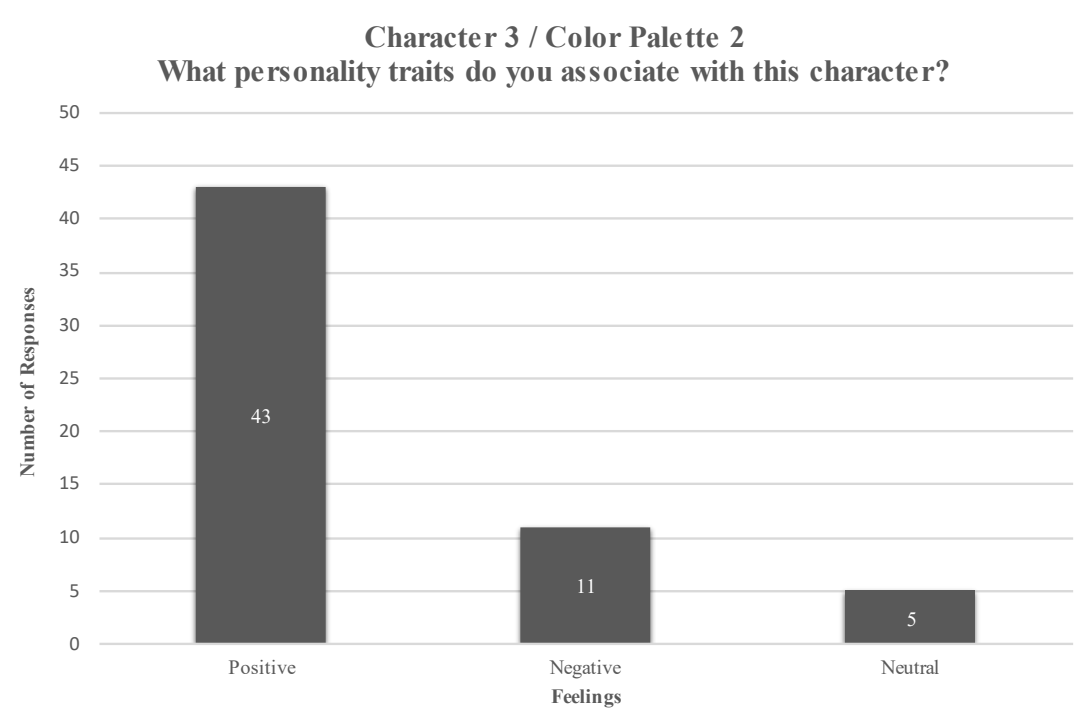

Figure 4.18: Character 3 / Color Palette 2 (What personality traits do you associate with this character?)

Once a different color palette was presented, many of the respondent's opinions changed. Their overall perception shifted predominately to positive. Words like happy, bright, nice, friendly, helpful, and cuddly filled the respondent's answers. Fourteen people saw the character positively compared to seven negative descriptions. When respondents were asked to assign character traits, most of the viewers typed in forty-three positive words as opposed to eleven negative words and five neutral words. When people were asked to describe their overall impression of the character, the responses were mostly positive. Many respondent's answers featured words like optimistic, good, bright, cheerful, good, silly, cuddly, nice, and gentle. However, not by as wide of a margin as when people were asked to state character traits. $73 \%$ of the character traits given were categorized as positive.

\section{RQ2: What role does gender play in how people perceive character design?}




\section{Character 1}

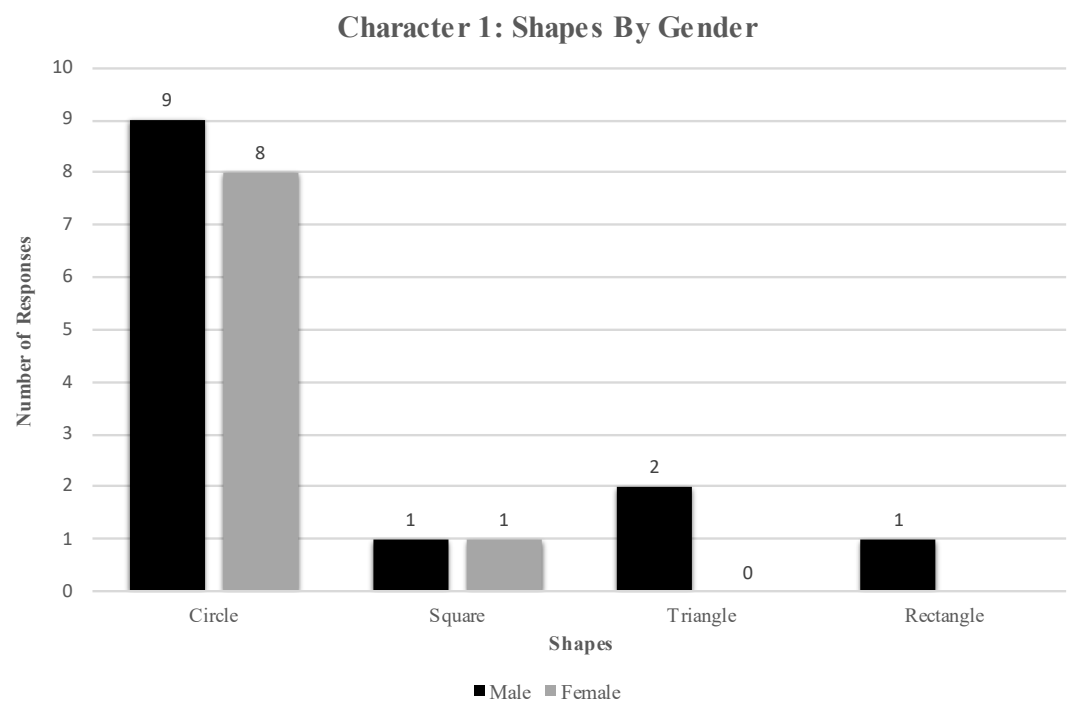

Figure 4.19: Character 1 (Shapes by gender)

Both genders appear to interpret the shapes of characters in similar ways. For Character 1, nine males selected a circle as compared to eight that select circle among females. However, there were a few males that chose a triangle and a rectangle. Still, the data looks similar for both genders. 


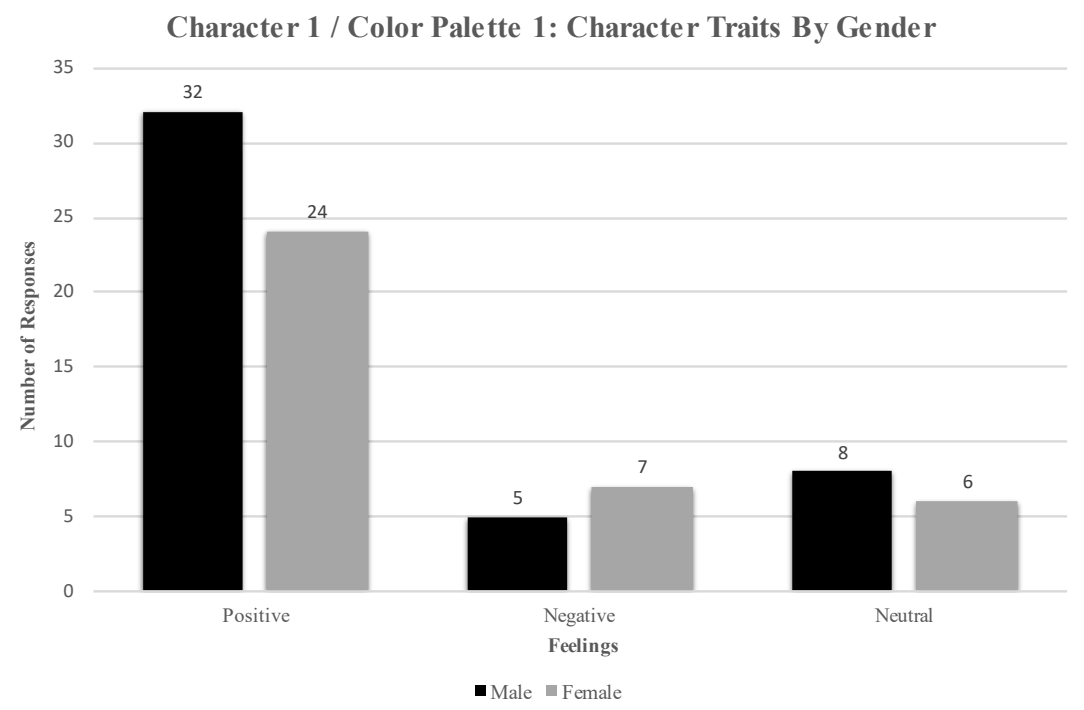

Figure 4.20: Character 1 / Color Palette 1 (Character traits by gender)

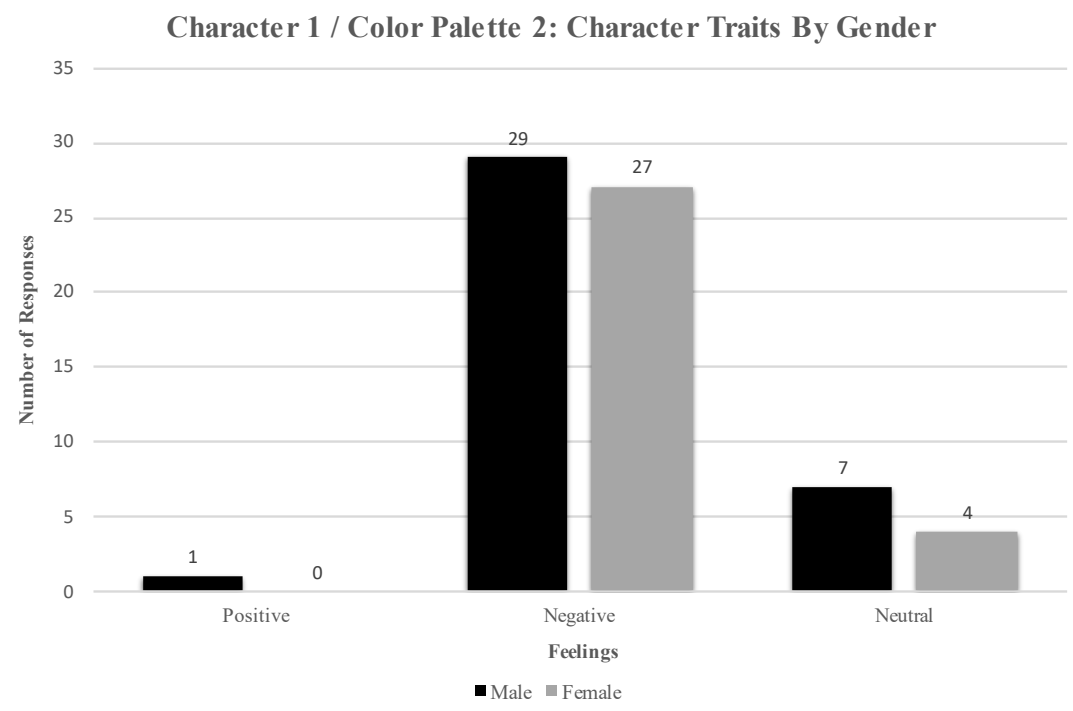

Figure 4.21: Character 1 / Color Palette 2 (Character traits by gender) 
When respondents were asked to list character traits associated with Character 1 / Color Palette 1, the choices were slightly different but still similar. It should be noted that among the twenty participants, eleven were male, and nine were female, to explain the slight deviation in the results. However, most males and females viewed the character positively, with thirty-two positive words coming from males and twenty-four coming from females.

For Character 1 / Color Palette 2, the perception flipped with color palette one, but the answer deviation narrowed. The majority of responses were categorized as negative words, with twenty-nine coming from males and twenty-seven from females. The number of neutral words was similar, with seven words being listed from males and four from females.

\section{Character 2}

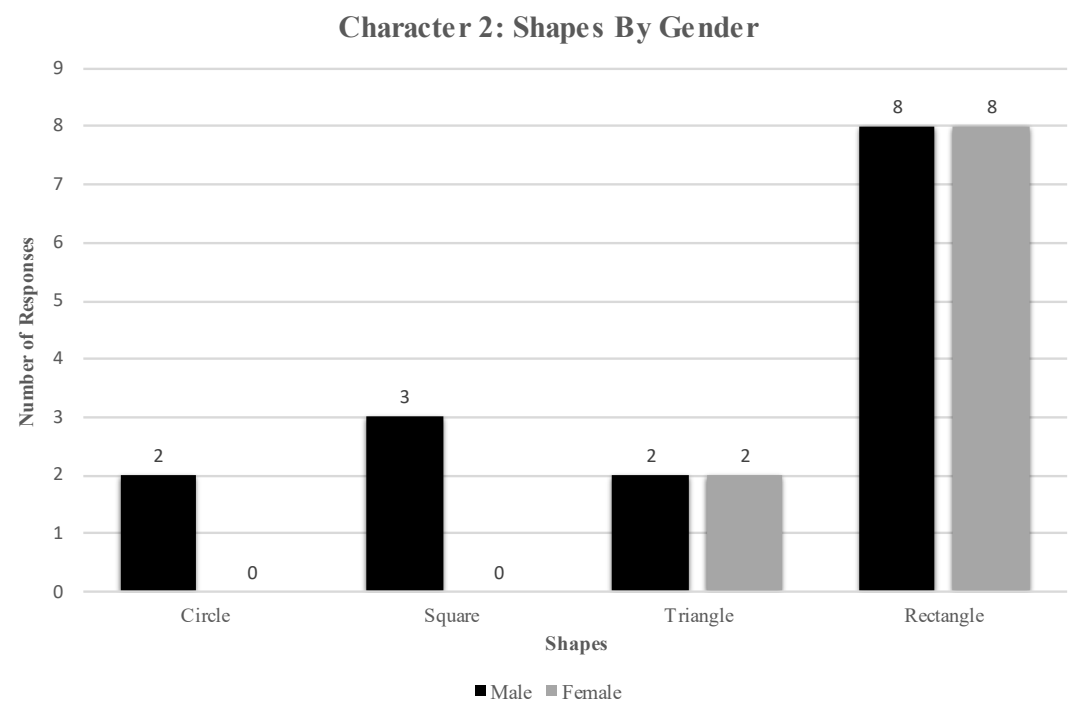

Figure 4.22: Character 2 (Shapes by gender)

For Character 2, there was an even split among both genders that selected rectangle, with eight. An even split also occurred when two respondents from both genders associated a triangle 
with the character. However, three males thought the character looked like a square, and two males saw a circle. No female among the respondents selected either a circle or a square.

Character 2 / Color Palette 1: Character Traits By Gender

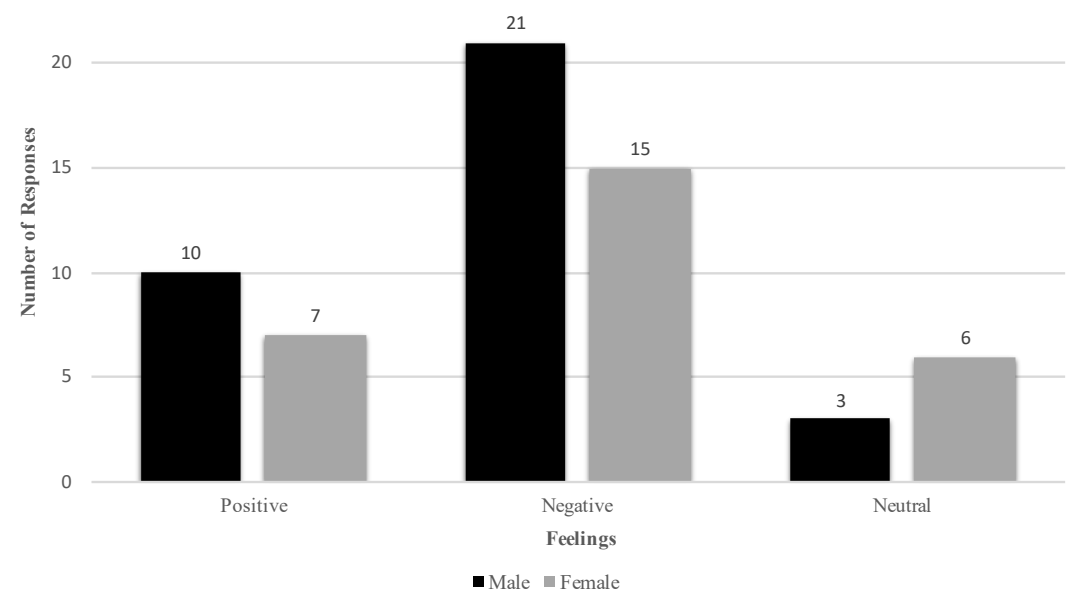

Figure 4.23: Character 2 / Color Palette 1 (Character traits by gender)

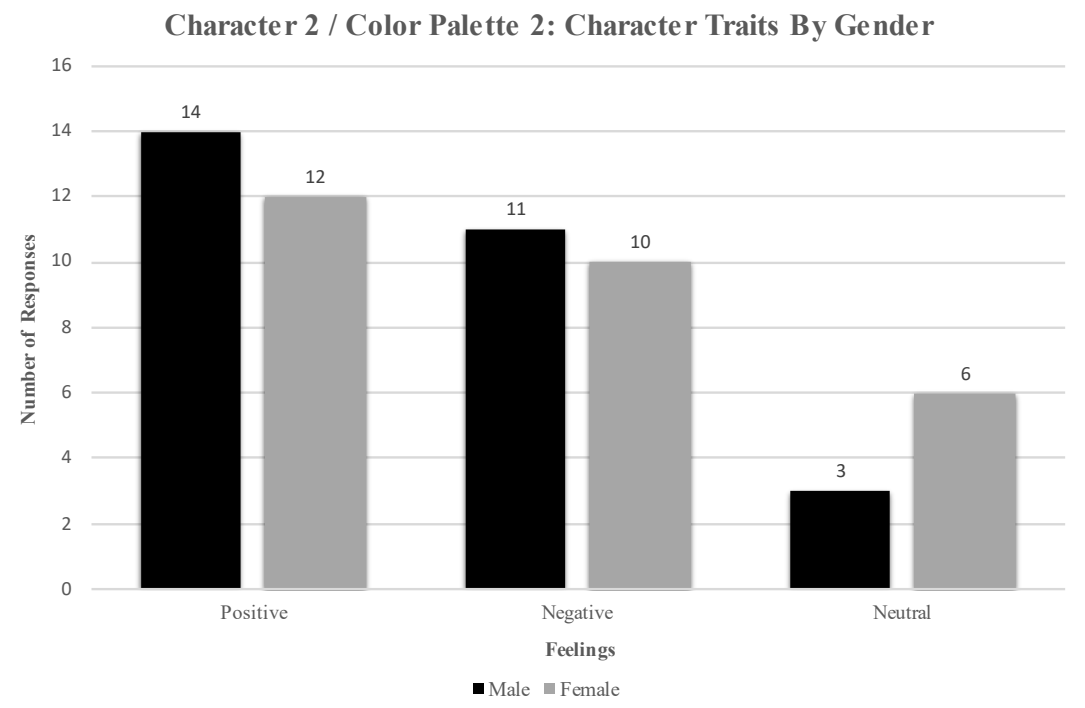


Figure 4.24: Character 2 / Color Palette 2 (Character traits by gender)

When Character 2 / Color Palette 1 was presented, many of the respondents viewed the character negatively, but there was a decent number of positive responses as well. Males contributed twenty-one negative words, while females contributed fifteen. Ten positive words came from males, where seven came from females. Females were more indecisive with their responses, with six words being categorized as neutral compared to three words by males.

For Character 2 / Color Palette 2, the results were more even across positive, negative, and neutral, but the responses remained consistent among genders. Most responses were categorized as positive words, with fourteen coming from males and twelve coming from females. However, negative words were still represented with eleven from males and ten from females. The number of neutral words remained the same from color palette 1; six females to three males.

\section{Character 3}




Figure 4.25: Character 3 (Shapes by gender)

Among the respondents, the majority viewed Character 3 as a triangle, but there is a rather large difference between what both genders perceived. Eight males categorized this character as a circle, as opposed to three females. Nearly all females selected a triangle, and only two did not. Not even half of the male respondents chose a triangle, and most of them leaned toward a circle. Among the eleven male participants, five of them decided on a triangle to represent this character.

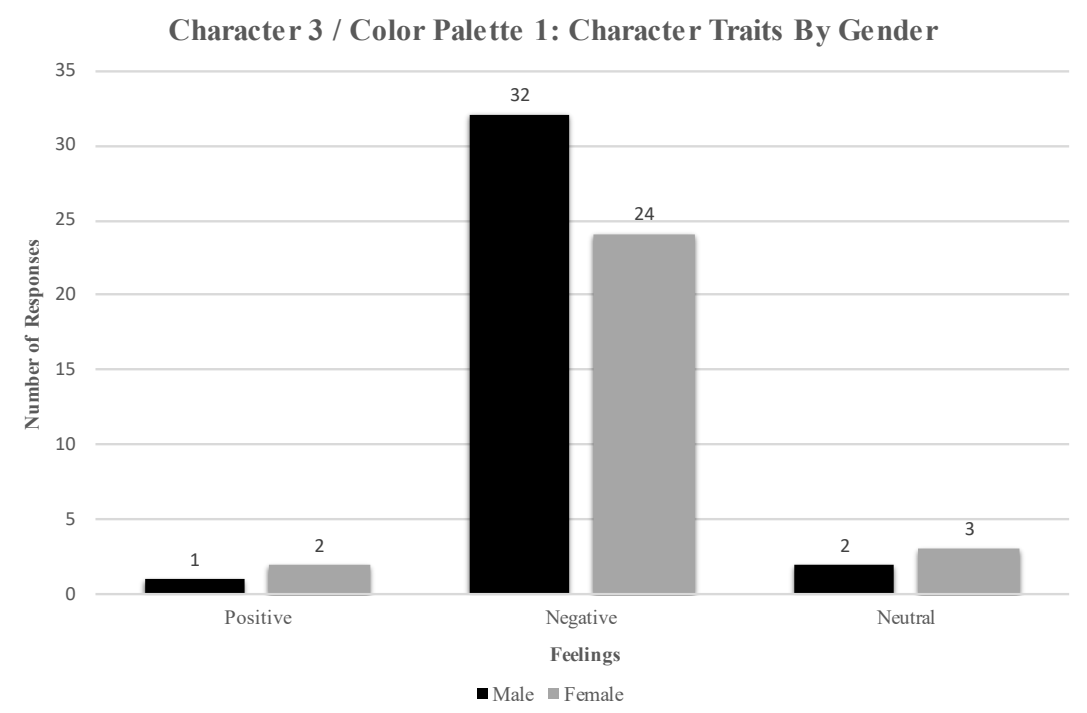

Figure 4.26: Character 3 / Color Palette 1 (Character traits by gender) 


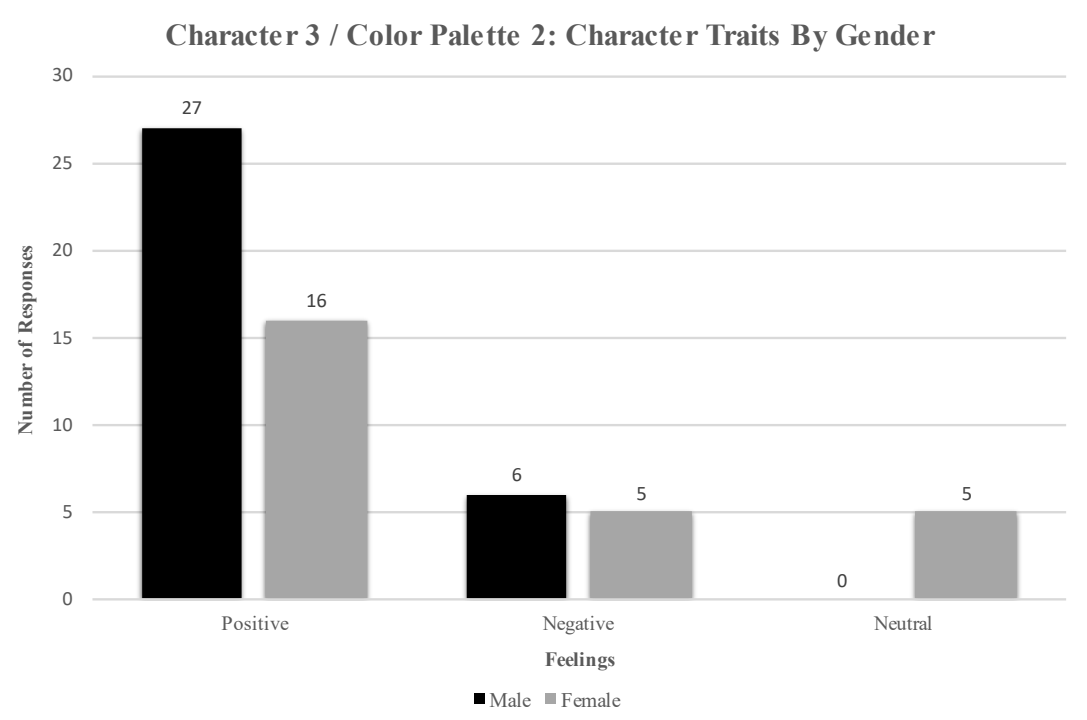

Figure 4.27: Character 3 / Color Palette 2 (Character traits by gender)

The majority of character traits the respondents associated with Character 3 / Color Palette 1 were negative. However, there is a slight difference in the number of words each gender listed. Males chose thirty-two negative words, while females chose twenty-four negative words. This is the same ratio of responses given to describe Character 1 / Color Palette 1 positively. Positive and neutral responses were similar, with females giving two positive descriptive words while the males shared only one, and females provided three neutral as opposed to two from males.

For Character 3 / Color Palette 2, the perception was opposite from color palette one, with most participants choosing positive words. Both genders found this character more positive, with twenty-seven coming from males and sixteen coming from females. The number of negative words was close, with six words being listed from males and five from females. Females gave five neutral words while the males did not provide any. 
RQ3: What role does age play in how people perceive character design?

\section{Character 1}

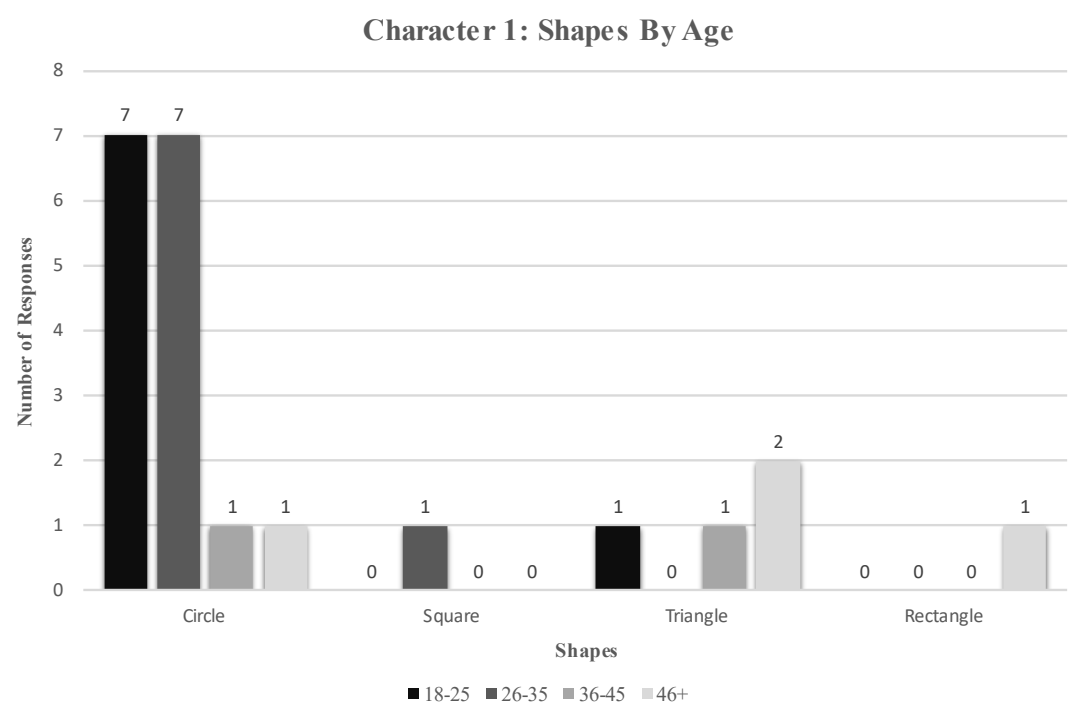

Figure 4.28: Character 1 (Shapes by age)

For Character 1, the majority of the respondents categorized it as a circle. Almost all the respondents aged 18-25 and 26-35 saw the character as a circle. However, one person from each age group saw a square and a triangle. The one respondent that fell into the $36-45$ age range did agree the character could be a circle, but they also selected a triangle. The majority of people ages $46+$ found the character to be more triangular as opposed to circular. Also, one person saw a circle, and another saw a rectangle from the $46+$ category. 


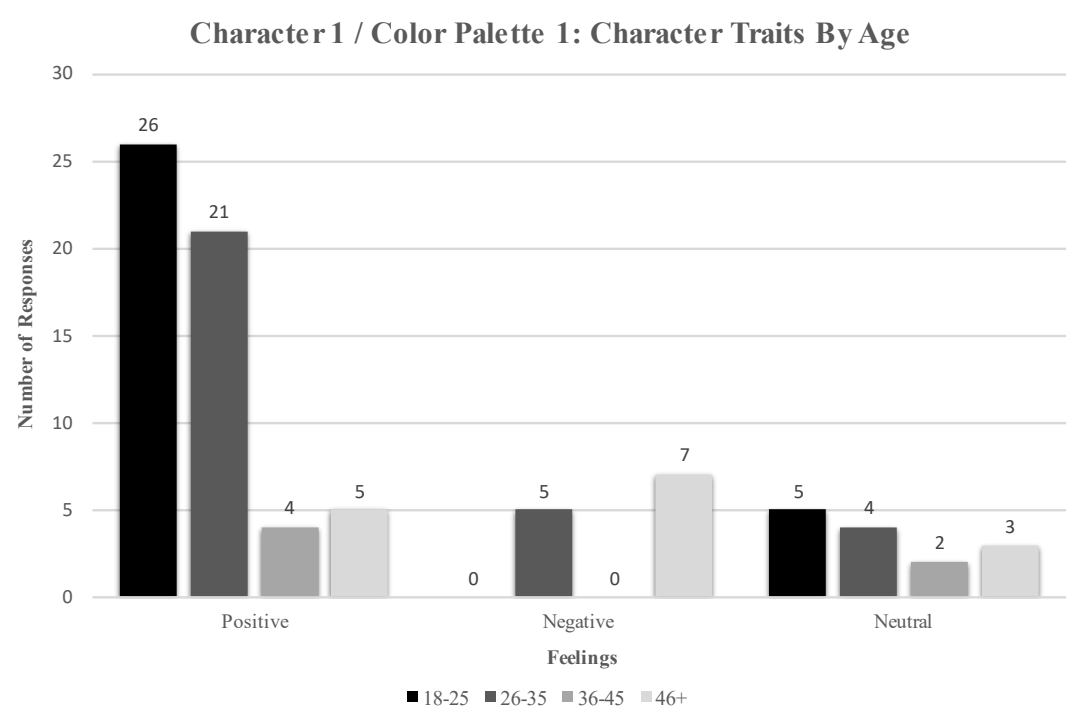

Figure 4.29: Character 1 / Color Palette 1 (Character traits by age)

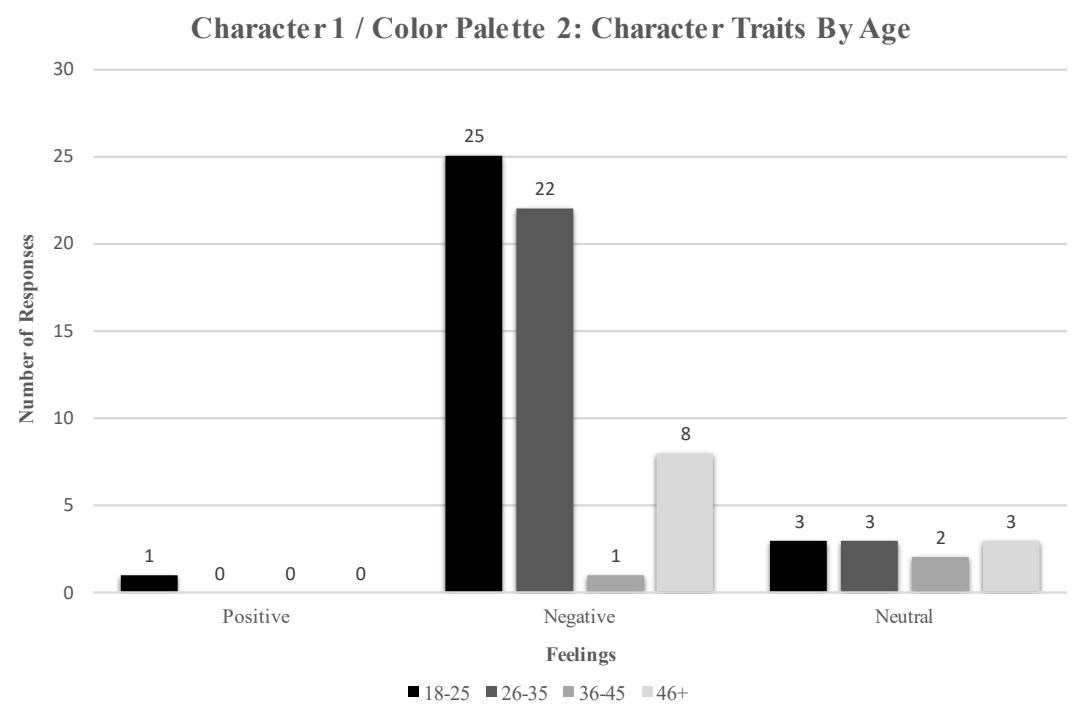

Figure 4.30: Character 1 / Color Palette 2 (Character traits by age) 
When respondents were asked to list character traits they associated with Character 1 / Color Palette 1, each age group seemed to be on the same page except age 46+. However, most ages 18-25, 26-35, and 36-45 viewed this character positively, with twenty-six positive words from 18-25, twenty-one from 26-35, and four from 36-45. Ages 46+ saw this color palette negatively, but it was close, with five words being positive and seven being negative.

For Character 1 / Color Palette 2, the overall perception stayed consistent, with many participants viewing the color change negatively. However, the 36-45 group did not feel as strongly. It should be noted that only one participant identified in the $36-45$ demographic, which could explain the slight difference to other age groups that were more represented. The majority of responses were categorized as negative words, with twenty-five coming from 18-25, twentytwo from 26-35, and eight from 46+.

\section{Character 2}

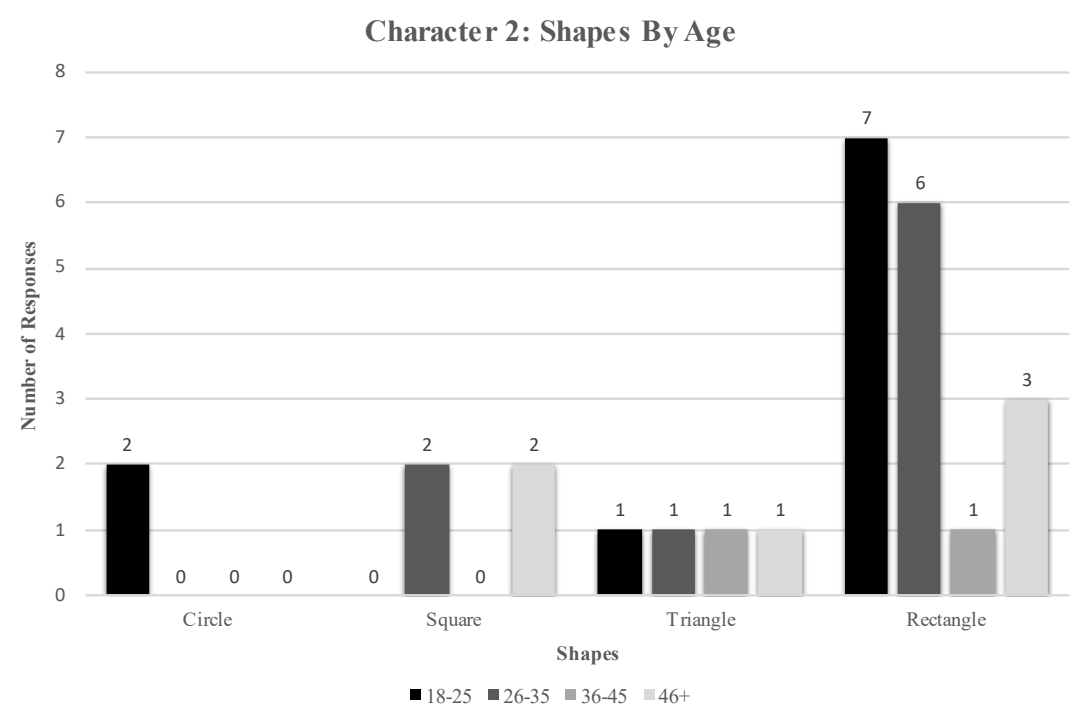

Figure 4.31: Character 2 (Shapes by age) 
All the studied age groups viewed Character 2 as a rectangular figure. The one participant from ages 36-45 saw both a rectangle and triangle but still chose the response that most people selected. All the shapes were represented at least once, with one person choosing a triangle from every age demographic.

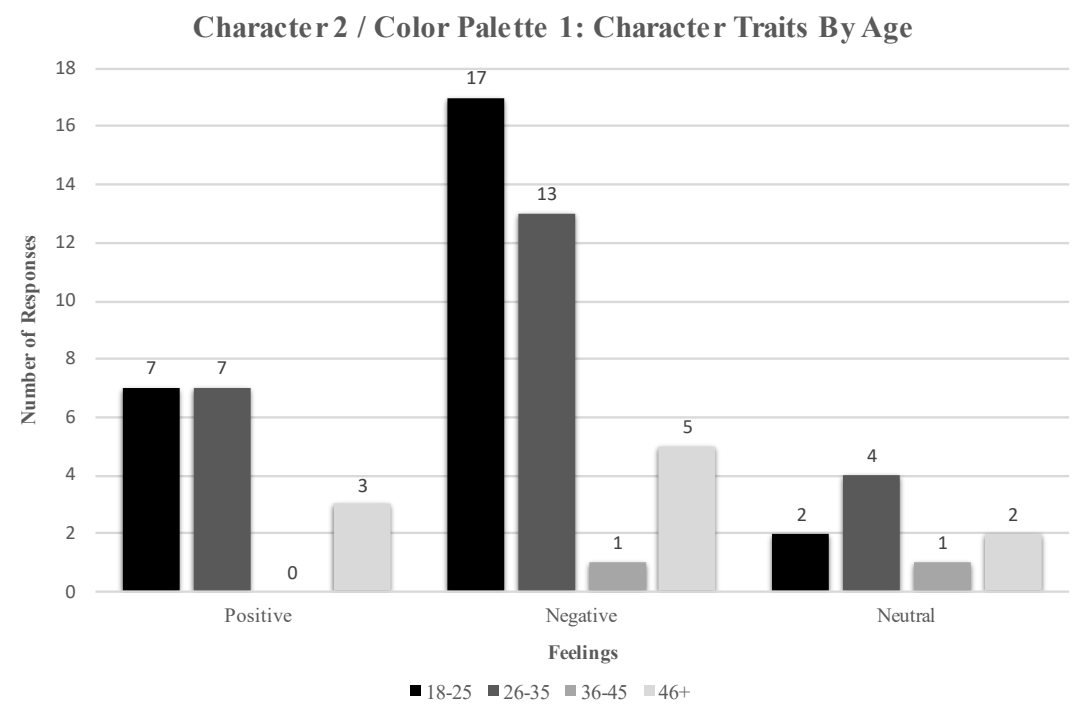

Figure 4.32: Character 2 / Color Palette 1 (Character traits by age) 


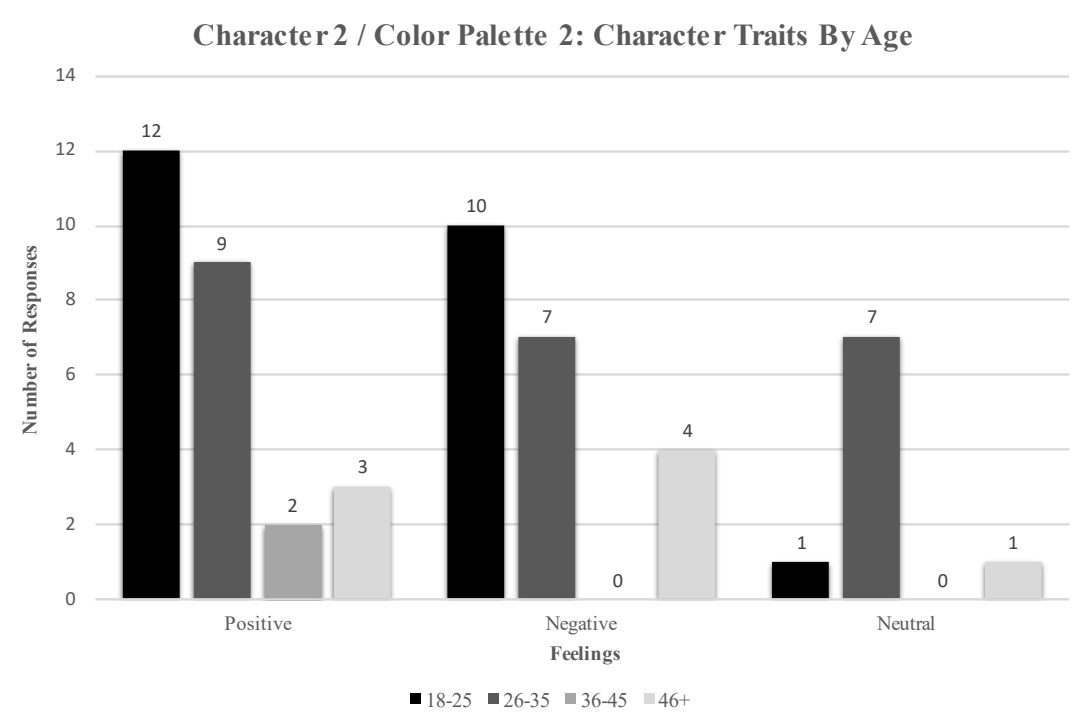

Figure 4.33: Character 2 / Color Palette 2 (Character traits by age)

Among the age demographics, most viewed Character 2 / Color Palette 1 negatively. Each age group agreed with the character design being classified as negative, except for 36-45, which presented a tie with neutral descriptive words. Seventeen negative words came from 1825 , thirteen from $26-35$, one from $36-45$, and five from $46+$.

When the second color palette was introduced, many of the participants became conflicted. The majority of the responses shifted positively, but negative reactions remained high in comparison. Twelve reactions in the 18-25 range were positive, while nine responses were negative from the same age group. Ages 26-35 had similar results, but this age group produced more neutral words, with nine positive, seven negative, and seven neutral. The person from 3645 became sure of their perception and fully committed to positive words, while $46+$ remained unchanged, with the majority feeling negative about the design.

\section{Character 3}




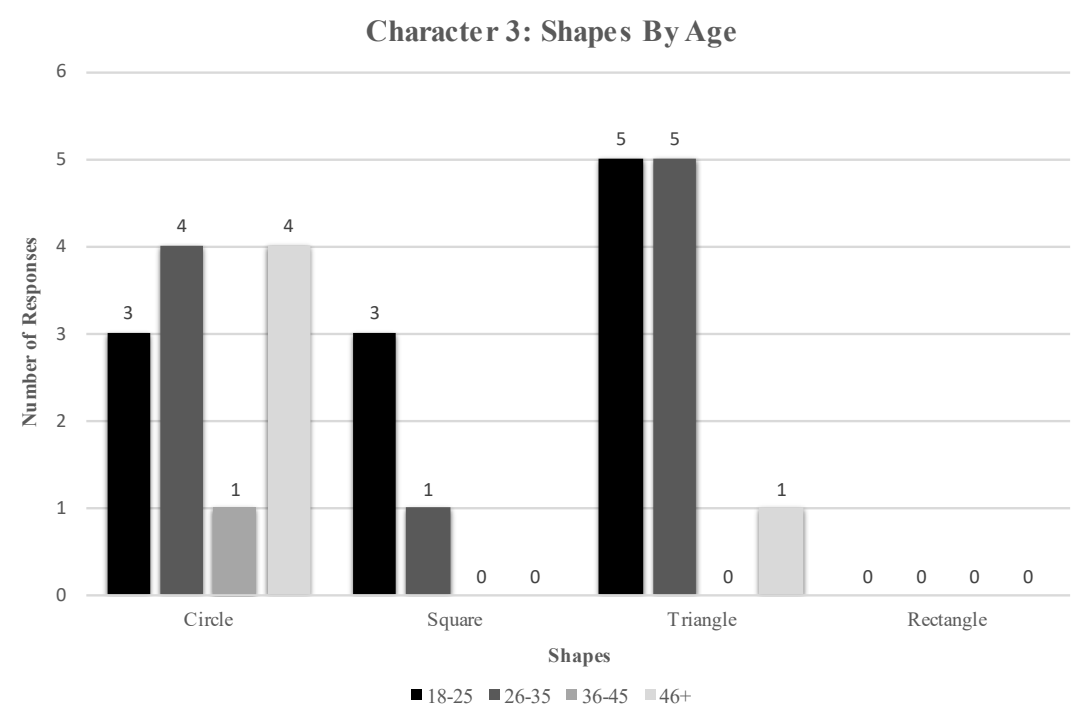

Figure 4.34: Character 3 (Shapes by age)

Once Character 3 was introduced, pinpointing a specific shape became more challenging for the respondents. The majority of the responders leaned toward a triangle, but a circle was a close second. Most participants from two age groups saw a circle, where most people from age groups from 18-25 and 26-35 saw a triangle. A triangle was selected five times by 18-25 and 2635, but a fair number of responders from these groups also saw a circle. Most people from 36-45 and 46+ agree with this character looking like a circle. Every participant from 46+ saw at least a circle in the design, with only one person choosing a triangle. 


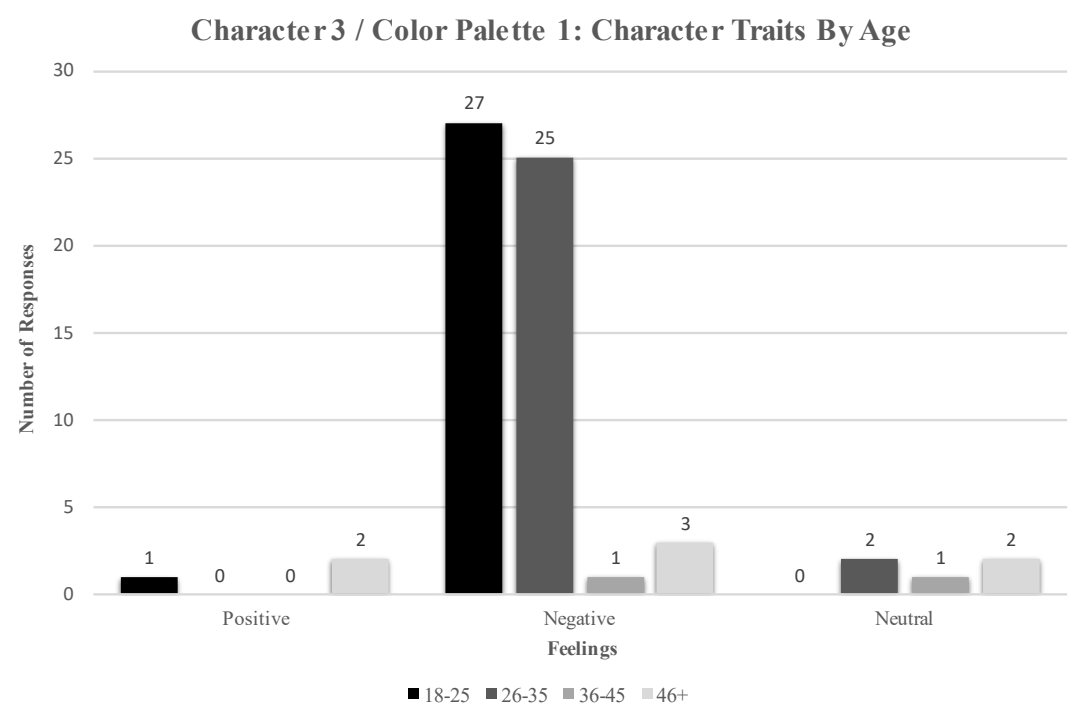

Figure 4.35: Character 3 / Color Palette 1 (Character traits by age)

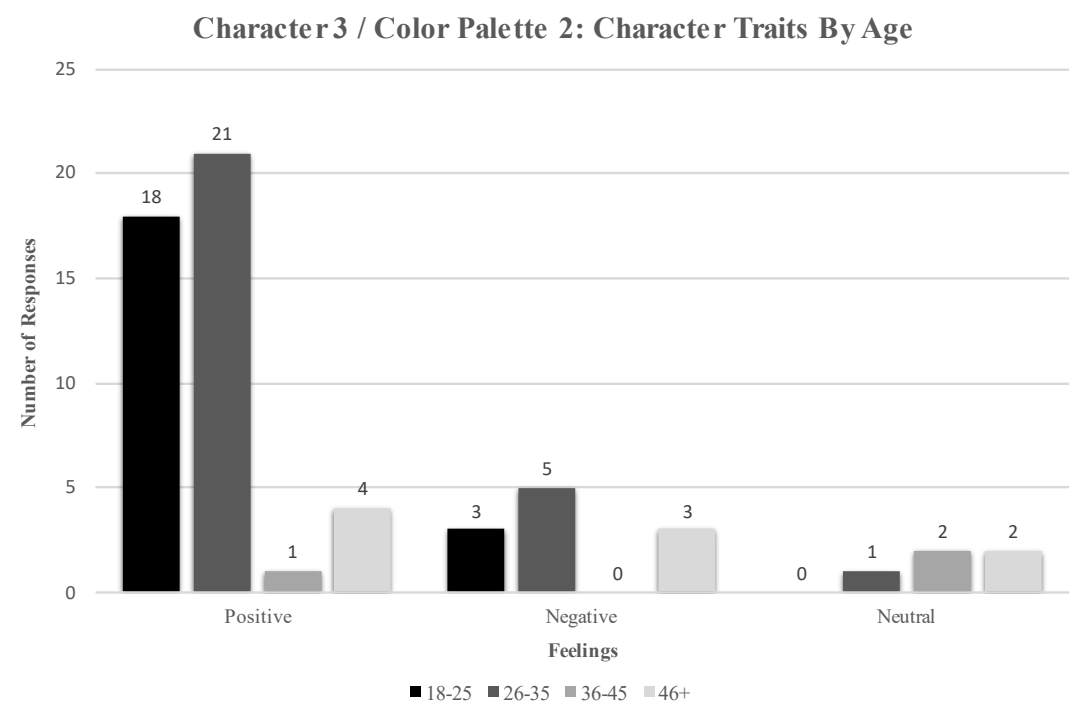

Figure 4.36: Character 3 / Color Palette 2 (Character traits by age) 
When color was introduced, the overall perception became more agreeable across the demographics. Every age group viewed this character negatively, with twenty-seven positive words from 18-25, twenty-five from 26-35, one from 36-45, and three from 46+. The person in the 36-45 range also gave a neutral word to tie their negative response one for one.

For Character 3 / Color Palette 2, the overall perception stayed consistent, with many participants agreeing, but their perception shifted positively. However, the 36-45 group did not feel strongly and added two neutral words to their new positive word. The majority of responses were categorized as positive words, with eighteen coming from 18-25, twenty-one from 26-35, and four from 46+. Not many negative words remained, but ages 26-35 stated most of them with five.

\section{CHAPTER 5 DISCUSSION}

These three characters presented some compelling results. This study aimed to successfully develop characters that expressed intended personality traits to see if there is a way of predicting audience perception during the creative process. Color and shape theories both state certain psychological emotions are triggered in individuals when they view shapes and colors (Solarski, 2012, pp. 176, 224). Based on the data I collected, I would say there may be some truth to these theories. This study's main objective was to gain insight into an audience's thoughts and perceptions, which I believe was revealed in the compiled data.

\section{RQ1: How do people associate character personality traits with geometric shapes and color}

\section{palettes?}

When asking the respondents to select the shapes they would use to describe the character, for the most part, all three characters succeeded. For instance, Character 1 was designed based on a circular concept, and a majority of the respondents chose a circle. The same 
goes for Character 2. Character 2 was developed based on a rectangular idea, and the majority selected a rectangle. However, when the respondents were given Character 3, they were somewhat conflicted. Character 3 was designed based on a triangular concept and, technically, a triangle was selected more than any other shape. Still, a circle was almost selected more, which brings shape theory into question. The responses for Character 3 / Color Palette 1 were mostly perceived as negative, while Character 3 / Color Palette 2 was viewed more positively. According to the data, a fair amount of people viewed this character as both shapes, which could explain why there were opposite outcomes after changing the color palette. However, the results of Character 3 may indicate the perception of color could be more significant than shape theory. It may also suggest that more complex designs make it more difficult to pinpoint a specific shape, considering this character had more complexity to its overall design. However, designers can still focus on these basic design principles at the start of building a character.

When testing audience perception on shape only in the form of a silhouette, most of the responses indicated a negative interpretation, except for Character 1, where neutral descriptive words were primarily dominant. Based on the design and the character's back story, this design should have been seen positively. Character 2 was similar, and negative responses were predominantly discussed. However, this character should have given more of an even split between positive and negative. The silhouette of Character 3 did provide an intended outcome, with a majority of descriptive words being viewed negatively. When breaking down the data further, the silhouette's dark outline was brought up frequently in the responses, indicating that the entire black/dark color scheme could have played a role in how people interpreted the design. In other words, the shape may not have been the only aspect people were looking at when they responded. 
When the characters were fully revealed, many respondents gave more descriptive answers. For all the characters, I would say there was a dramatic shift in how people perceived each figure once a new color palette was introduced. For Character 2, there was not as much of a change from negative to positive, but there was still a slight shift in perception. However, Character 1 and Character 3 revealed clear evidence that changing the color palette made a big difference in the audience's interpretation. When Character 1 was presented in a bright and vibrant color scheme, many respondents saw the character positively, but their perception completely changed negatively when the same figure was given a dark and sober color scheme. The same scenario occurred when Character 3 was introduced. The respondents overwhelmingly described this character negatively when viewing a dark and somber color palette, but when the same character was given a light and airy color scheme, their interpretation reverted to a positive outlook.

Based on the data collected in this study, I conclude that choosing the right colors may be more critical when gauging how an audience will react to characters than their shape. Shape theory is more of a guiding principle than a clear-cut answer on how a viewer will respond, but when a majority of the respondents looked at Character 1, which had a circular design, they were more drawn to color than to the overall shape. The same thing occurred with Character 3 . Despite many respondents choosing both a circle and a triangle, they still viewed this character positively with bright colors and negatively with dark colors. Even Character 2 supports this assumption, although it is not as clear. This could be because of the color choices. I purposefully chose color schemes that were more neutral, based on color theory principles. Also, considering how close the data was compared to the other characters, I would say the respondents did not feel strongly one way or another. 
I am not discounting shape theory altogether because I feel this theory may provide a good starting place for designers. However, as the creative process starts to take form, the character may skew from this initial theory, and that is fine if the designer makes the right color choices for their desired intentions. I feel this study's data supports the belief that color is more powerful than the character's overall shape.

\section{RQ2: What role does gender play in how people perceive character design?}

Based on the data gathered, I believe gender does not play a large role in how people perceive character design. The theory of color indicates that different cultural backgrounds and gender can influence a person's interpretations of the design (Tillman, 2011, p. 116). While this may be true for some people, I found minimal proof this theory holds up. My data is more in line with Fogolstrom's (2013), who did not find a pattern regarding gender and character interpretations. It is possible with a larger sample pool, the answer to this question may become more apparent, but for this study, both genders seemed to agree with every character design except for one, and that was Character 3's shape. The majority of males saw a circular design with this character, while most females saw a triangle. This does little to strengthen color theory, as it only pertains to color, but it could indicate different genders perceive shapes differently. Even so, the other two characters had similar results regarding shape, so further testing is required.

\section{RQ3: What role does age play in how people perceive character design?}

The data compiled from this study does show some evidence that a person's age may affect how they perceive a particular character. Fogolstrom (2013) did not find a pattern regarding age and character interpretations. However, the results indicated, at times, that some ages felt differently when given the same character. The two largest sample pools of respondents 
came from ages 18-25 and 26-35. The results indicated little difference in how these two age groups felt about a design, but the 36-45 and 46+ demographics did not always agree with them. Unfortunately, this study only had one participant from ages 36-45, so it is possible with more input, the data may be more consistent between this age range and 18-35.

While looking at the $46+$ demographic, there were some interesting differences. A triangle was chosen more than any other shape when viewing Character 1 among ages $46+$. These results are interesting because both ages 18-25 and 26-35 saw a circle. A similar result occurred again when asking the respondents to select a shape for Character 3. The majority of both ages 18-25 and 26-35 chose a triangle, where the majority of ages 36-45 and 46+ selected a circle. Character 1 / Color Palette 1 also had the 46+ demographic give mostly negative responses to describe the character, where the majority of every other age range gave positive words. This happened again for Character 2 / Color Palette 2 when most saw the character negatively compared to the different ages who saw the character more positively. Even though the $46+$ respondents overall agreed with the additional ages for the other character designs, the data was not reassuring. Both color palettes for Character 3 were close to either being a tie or skewing in the opposite direction. This indicates that this age group may have been conflicted in how they wanted to respond, compared to ages 18-25 and 26-35, where they were more conscious of their perception.

There is no doubt each age demographic has been exposed to different experiences throughout their lives, and there may be a difference in how these audiences view character design. Still, it is difficult to say from this one study. My results did indicate that there may be something here worth pursuing, but it should be noted that I did not receive many participants 
from ages $36+$. Only one respondent fell into the $36-46$ category and four in the $46+$. More participants would, most likely, clarify these findings.

\section{Limitations}

As with most studies, the design of the current study is subject to limitations. The primary limitation is the small sample of participants and the limited time available to complete this study. Due to time constraints, I only accepted twenty participants. To thoroughly answer these three research questions, a more extensive study may be appropriate. As noted previously, $75 \%$ of the twenty respondents were from the ages of $18-35$. That left only $25 \%$ of participants from ages $36+$. This possibly affected some of the outcomes of this study.

Another potential limitation was how I asked the respondents the question about each silhouette design, "Describe your overall impression of the above image." Many of the respondents took this as an opportunity to describe what they thought the silhouette was, rather than expressing their feelings. Despite this, I was able to make informed decisions based on their responses, but if I had rephrased this question to something like, "Describe how you feel about the image," the results would have been more conclusive.

Like most qualitative studies, this research is not subject to my own bias. I made a conscious effort to limit bias by documenting everything, but I designed these characters with a preconceived notion of how I wanted them to be portrayed. I attempted to limit coding discrepancies by specifically stating my thought process for each coding category as I categorized words and phrases. This helped me stay consistent when analyzing the data as I did not complete the coding process in one sitting. It took many days and weeks to compile this data, and I needed to look back at my notes often to ensure consistency was practiced fully. I also implemented a test-retest method that required me to code the data sets without looking at the 
results until the very end. Once I had compiled everything, then I made comparisons and checked for consistency with the other questions.

Designing a method for this study was also tricky, considering the limited amount of previous academic research regarding the audience's interpretation of character design. A few studies were available that I referenced in the literature review, but most of them were quantitative in their design. I decided to take a different approach and focus on qualitative data because all art is subjective, and I did not want to limit my participants to predetermined responses. I did, however, find it necessary to incorporate some quantitative questions as I determined the demographic analysis part of this study was better suited with quantifiable data. During the pilot study, where I tested this survey out on a couple of respondents, it became apparent that I needed to implement some prompts in the form of example words to get the answers that I was truly after. I believe doing this helped the respondents formulate qualitative responses, and I received many words and phrases that were not represented in the examples given. These prompts acted as merely a guide for the respondents.

\section{Future Research}

Character design and how viewers perceive those characters is an under-researched topic, and there are many ways to expand upon this study. I designed all my characters with the preconceived notion that circles are good, squares are neutral, and triangles are bad. I also designed the characters with the idea that what is bright and beautiful is good and what is dark and ugly is evil. It would be interesting to try to push these beliefs further to see how far a designer can manipulate these concepts before the character becomes indistinguishable.

In this study, I chose to focus strictly on the person's gender affecting their design interpretation. However, Tillman (2011) indicated that different cultures had affected color 
theory in past studies (p. 116). Testing the cultural backgrounds of individual participants and not just gender could be a worthwhile experiment. I did not find any evidence to suggest that a person's gender has any bearing in how they interpret design, but that does not mean a person's ethnicity could not influence their overall perception. Recording a person's cultural orientation and then asking them similar questions from this study could produce some evidence to support Tillman's statement.

While compiling the results for Character 3, I noticed a conflict with how different people were interpreting the design's overall shape. This is subjective, but I believe this character had the most detail in its design, leading me to think that maybe more complex designs may make it more difficult to pinpoint a specific shape. This is undoubtedly a subject that could be explored further. In my study, I tried to simplify my characters and focus more on shape and colors, but a more complex character based on these theories is achievable.

Another route this study could go in the future is to test the effectiveness of adding facial expressions. Considering I tried to create simplified characters with minimal expression, adding more facial detail, and then testing an audience's perception could reveal some compelling results. "Facial expressions can display personal emotions and indicate an individual's intentions within a social situation. They are essential to the social interaction of individuals" (Xu, Yang, \& Zhang, 2017, p. 1). It would be interesting to see how color and shape work with expressions.

A character's pose may also influence how a person perceives a character. I attempted to nullify action poses when I presented my characters in traditional concept poses. I tried to mimic the universal standard for character designs with a front and side pose for each character. This is traditionally seen as a neutral orientation early in the creation process. Fredriksson (2017) researched poses in character design, and there is an opportunity to use these three characters to 
further this area of study. Researching how shape, color, expression, and pose choices work together is valuable for any artistic designer. I believe this research has established the groundwork to study these perceptions in more detail in the future.

\section{Conclusion}

Video game design has quickly become an essential part of interactive media entertainment. Characters are at the heart of most video games. Some of the most successful video games have excellent character design that often communicates a character's background through their visual design (Solarski, 2012, p. 32). Successful character design will communicate specific character traits visually, and the audience has to buy into those traits. Understanding the design factors that contribute to the character's origins is vital to establish a connection with the players.

This study aimed to add further examination into an area that lacks adequate research and attempts to add additional data to the developing video game industry. The study was created while keeping traditional shape and color theory and previous research regarding character design perception in mind. It is essential to know this kind of information when making characters because a game designer does not want their characters to suggest something they did not intend to imply. Analyzing data about character design perception strengthens the player's connection to the game. Video game companies can use this data to enhance their development and focus their attention on resonating with their intended audience. As gaming companies work towards future profitability, understanding the impact of visual design on audience perception will help them better connect with their audience and achieve favorable results. 


\section{REFERENCES}

Bancroft, T. (2006). Creating Characters with Personality: For Film, TV, Animation, Video Games, and Graphic Novels. New York, NY: Crown Publishing Group.

Brennen, B. S. (2013). Qualitative Research Methods for Media Studies. New York: Routledge.

Ekstrom, H. (2013). How Can a Character's Personality be Conveyed Visually, through Shape. Hogskolan pa Gotland. 1-54. Retrieved from: http://www.divaportal.org/smash/get/diva2:637902/FULLTEXT01.pdf.

Entertainment Software Association. (2019). Essential Facts about the Computer and Video Game Industry. Retrieved from: https://www.theesa.com/wpcontent/uploads/2019/05/ESA_Essential_facts_2019_final.pdf.

Esaak, S. (2019, July 3) The Definition of Shape in Art. ThoughtCo. Retrieved from: https://www.thoughtco.com/definition-of-shape-in-art-182463.

Esaak, S. (2019, August 17). What Is the Definition of Color in Art? ThoughtCo. Retrieved from: https://www.thoughtco.com/definition-of-color-in-art-182429.

Fogelstrom, E. (2013). Investigation of Shapes and Colours as Elements of Character Design. Uppsala University. 1-41. Retrieved from: http://www.divaportal.org/smash/get/diva2:651309/FULLTEXT01.pdf.

Fredriksson, E. (2017). Combining Shape, Color and Postures for Ambiguous Character Roles. Uppsala University. 1-90. Retrieved from: http://uu.divaportal.org/smash/get/diva2:1139932/FULLTEXT01.pdf.

IGN. (2019). Top 100 Video Games of All Time. Retrieved from: https://www.ign.com/lists/top$\underline{100 \text {-games/100. }}$. 
Islam, T., Nahiduzzaman, K., Why, Y. P., Ashraf, G. (2010, November) Learning Character Design from Experts and Laymen. Singapore. 1-9. DOI: 10.1109/CW.2010.66.

Ivan, T. (2019, July 29). Overwatch In-Game Spending Tops \$1 Billion. VGC. Retrieved from: https://www.videogameschronicle.com/news/overwatch-in-game-spending-tops-1billion/.

Jankowski, N. W. \& Wester, F. (1991). The Qualitative tradition in social science inquiry. In Jensen, K. B. \& Jankowski, N. W. (Eds.). A Handbook of Qualitative Methodologies for Mass Communication Research. New York: Routledge. 17-43.

Martin, G. (2019, October 2). The Best-Selling Videogame Franchises of All Time. Paste Magazine. https://www.pastemagazine.com/articles/2019/10/the-best-selling-videogamefranchises-of-all-time.html\#20-resident-evil.

Merriam-Webster. (n.d.). In Merriam-Webster.com dictionary. Retrieved February 8, 2021. https://www.merriam-webster.com/dictionary.

Nieminen, M. (2017). Psychology in Character Design: Creation of a Character Design Tool. South-Eastern Finland University of Applied Sciences. 1-76. Retrieved from: https://www.theseus.fi/bitstream/handle/10024/126784/MarikaNieminen_Thesis.pdf?seq $\underline{\text { uence }=1 \& \text { is Allowed }=\mathrm{y}}$.

Ouverson, C. M. (1992). The effects of color and design on audience attitude, behavior, and perception of media. Iowa State University. 1-109. https://lib.dr.iastate.edu/cgi/viewcontent.cgi?article=17980\&context=rtd.

Saldana, S. (2008). An introduction to codes and coding: Chapter 1 in the New Coding Manual for Qualitative Researchers. Los Angeles: Sage, Ed. 3. 1-42.

Solarski, C. (2012). Drawing Basics and Video Game Art. Watson-Guptill, New York. 
Tillman, B. (2011). Creative Character Design. Waltham, MA: Elsevier Inc.

Xu, Q., Yaping, Y., Qun, T., \& Zhang, L. Facial Expressions in Context: Electrophysiological Correlates of the Emotional Congruency of Facial Expressions and Background Scenes. Frontiers in Psychology. Ningbo University, China. 1-11. DOI: 10.3389/fpsyg.2017.02175.

Zade, H., Drouhard, M., Chinh, B., Gan, L., \& Aragon, C. (2018). Conceptualizing Disagreement in Qualitative Coding. University of Washington, Seattle, WA. 1-11. https://faculty.washington.edu/aragon/pubs/chi2018-zade.pdf. 


\section{APPENDIX A: ANALYSIS AND CODING}

The following are descriptive words that appeared while reading through all the responses for each character design. These are the definitions I used to categorize each word. All definitions were gathered from the Merriam-Webster dictionary (n.d.).

\section{Positive}

$\underline{\text { Sweet }}$ - marked by gentle good humor or kindliness.

Cheerful - full of good spirits.

Humble - not proud or haughty: not arrogant or assertive.

Gentle - free from harshness, sternness, or violence.

Quiet - making or involving no noise or very little noise.

Good - of a favorable character or tendency.

Happy - enjoying or characterized by well-being and contentment.

Innocent - free from guilt or sin especially through lack of knowledge of evil.

Caring - feeling or showing concern for or kindness to others.

Loving - affectionate.

Generous - liberal in giving.

Playful - full of play.

Dependable - capable of being trusted or depended on.

Cunning - prettily appealing.

Obedient - submissive to the restraint or command of authority: willing to obey.

Funny - affording light mirth and laughter.

Courageous - having or characterized by courage.

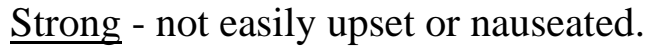


Festive - of, relating to, or suitable for a feast or festival: joyful.

\section{Negative}

Depressed - low in spirits: sad.

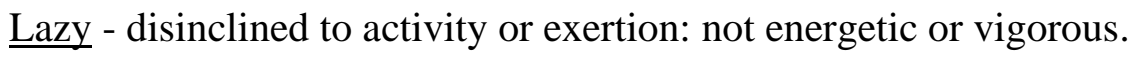

$\underline{\text { Sad }}$ - affected with or expressive of grief or unhappiness.

Upset - to trouble mentally or emotionally: disturb the poise of.

Lonely - sad from being alone.

Frustrated - feeling discouragement, anger, and annoyance because of unresolved problems or unfulfilled goals, desires, or needs.

Scary - causing fright.

Angry - seeming to show anger or to threaten in an angry manner.

Pessimistic - of, relating to, or characterized by pessimism: gloomy.

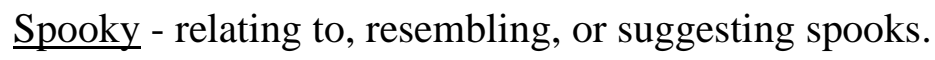

Obnoxious - odiously or disgustingly objectionable: highly offensive.

Arrogant - exaggerating or disposed to exaggerate one's own worth or importance often by an overbearing manner

Dangerous - involving possible injury, pain, harm, or loss.

Aggressive - tending toward or exhibiting aggression.

Loud - marked by intensity or volume of sound.

Evil - arising from actual or imputed bad character or conduct.

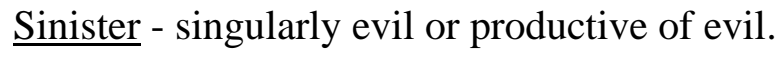

Deceptive - tending or having power to cause someone to accept as true or valid what is false or invalid: tending or having power to deceive 
Dark - arising from or showing evil traits or desires.

Fickle - marked by lack of steadfastness, constancy, or stability; given to erratic changeableness.

Demonic - of, relating to, or suggestive of a demon.

Malicious - having or showing a desire to cause harm to someone.

Intimidating - producing feelings of fear or timidity.

Threatening - expressing or suggesting a threat of harm, danger, etc.

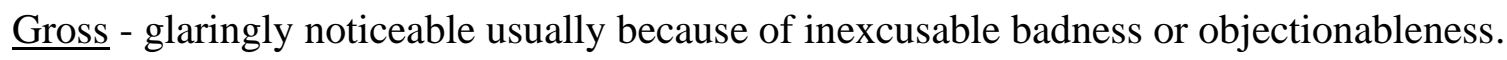

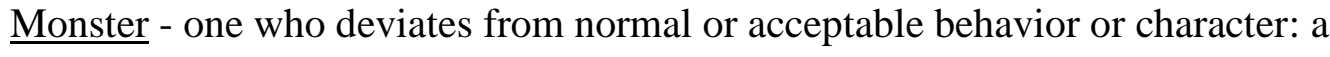
threatening force.

\section{Neutral}

Shy - disposed to avoid a person or thing.

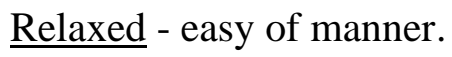

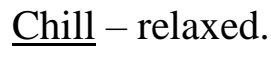

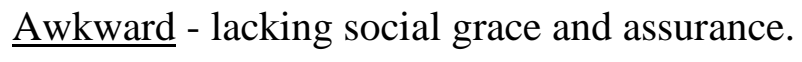

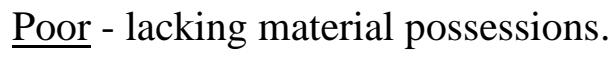

Unpredictable - not able to be known or declared in advance.

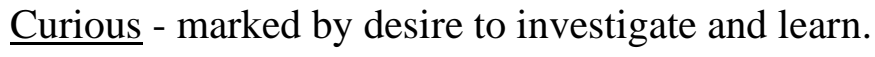

High Energy - yielding a relatively large amount of energy.

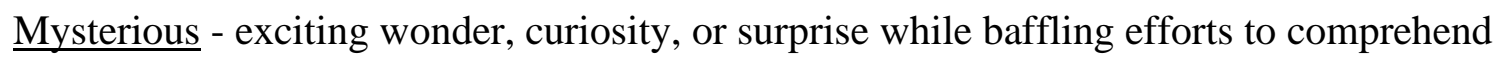
or identify.

Brainless - devoid of intelligence. 
Supernatural - of or relating to an order of existence beyond the visible observable universe.

Powerful - having great power, prestige, or influence.

Expensive - commanding a high price and especially one that is not based on intrinsic worth or is beyond a prospective buyer's means

Mindless - marked by a lack of mind or consciousness.

Emotionless - showing, having, or expressing no emotion.

Confused - being perplexed or disconcerted.

Fast - characterized by quick motion, operation, or effect.

Fancy - to visualize or interpret as.

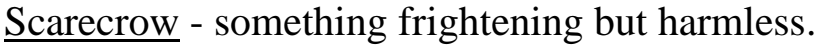

Confused - being perplexed or disconcerted.

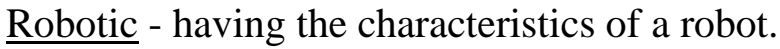

Strange - different from what is usual, ordinary, or expected: odd.

Solid - of good substantial quality or kind.

Hipster - a person who is unusually aware of and interested in new and unconventional patterns. 


\title{
APPENDIX B: SURVEY
}

\section{The Use of Shape and Color Theory in Interpreting Character Traits Consent to take part in research}

- You understand that you voluntarily agree to participate in this research study.

- You understand that even if you agree to participate now, you can withdraw at any time or refuse to answer any question without any consequences of any kind.

- You understand that you can withdraw permission to use data from your answers within two weeks after the questionnaire, in which case the material will be deleted.

- You have had the purpose and nature of the study explained to you in writing, and you have had the opportunity to ask questions about the study.

- You understand that participation involves looking at character designs and answering the corresponding questions.

- You understand that you are free to contact any of the people involved in the research to seek further clarification and information.

If you want to talk privately about your rights or any issues related to your participation in this study, you can contact the University of Missouri Research Participant Advocacy by calling 888280-5002 (a free call) or emailing MUResearchRPA@missouri.edu.

I, Curtis Henderson, am conducting this questionnaire in partial fulfilment of The University of Missouri's Master of Arts in Journalism with an emphasis in Media Management program.

\section{Curtis Henderson}

The University of Missouri

\section{Master of Arts in Journalism with an emphasis in Media Management}

Email Curt0058@gmail.com for all questions or concerns.

\section{Academic Supervisors}

\author{
James Flink \\ Mike Kearney \\ Fang Wang \\ Mark Swanson
}

By clicking submit you are agreeing to the Terms and Conditions. 


\section{Questionnaire}

1. What is your gender?

Female

Male

Prefer Not to Say

2. What is your age?

18 years or under

18-25 years

26-35 years

36-45 years

46 years or older

3. Have you ever played a video game?

Yes

No 
Look at the image below and answer all questions to the best of your ability.
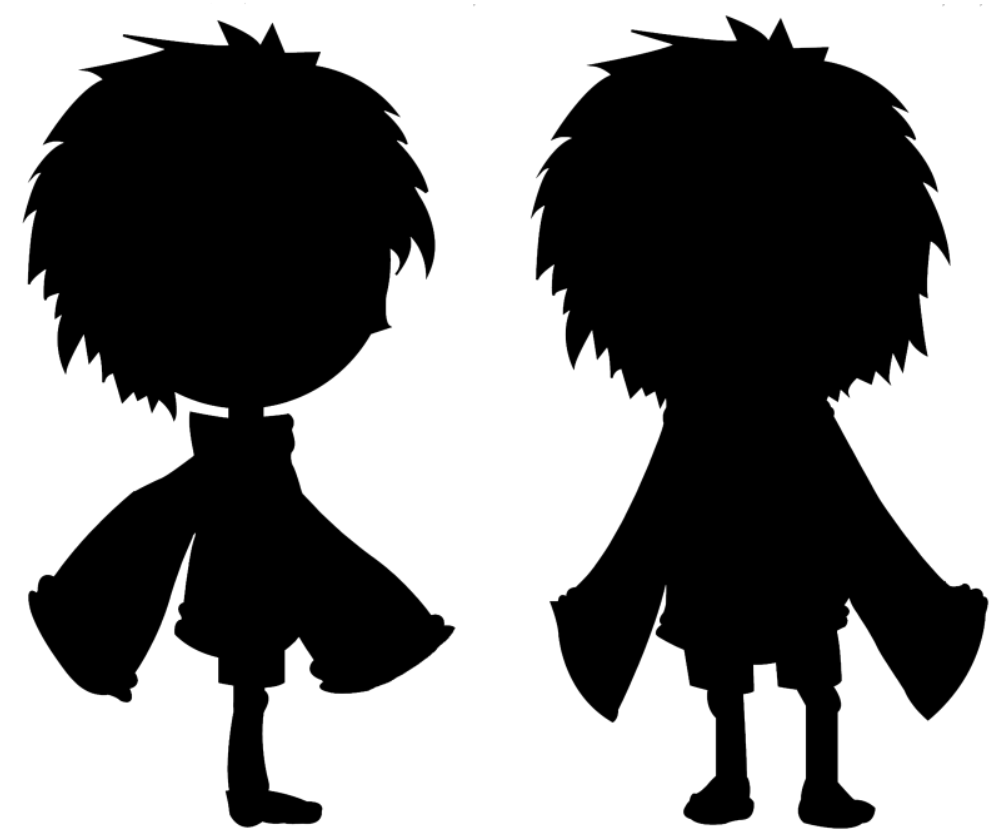

1. Describe your overall impression of the above image.

2. What is the overall shape of the above character? (Select all that apply)

Circle $\quad \square \quad$ Square $\quad \square \quad$ Triangle $\quad \square \quad$ Rectangle 
Look at the image below and answer all questions to the best of your ability.
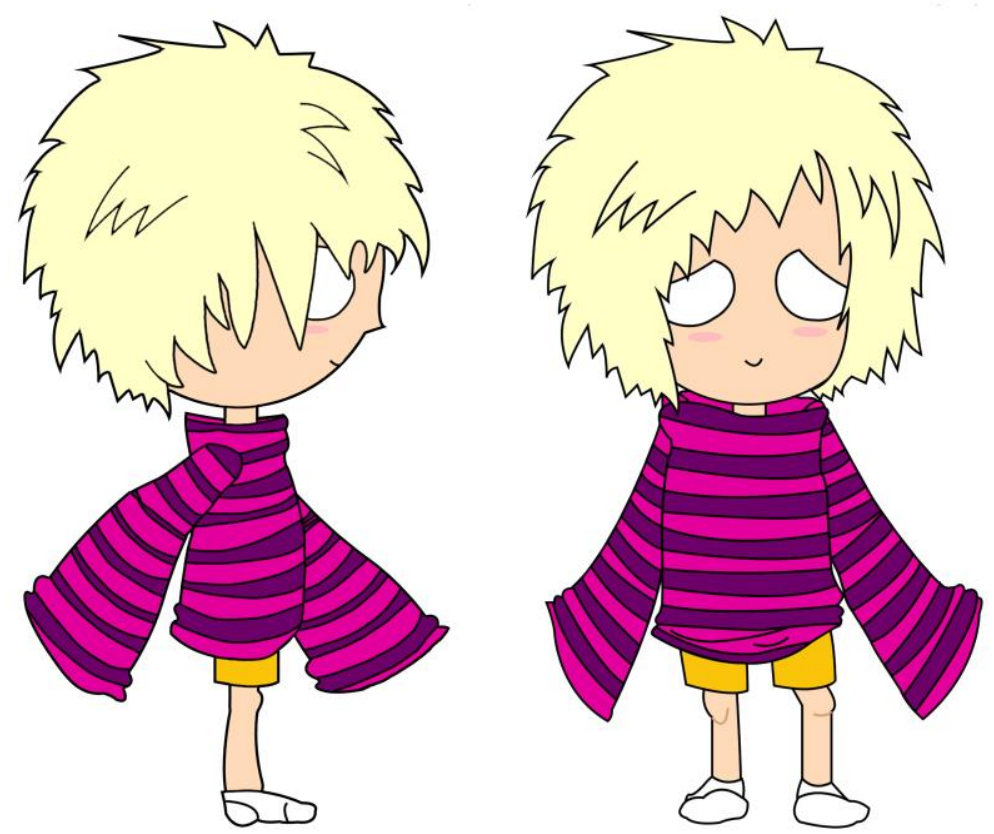

1. Describe your overall impression of the above character.

2. What personality traits do you associate with the above character? (Example: Cheerful, Humble, Gentle, Good, Quiet, Dependable, Optimistic, Angry, Arrogant, Aggressive, Loud, Evil, Fickle, and Pessimistic) 
Look at the image below and answer all questions to the best of your ability.
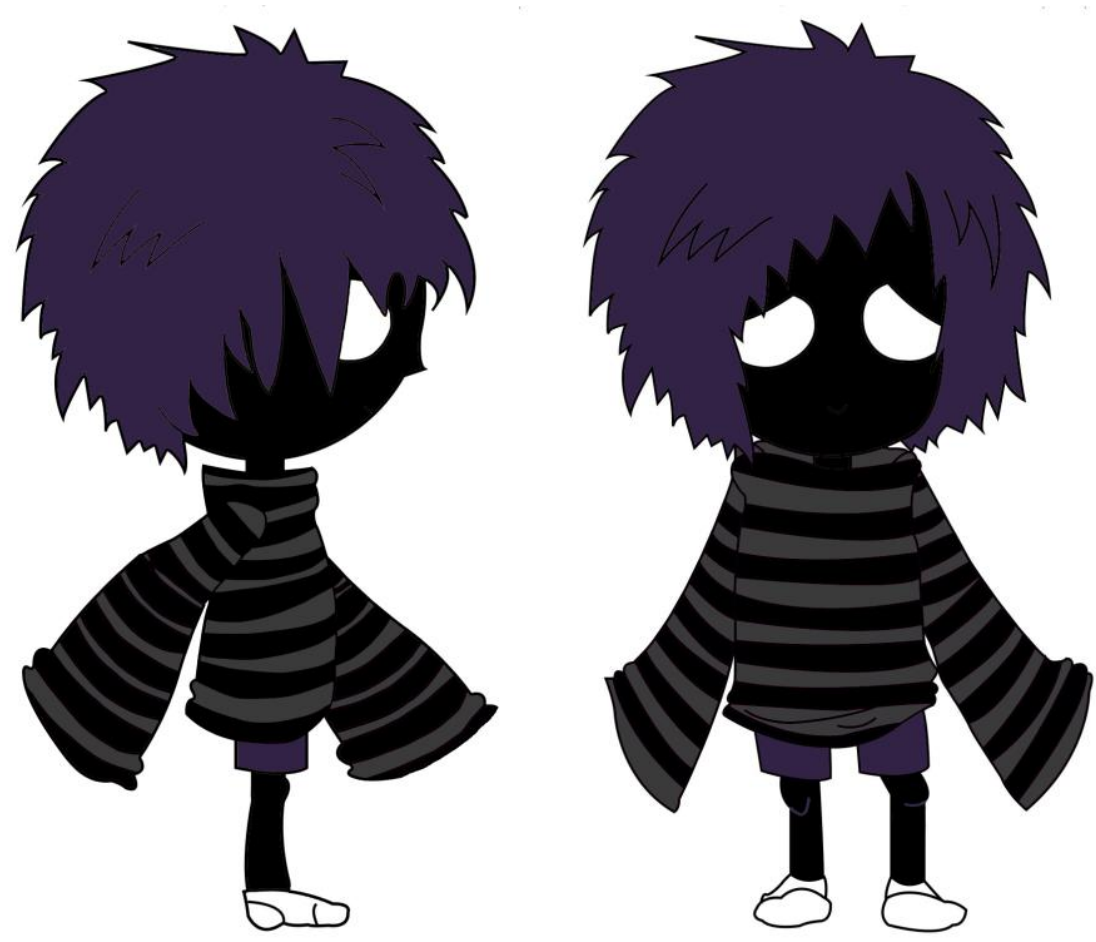

1. Describe your overall impression of the above character. Did your impression change from the first character design?

2. What personality traits do you associate with the above character? (Example: Cheerful, Humble, Gentle, Good, Quiet, Dependable, Optimistic, Angry, Arrogant, Aggressive, Loud, Evil, Fickle, and Pessimistic) 
Look at the image below and answer all questions to the best of your ability.

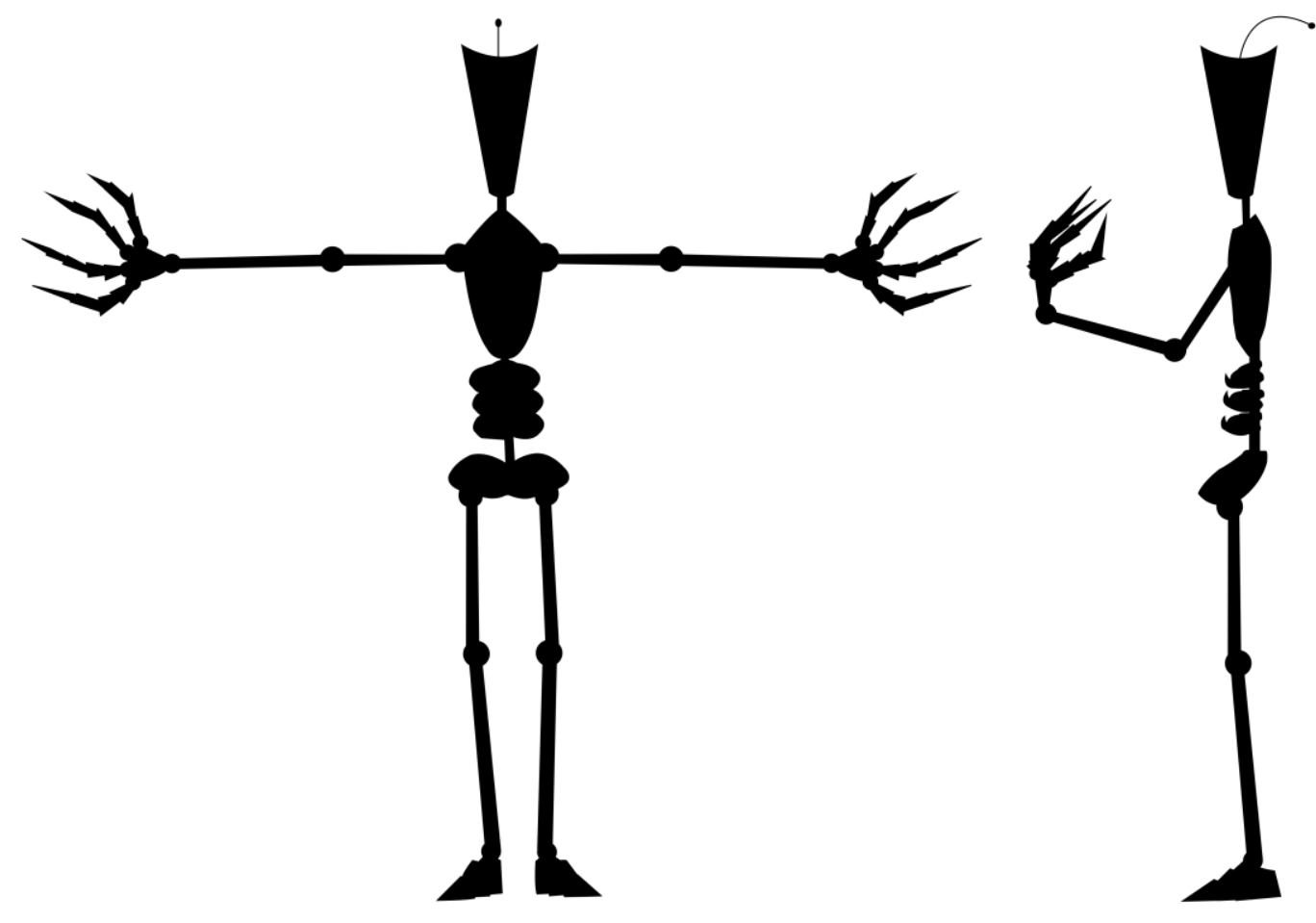

1. Describe your overall impression of the above image.

2. What is the overall shape of the above character? (Select all that apply)
Circle
Square
Triangle
Rectangle 
Look at the image below and answer all questions to the best of your ability.

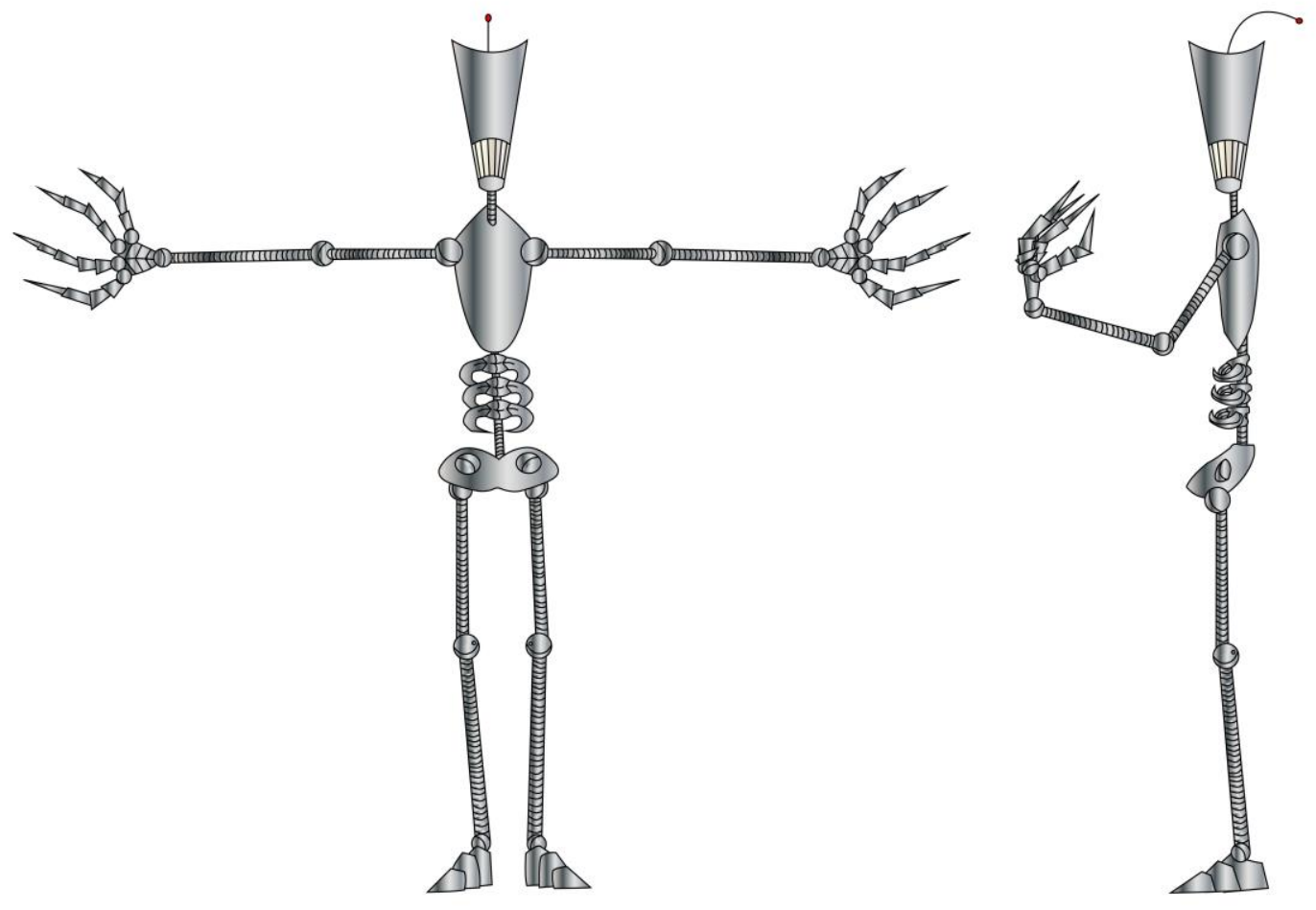

1. Describe your overall impression of the above character.

2. What personality traits do you associate with the above character? (Example: Cheerful, Humble, Gentle, Good, Quiet, Dependable, Optimistic, Angry, Arrogant, Aggressive, Loud, Evil, Fickle, and Pessimistic) 
Look at the image below and answer all questions to the best of your ability.

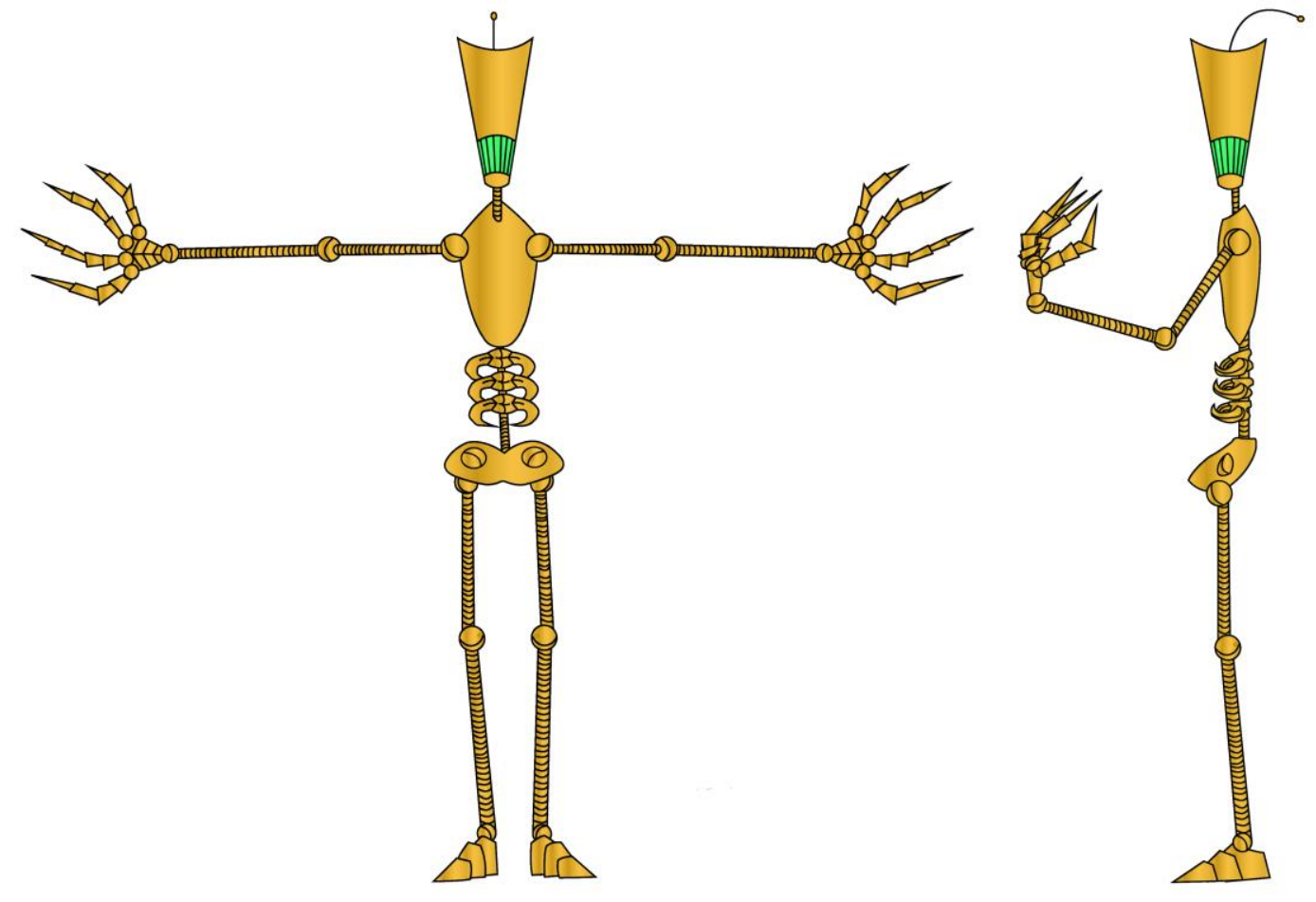

1. Describe your overall impression of the above character.

2. What personality traits do you associate with the above character? (Example: Cheerful, Humble, Gentle, Good, Quiet, Dependable, Optimistic, Angry, Arrogant, Aggressive, Loud, Evil, Fickle, and Pessimistic) 
Look at the image below and answer all questions to the best of your ability.
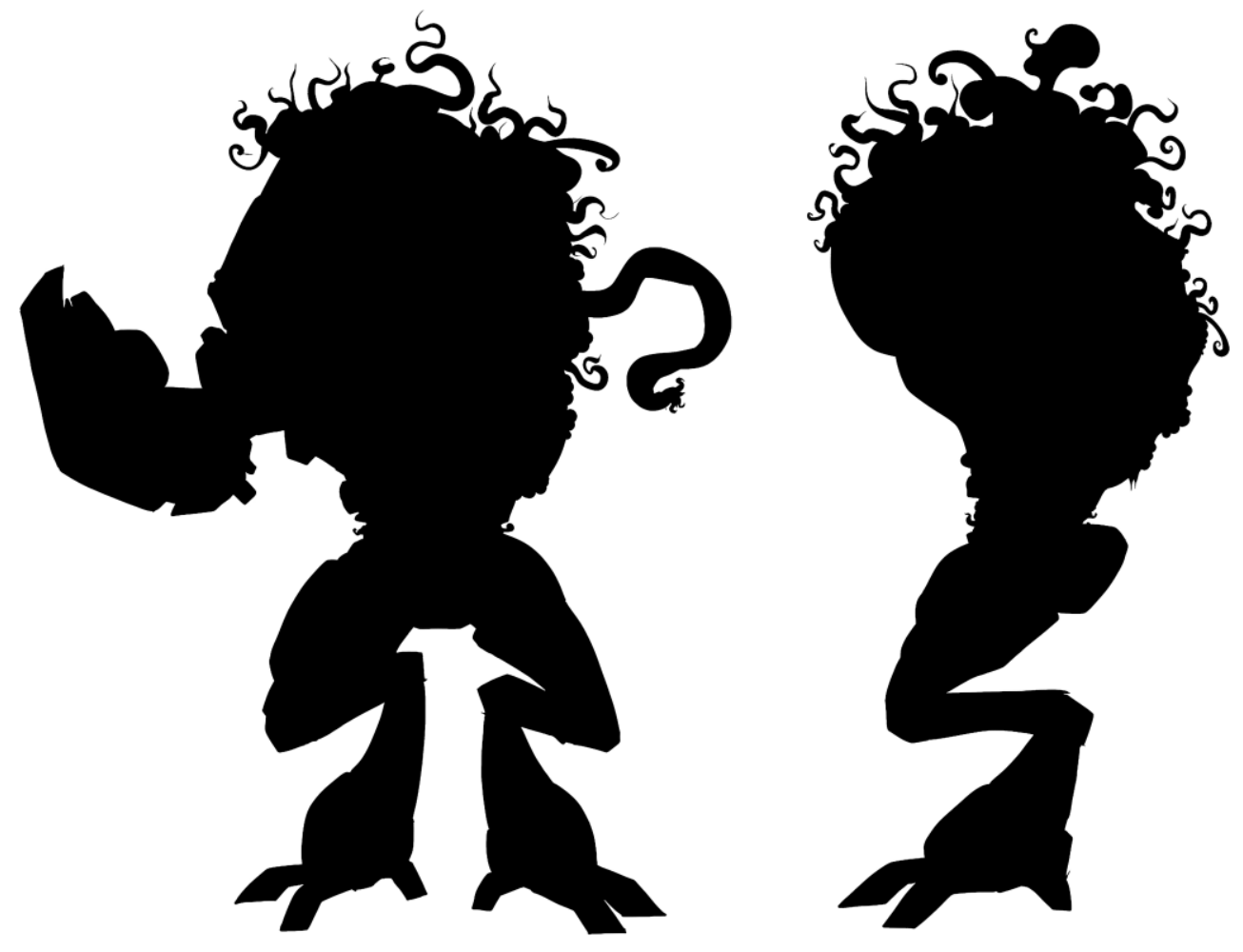

1. Describe your overall impression of the above image.

2. What is the overall shape of the above character? (Select all that apply)
Circle
Square
Triangle
Rectangle 
Look at the image below and answer all questions to the best of your ability.
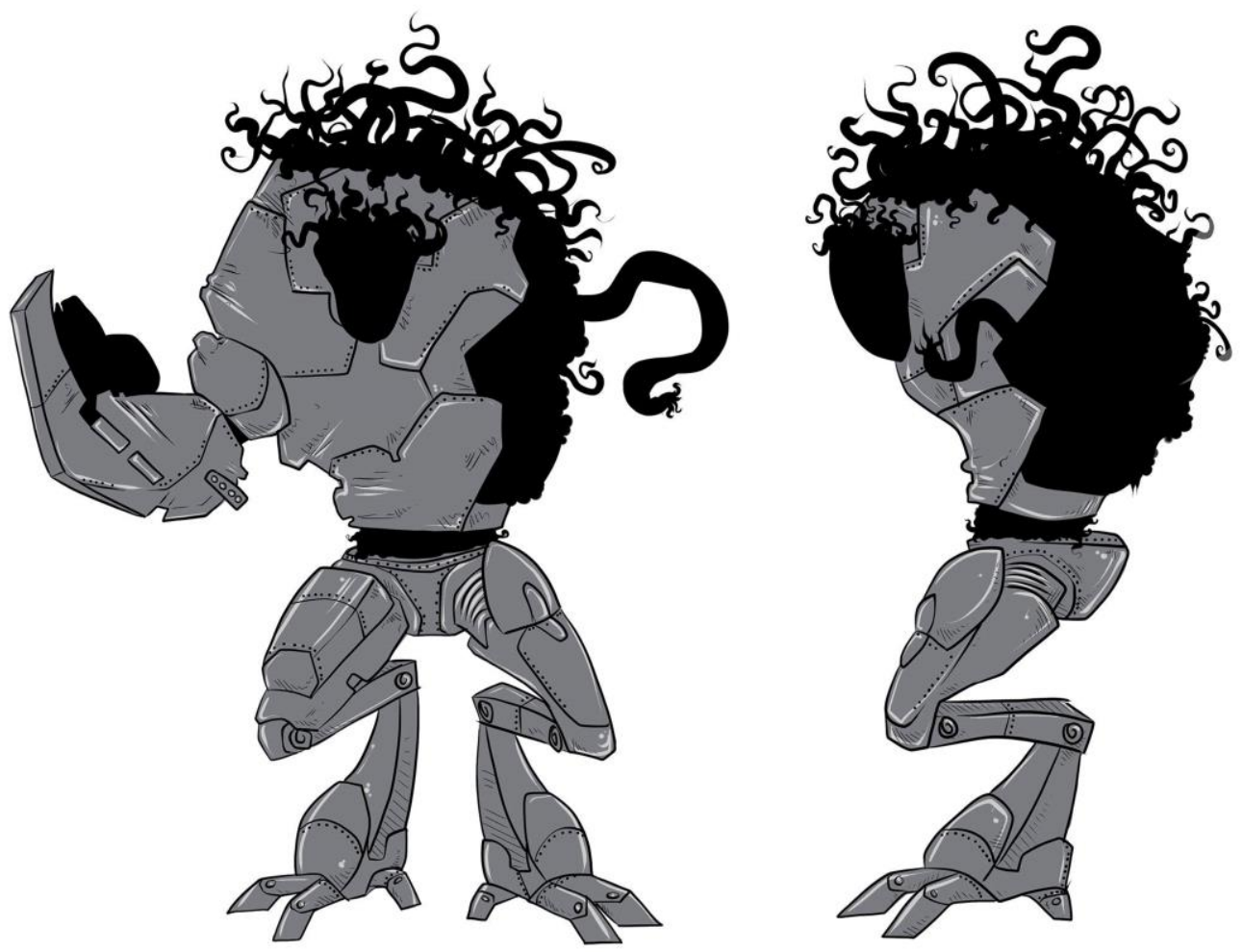

1. Describe your overall impression of the above character.

2. What personality traits do you associate with the above character? (Example: Cheerful, Humble, Gentle, Good, Quiet, Dependable, Optimistic, Angry, Arrogant, Aggressive, Loud, Evil, Fickle, and Pessimistic) 
Look at the image below and answer all questions to the best of your ability.
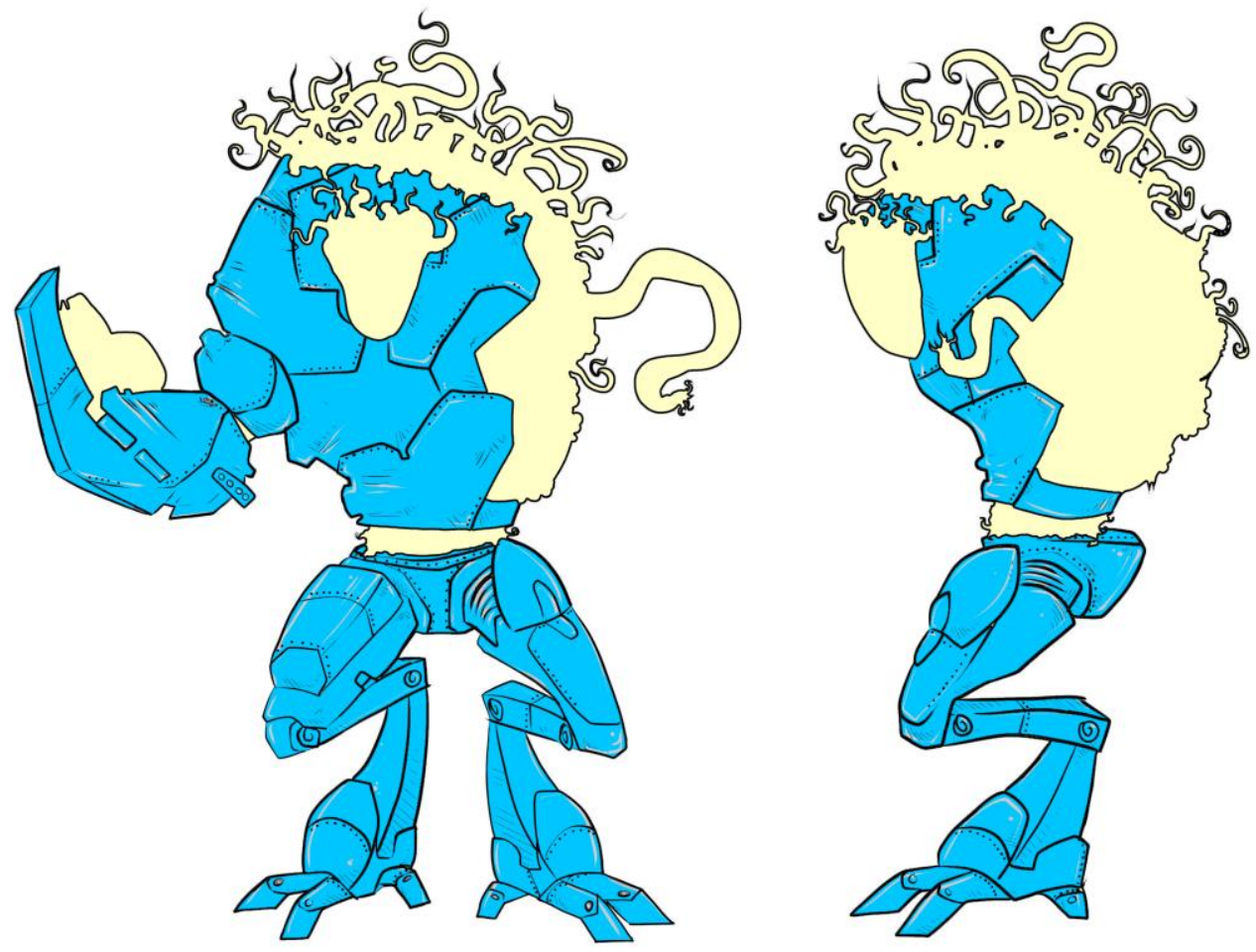

1. Describe your overall impression of the above character.

2. What personality traits do you associate with the above character? (Example: Cheerful, Humble, Gentle, Good, Quiet, Dependable, Optimistic, Angry, Arrogant, Aggressive, Loud, Evil, Fickle, and Pessimistic) 